University of Tennessee Health Science Center UTHSC Digital Commons

\title{
Changes in Pharyngeal Airway Dimensions Due to MARA Treatment in Class II Malocclusions
}

James K. Dillehay

University of Tennessee Health Science Center

Follow this and additional works at: https://dc.uthsc.edu/dissertations

Part of the Orthodontics and Orthodontology Commons

\section{Recommended Citation}

Dillehay, James K. , "Changes in Pharyngeal Airway Dimensions Due to MARA Treatment in Class II Malocclusions" (2013). Theses and Dissertations (ETD). Paper 65. http://dx.doi.org/10.21007/ etd.cghs.2013.0071.

This Thesis is brought to you for free and open access by the College of Graduate Health Sciences at UTHSC Digital Commons. It has been accepted for inclusion in Theses and Dissertations (ETD) by an authorized administrator of UTHSC Digital Commons. For more information, please contact jwelch30@uthsc.edu. 


\title{
Changes in Pharyngeal Airway Dimensions Due to MARA Treatment in Class II Malocclusions
}

\begin{abstract}
Orthodontic treatment effects on the pharyngeal airway have recently become a hot topic in the field of orthodontics. Current literature has shown facial skeletal morphology to be correlated with pharyngeal airway shape and volume. This study used CBCT imaging to identify what, if any, effects two different treatment modalities for correcting Class II malocclusions have on the pharyngeal airway volume. This retrospective study consisted of two groups of Class II patients: 38 patients (15 females, 23 males) treated with the MARA and an Edgewise appliance and 32 patients treated with an Edgewise appliance and Class II elastics. Both pre and post treatment CBCT images $(n=140)$ were analyzed using Dolphin3DC imaging software and a custom cephalometric analysis module. Analysis of the airway was done in three regions defined as 1 ) the nasopharynx (area superior and posterior to the posterior nasal spine), 2) the oropharynx (inferior to the PNS and superior to the epiglottis), and 3 ) the total airway volume (nasopharynx + oropharynx). ANOVA models were employed to simultaneously test variables for group differences (sex, treatment, sex + treatment). The results did not identify any significant in-treatment differences between the treatment groups with regard to the pharyngeal airway volume. It was concluded that the dentofacial treatment differences obtained with these two Class II correction methods were not enough to have a significant effect on the pharyngeal airway volume.
\end{abstract}

\section{Document Type}

Thesis

\section{Degree Name}

Master of Dental Science (MDS)

\section{Program}

Orthodontics

\section{Research Advisor}

Edward F. Harris, Ph.D.

\section{Keywords}

Airway, CBCT, Development, Growth

\section{Subject Categories}

Dentistry | Medicine and Health Sciences | Orthodontics and Orthodontology 


\title{
Changes in Pharyngeal Airway Dimensions Due to MARA Treatment in Class II Malocclusions
}

\author{
A Thesis \\ Presented for \\ The Graduate Studies Council \\ The University of Tennessee \\ Health Science Center
}

\author{
In Partial Fulfillment \\ Of the Requirements for the Degree \\ Master of Dental Science \\ From The University of Tennessee
}

By

James K. Dillehay

May 2013 
Copyright (C) 2013 by James K. Dillehay. All rights reserved. 


\section{ACKNOWLEDGEMENTS}

First, I would like to thank Dr. Edward Harris for his guidance and expertise during this process. Without him none of this would be possible. Under his direction I gained great knowledge and ability to critically assess orthodontic literature and research. I would also like to thank Dr. Preston Miller for serving on my thesis committee. I would like to extend a special thank you to my father Dr. Ken Dillehay; it is through him I developed my interest in orthodontics as a career path. I appreciate more than anything his unyielding support and inspiration in this journey. I am truly blessed to continue my career in his footsteps. I would like to thank both Dr. Dan Merwin, and Dr. Preston Miller for allowing me access to their CBCT images. I would also like to thank my mother, brother and girlfriend for their support during this three-year process. I would also like to thank Dr. Trojan and Dr. Yates for their guidance during residency. 


\begin{abstract}
Orthodontic treatment effects on the pharyngeal airway have recently become a hot topic in the field of orthodontics. Current literature has shown facial skeletal morphology to be correlated with pharyngeal airway shape and volume. This study used CBCT imaging to identify what, if any, effects two different treatment modalities for correcting Class II malocclusions have on the pharyngeal airway volume. This retrospective study consisted of two groups of Class II patients: 38 patients (15 females, 23 males) treated with the MARA and an Edgewise appliance and 32 patients treated with an Edgewise appliance and Class II elastics. Both pre and post treatment CBCT images $(n=140)$ were analyzed using Dolphin $3 \mathrm{D}^{\odot}$ imaging software and a custom cephalometric analysis module. Analysis of the airway was done in three regions defined as 1) the nasopharynx (area superior and posterior to the posterior nasal spine), 2) the oropharynx (inferior to the PNS and superior to the epiglottis), and 3) the total airway volume (nasopharynx + oropharynx). ANOVA models were employed to simultaneously test variables for group differences (sex, treatment, sex + treatment). The results did not identify any significant in-treatment differences between the treatment groups with regard to the pharyngeal airway volume. It was concluded that the dentofacial treatment differences obtained with these two Class II correction methods were not enough to have a significant effect on the pharyngeal airway volume.
\end{abstract}




\section{TABLE OF CONTENTS}

CHAPTER 1. INTRODUCTION .........................................................................................1

CHAPTER 2. LITERATURE REVIEW .................................................................2

Class II Malocclusion ........................................................................................

Functional Appliances ..........................................................................................

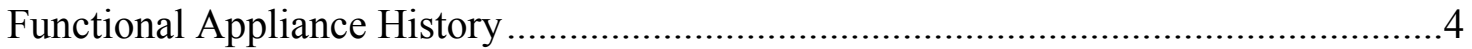

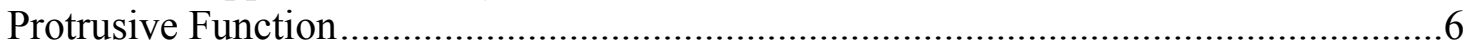

Class II Correction with the MARA ...................................................................... 11

The Pharynx ................................................................................................... 14

Treatment Effects on Pharyngeal Airway.......................................................... 15

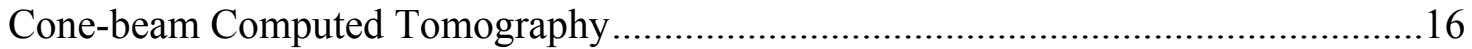

Cone-beam Computed Tomography Accuracy..................................................... 17

Pharyngeal Analysis Using Cone-beam Computed Tomography ............................18

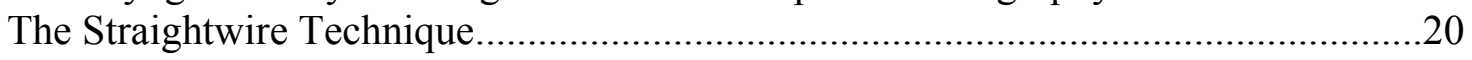

CHAPTER 3. METHODOLOGY ................................................................21

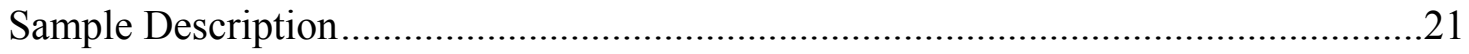

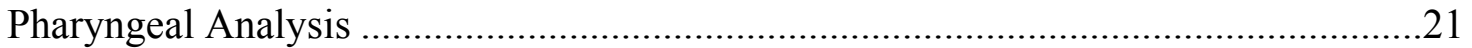

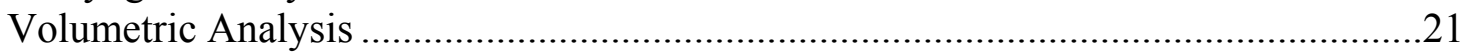

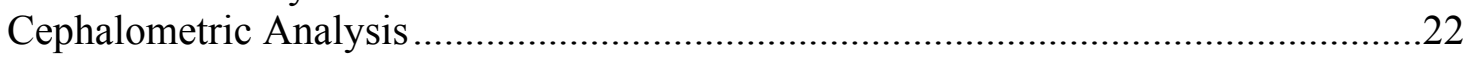

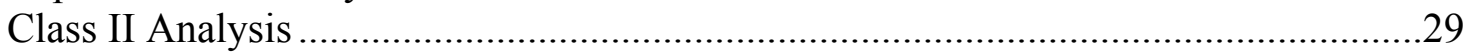

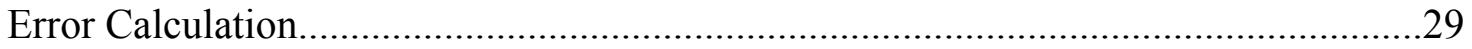

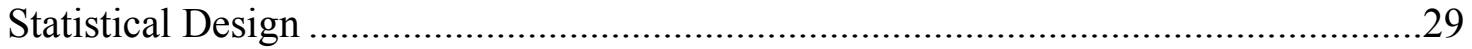

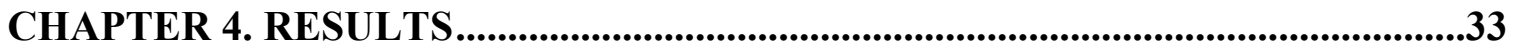

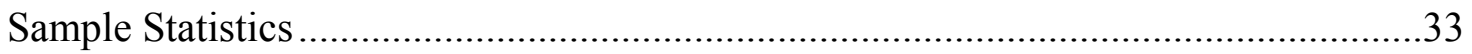

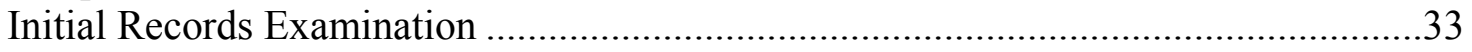

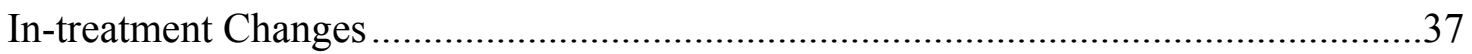

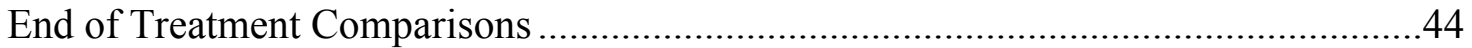

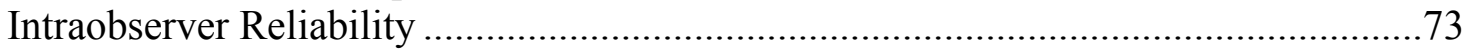

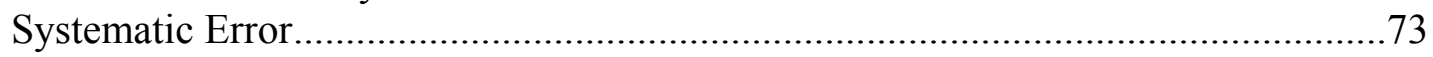

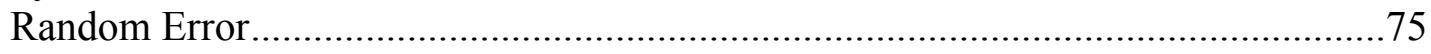

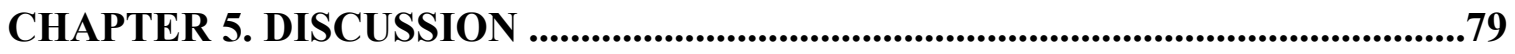

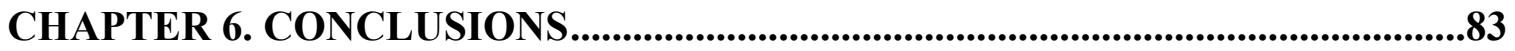

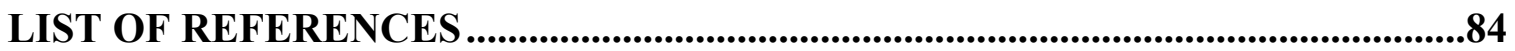

APPENDIX A. RESULTS OF TESTING FOR SEX AND TREATMENT

DIFFERENCE AT START OF TREATMENT ..................................................89 
APPENDIX B. RESULTS OF TESTING FOR SEX AND TREATMENT

DIFFERENCES FOR THE IN-TREATMENT CHANGES ....................................104

APPENDIX C. RESULTS OF TESTING FOR SEX AND TREATMENT

DIFFERENCES AT THE END OF TREATMENT..............................................119

APPENDIX D. RESULTS OF PAIRED T TESTS ............................................133

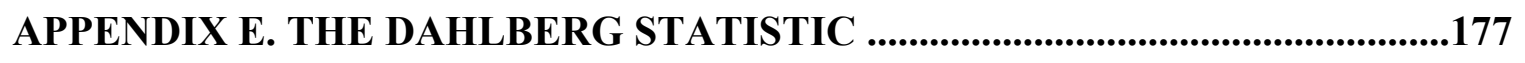

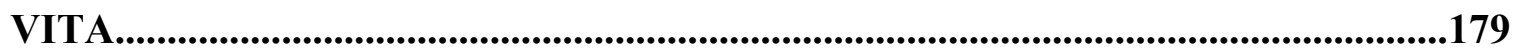




\section{LIST OF TABLES}

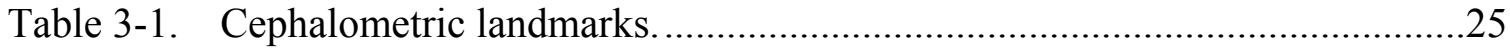

Table 3-2. Linear (millimetric) dimensions and angles measured on the lateral cephalograms.

Table 3-3. A list of the variables measured from the lateral cephalometric images in the present study.

Table 4-1. Results of two-way ANOVAs for age at examinations by patient's sex and source of the sample (Kansas or Tennessee), sexes pooled.

Table 4-2. Descriptive statistics for the chronological ages of the samples at the examinations (years).

Table 4-3. Listing of the statistically significant differences by two-way ANOVA at the initial records examination.

Table 4-4. Listing of the statistically significant variables as assessed from two-way ANOVAs...

Table 4-5. Listing of the 23 statistically significant variables found between the samples at the end of treatment and which factors attained significance. ....46

Table 4-6. Descriptive statistics for U1 to NA (degrees) at the end of treatment.

Table 4-7. Descriptive statistics for the statistically significant differences between measurement sessions (alpha $=0.05)$.

Table 4-8. Dahlberg statistic calculated for the remeasurement subset of the sample ( $\mathrm{n}=15$ pairs $)$. 


\section{LIST OF FIGURES}

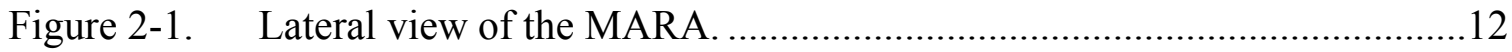

Figure 3-1. Sketch of lateral view of skull with skeletal and soft tissue landmarks identified and the airway segments delineated and defined........................23

Figure 3-2. Two-dimensional rendering of the pharyngeal airway ............................24

Figure 4-1. Percentages of the total sample by sex of the subject and geographical

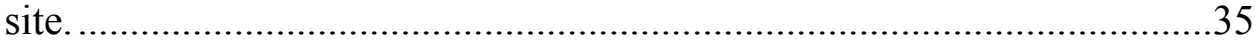

Figure 4-2. Box plots, by mechanics and sex, for the in-treatment changes in

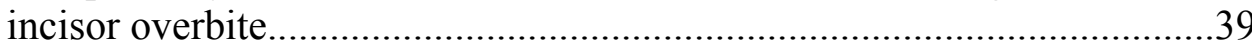

Figure 4-3. Box plots of the treatment changes in the angle SNA, by treatment. ........40

Figure 4-4. Box plots of the changes in the angle SNB..............................................41

Figure 4-5. Box plots of the changes in FMA by treatment group...............................42

Figure 4-6. Box plots of the treatment differences in the Interincisal Angle...............43

Figure 4-7. Box plots of the treatment changes in the dental angle U1 to the Sella-

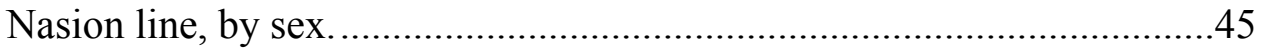

Figure 4-8. Box plots of the distributions of inferior pharyngeal volume $\left(\mathrm{mm}^{3}\right)$ between treatments evaluated at the end of treatment.

Figure 4-9. Box plots of the distributions of the Y-axis (degrees) between treatments evaluated at the end of treatment.

Figure 4-10. Box plots of the distributions of the angle FMA (degrees) between treatments evaluated at the end of treatment.

Figure 4-11. Box plots of the distributions of the angle IMPA (degrees) between treatments evaluated at the end of treatment.

Figure 4-12. Box plots of the distributions of the angle FMIA (degrees) between treatments evaluated at the end of treatment.

Figure 4-13. Box plots of the distributions of the Interincisal Angle (degrees) between treatments evaluated at the end of treatment.

Figure 4-14. Box plots of the distributions of the U1-Sella-Nasion angle (degrees) between treatments and between sexes evaluated at the end of treatment. 
Figure 4-15. Box plots of the distributions of the L1-Nasion-B angle (degrees)

between treatments evaluated at the end of treatment.

Figure 4-16. Box plots of the distributions of the L1-Nasion-B distance

(millimeters) between treatments at the end of treatment.

Figure 4-17. Box plots of the distributions of the U1 to the Nasion-A line (degrees)

between treatments and between sexes evaluated at the end of

treatment.

Figure 4-18. Box plots of the distributions of incisor Overjet (millimeters) between treatments at the end of treatment.

Figure 4-19. Box plots of the distributions of Condylion-to-A Point length at the end of treatment, by treatment and sex.

Figure 4-20. Box plots of the distributions of Condylion-to-Gnathion distance at the final records, by treatment and sex.

Figure 4-21. Box plots of the distributions of the distance A-to-NasionPerpendicular at the final records, by treatment and sex.

Figure 4-22. Box plots of the distributions of the distance Pogonion-to-Nasion-

Perpendicular at the final records, by treatment and sex.

Figure 4-23. Box plots of the distributions of Molar Relationship at the final records, by treatment

Figure 4-24. Box plots of the distributions of Posterior Facial Height (mm) at the final records examination, by sex.

Figure 4-25. Box plots of the distributions of Gonion-Menton at the final records, by treatment.

Figure 4-26. Box plots of the distributions of Sella-Vertical to A Point at the final records, by treatment.

Figure 4-27. Box plots of the distributions of Sella-Vertical to B Point at the final records, by treatment.

Figure 4-28. Box plots of the distributions of Anterior Facial Height (AFH) at the final records, by treatment.

Figure 4-29. Box plots of the distributions of Sella-Vertical to Pogonion at the final records, by treatment.

Figure 4-30. Box plots of the distributions of Sella-Vertical to M Point at the final records, by treatment. 


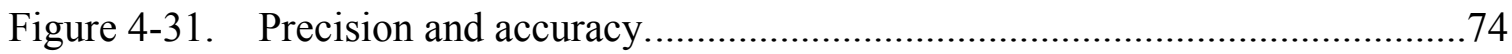




\section{CHAPTER 1. INTRODUCTION}

The correction of Class II skeletal malocclusion is a common problem in the United States population (Brunelle et al. 1996). Previous studies have shown that Class II malocclusion represents as much as $29 \%$ of the patients seen in a clinician's office (Massler et al. 1951). Class II malocclusion stems from a diverse array of size malrelationships including a combination skeletal and dento-alveolar components. Despite the variability among Class II patients, McNamara (1981) observed that of 16 studies, 12 supported mandibular retrusion as the primary cause of Class II malocclusion.

There are numerous methods for the dentist to treat anteroposterior skeletal discrepancies. Treatment modalities to correct a Class II malocclusion include an array of intra- and extra-oral appliances, extraction patterns, functional jaw orthopedic appliances, as well as surgical approaches to correct a severely retrusive mandible (Graber et al. 2005). Many clinicians seek to increase mandibular growth to correct a Class II skeletal malocclusion through the use of functional appliances.

The mandibular anterior repositioning appliance (MARA) is a functional appliance developed in 1991 by Douglass Toll of Germany (Allen-Nobel 2002). Clinicians who use the MARA seek to achieve growth alteration and advancement of the mandible to correct Class II skeletal malocclusions. However, there is little research on the clinical outcomes of MARA use or the resulting soft tissue changes associated with the pharyngeal airway dimensions.

Pharyngeal airway volume is of concern to the orthodontic treatment provider because the pharynx is the only passageway for air to travel into and out of the lungs. If orthodontic treatment modalities exist that positively or negatively affect the pharyngeal airway volume, they can play a significant role in the dentists' diagnosis and treatment planning of a given patient.

The purpose of the present study is to use cone beam computer tomography (CBCT) technology to compare volumetric pharyngeal airway changes between two different orthodontic treatments. The study will test for differences in pharyngeal airway changes between treatments with (1) the MARA, followed by conventional Straighwire fixed appliances and (2) conventional Straightwire orthodontic appliances used alone. The focus of this CBCT study is to identify any airway changes obtained from the use of the MARA compared to conventional fixed appliances alone. 


\section{CHAPTER 2. LITERATURE REVIEW}

\section{Class II Malocclusion}

Class II malocclusion is a common problem in the U.S. population (Brunelle et al. 1996). It is a malrelationship between the maxilla and mandible in which the mandible is relatively posterior to the maxilla. Fisk et al. (1953) described six morphologic variations in the dentofacial complex of Class II patients: (1) the maxilla and the teeth are positioned anteriorly in relation to the cranium; (2) the maxillary teeth are positioned anteriorly in the maxilla; (3) the mandible is of normal size but it is positioned posterior relative to the maxilla; (4) the mandible is underdeveloped and therefore retrusive relative to the maxilla; (5) the mandibular teeth are posteriorly positioned on an adequate base; and (6) various combinations of the aforementioned factors.

Due to the numerous morphological variations that can result in a Class II relationship, some studies have attempted to classify the Class II relationship using welldefined classification subtypes. In a 1980 study by Moyers et al., the lateral cephalograms of 697 North American white children were examined. The group consisted of both untreated controls, and patients who had received Angle Class II corrective orthodontic treatment. This study identified many general characteristics of Class II malocclusions. Moyers et al., identified many patients within the Class II group to possess smaller skeletal linear measurements than the untreated controls. Generally the Class II patients were seen to have smaller faces. Five subgroups were identified based on horizontal measures (Types A, B, C, D, and E). Of these subgroups, types B, C, $\mathrm{D}$, and $\mathrm{E}$, are identified as true "syndromal" types with distinctively different skeletal and dental features (Moyers et al. 1980).

Type A is characterized as having a normal skeletal profile and occlusal plane, in addition to a normal anteroposterior relation of the maxilla and mandible. The maxillary dentition is located in a protracted relationship, with the mandibular dentition being upright over basal bone. This relationship creates a Class II molar relationship with a large overjet and overbite.

Type B patients have a Class II skeletal relationship with a prominent maxilla and a mandible in a normal anteroposterior relationship. Type $\mathrm{C}$ patients have a severe Class II skeletal pattern with a short mandible and maxilla, a square gonial angle, and a flat anterior cranial base. The maxillary incisors are either upright or labially inclined, while the mandibular incisors are tipped labially.

Type $\mathrm{D}$ patients possess a retrognathic skeletal profile with midface that is deficient to normal, in combination with a small mandible. The mandibular incisors are lingually inclined or upright, while the maxillary incisors are extremely labially inclined. Type E patients exhibit a severe Class II profile due to a prognathic midface combined with a normal mandible. Maxillary and mandibular dentitions are flared anteriorly of their base and inclined facially. 
In addition to the horizontal types, Moyers et al., also identified five vertical subgroups of Class II malocclusion (Types 1 through 5). The vertical subgroups identified, however, are not as clearly differentiated as the horizontal types. While some horizontal types were identified to have normal vertical measures, many horizontal types were seen associated with specific vertical types.

Vertical Type 1 patients possess an increased mandibular plane angle, a steep functional occlusal plane and an anteriorly downward tipped palate. These patients are identified by orthodontists as "high-angle" patients with a "long-face" presentation due to the increased anterior facial height. Vertical Type 2 patients present with mandibular, occlusal, and palatal planes that are flatter than normal, nearly perpendicular to a true horizontal. The incisors tend to be overly upright with an increased overbite.

Vertical Type 3 patients are characterized as having a palatal plane that is tipped upward anteriorly, resulting in a strong open bite tendency. The open bite tendency is further increased with an increase in the mandibular plane angle. Vertical Type 4 patients possess mandibular, occlusal, and palatal planes that are tipped downward. The resulting presentation is a high smile line. The maxillary incisors are tipped labially while the mandibular incisors are tipped lingually. The Type 4 subgroup is the most severe and the least common of the vertical groups. Vertical Type 5 is similar to Type 2 with mandibular and occlusal planes. In addition, the palatal plane is tipped downward, resulting in a skeletal deep bite. Maxillary incisors are nearly upright, while mandibular incisors are facially inclined.

\section{Functional Appliances}

Functional orthodontic appliances are orthopedic devices, generally used during the mixed dentition, for correction primarily of Class II, Division I malocclusions (Righellis 1983). Functional appliances have been use since the early twentieth century with the intent of enhancing mandibular condylar growth by changing muscle function and condyle- fossa relationships (Woodside, Metaxas and Altuna 1987). Despite the relatively long history, controversy still exists relating to their use, method of action, and effectiveness.

McNamara (1981) concluded that mandibular retrognathia rather than maxillary prognathism is the single most common component of Class II malocclusions. This finding might cause the clinician to consider using a functional appliance in children with a Class II malocclusion due to mandibular retrognathism with the intention of increasing mandibular length and, thus reducing skeletal imbalance. If a Class II, Division I malocclusion results from mandibular retrognathia rather than maxillary prognathism, treatment of the maxillary components may be unfavorable. In a growing patient, mandibular repositioning appliances may provide a better treatment result (Howe 1982). 


\section{Functional Appliance History}

The history of the functional appliance can be traced back to the late $19^{\text {th }}$ century when Norman W. Kingsley first used forward positioning of the mandible in orthodontic treatment (Wahl 2006). Kingsley's appliance and all functional appliances to follow were based on the work of Wilhelm Roux (1895), who studied the influences of natural forces and functional stimulation on form.

During the early $20^{\text {th }}$ century Pierre Robin of France developed a passive monoblock appliance used to treat neonates with micromandibular development to help prevent glossoptosis or blocking of the airway by the tongue. Monoblock therapy was indicated to stimulate the activity of the facial musculature and to normalize the occlusion (Graber 2005).

In 1909, Viggo Andresen, working on his own daughter, developed a new functional device, the activator. At the time of the activators inception, Andresen wanted to design a device that would eliminate the adverse effects of abnormal function, without the use of fixed appliances. He developed a Hawley-type maxillary retainer to be worn in combination with a mandibular retainer with a lingual horseshoe flange that guided the mandible forward about 3 to $4 \mathrm{~mm}$ (Wahl 2006). Following three months of nighttime activator wear by Andresen's daughter while she attended summer camp; Andresen was surprised to see the appliance had eliminated her Class II malocclusion, with stable results. Andresen continued to use this appliance on other patients to achieve significant sagittal corrections that he could not produce with conventional fixed appliances (Graber 2005).

Andresen's development of the activator was a decisive step in the course of orthodontic treatment history. The original activator was a tooth-borne, loosely fitting passive appliance with facets incorporated into the body of the appliance to direct erupting posterior teeth. The loose fit and mobility of Andresen's removable appliance allowed muscular stimuli to be transferred to the teeth, jaws, and supporting structures. Despite the simple design, the activator could alter dental relationships in three planes of space, effectively correcting Class II malocclusions (Wahl 2006).

Andresen's activator may have been ahead of its time, as the device was not initially well received. However, the activator did find a niche when Andresen, serving as the director of the orthodontic department at the University of Oslo, developed a government program to orthodontically treat Norwegian school children. He modified his retainer by using a wax bite to register the mandible in an advanced position, producing a simple and removable orthodontic device to be used to correct sagittal jaw relationships (Wahl 2006). The development and implementation of the activator as a removable functional appliance by Viggo Andresen would serve as a platform upon which numerous future removable fixed appliances would be based. 
Attempting to develop a less bulky removable functional appliance, Balters developed the Bionator. The purpose of the Bionator is to establish good muscle coordination and eliminate potentially deforming growth restrictions, while unloading the condyle through a protrusive mandibular position. The Bionator is composed of a horseshoe-shaped lower lingual acrylic flange that extends from the distal of the last erupted molar around to the corresponding point on the other side. The maxillary arch of the appliance has only lingual acrylic extensions covering the molar and premolar regions. The upper and lower components are joined in the correct protrusive bite relationship. The anterior portion is kept free so as not to interfere with tongue function and posture. Acrylic coverage of the lower incisors may be included for control of the lower incisors. A palatal bar and a labial bow with buccal extensions are used to control posture and function of the cheeks and lips (Graber 2005).

Rolf Fränkel designed the functional regulator, a removable functional appliance that corrects malocclusions with little or no contact with the dentition (Fränkel R, Fränkel C 1989). The Fränkel regulator utilizes the vestibule as an area of operation, keeping abnormal lip and cheek pressures away from the teeth. The functional regulator consists of a maxillary labial bow, buccal acrylic shields, and lower lip pads. A wire assembly anchors the appliance on the maxillary arch at the mesial first molar embrasure. Lingually the appliance consists of a cross-palatal stabilizing wire, a maxillary lingual arch, and a lower lingual plate. There is no interocclusal component, allowing eruption of mandibular teeth with interference. The lingual plate is the only contact of the appliance with the lower arch. The protrusive relationship is maintained in the trough provided by the lingual acrylic plate and the lower lip pads. Sagittal advancement is accomplished through incremental advancement of the "posturing trough" (Graber, 2005).

Fränkel reasoned that stability of treatment is possible only if the structural and functional deviations of the muscular system are corrected. The functional regulator (FR) was designed around the oral vestibule as the operational basis for treatment. Buccal shields are used to prevent arch narrowing forces applied by the buccal musculature, while lower lip pads regulate abnormal perioral muscle function and lingualizing forces. Fränkel designed three different models of the functional regulator to treat Class I, Class II, and Class III malocclusions, the FR-1, FR-2, and FR-3, respectively (Wahl 2006).

Many of the popular early functional orthodontic appliances were of the removable variety, including the appliances previously described. However, another type of functional appliance was also created during the early $20^{\text {th }}$ century, the fixed functional appliance. In 1909, Emil Herbst presented his functional appliance at the International Dental Congress in Berlin. The appliance was a fixed "bite-jumping" device. The device eliminated the need for patient compliance to maintain the mandible in a protrusive relationship, a factor that was necessary with the removable appliances (Graber 2005). The Herbst appliance appealed to clinicians because it was more suitable for older children with compliance issues. Despite the appliances introduction in 1909, it was not until 1934 that Herbst's findings were published (Wahl 2006). The work of Herbst was 
largely disregarded at the time, and very little study was done involving the Herbst appliance until its revival by Hans Pancherz in the late 1970's (Graber 2005).

The Herbst appliance is composed of a bilateral telescoping mechanism that maintains the protruded position of the mandible, even during function. This mechanism consists of a tube, a plunger, two pivots, and two locking screws that prevent the telescoping elements from slipping past the pivots. The tube pivot is soldered to the maxillary first molar band, while the plunger pivot is attached to the mandibular first premolar band. The length of the tube-plunger assembly determines the amount of mandibular advancement (Graber 1997).

\section{Protrusive Function}

In a study of mandibular hyperpropusion in rhesus monkeys, Elgoyhen et al. (1972) reported that a change in the maxillomandibular relationship can be obtained through forward alteration of the mandibular functional position. For the experiment, 16 juvenile rhesus monkeys were studied, with 6 being subjected to functional mandibular advancement through the use of cast gold appliances. The appliances postured the mandible forward either 2, 4, or $6 \mathrm{~mm}$. The remaining 10 primates were used as a control group. Following 3 months of functional appliance use in the experimental animals, all presented mandibular prognathism. At the end of 5 months, all 5 experimental monkeys exhibited a skeletal Class III molar relationship.

In this study, Elgoyhen et al. (1972) suggests that the resulting change in the maxillomandibular relationship seen in the primates was due to both "pronounced and subtle alterations" throughout the craniofacial complex rather than localized to a specific anatomic change or factor. Statistically significant increases were measured in the rate and amount of growth at the head of the condyle. The maxillary growth vector was altered to a more forward direction, with inhibition of vertical development.

Dentoalveolar adaption was exhibited by the inhibition of the normal eruption extent of the maxillary dentition, and limited mesial migration of the lower buccal segments. These changes, combined with other, less evident adaptations, led to the observed anteroposterior changes in jaw relationships.

In another study of primates, Stöckli and Willert (1971) examined the capacity of the temporomandibular joint to adapt to orthopedically induced forward displacement of the mandible. This study examined 8 growing Macaca irus monkeys, 2 of which were used as controls, while the remaining 6 served as the experimental group. Like the Elgoyhen study, Stöckli and Willert utilized a cast gold functional appliance to induce forward displacement of the mandible. Anterior displacement of the mandible 5 to $6 \mathrm{~mm}$ was carried out during increasing periods of time either $5,25,65,120$, and 210 days, in 5 of the experimental animals. A sixth experimental animal received occlusal therapy for 180 days, followed by 90 days without the anterior positioning appliance. Following the experimental time period, the animals were sacrificed, and undecalcified sagittal sections 
of the middle third of the temporomandibular joints were obtained and examine histologically.

Histological examination revealed a distinct tissue reaction in the 25-day experimental animal. The condylar cartilage in the posterior region of the condylar head had increased to several times the normal width, with an extremely high proliferative activity seen in the intermediate zone. A compensation reaction to the altered topographic relationship was also evident in the temporal portion of the joint (Stöckli et al. 1971).

The 65-day experimental animal did not exhibit the same hyperactivity in the intermediate zone of the condylar cartilage, but, rather, intensified endochondral ossification. The histological appearance of the temporomandibular joint did not differ significantly from the normal control animals exposed to occlusal therapy for 120 days or longer. The remodeling process had consolidated the new, altered articular location. The sixth experimental animal, the one that was followed 180 days of appliance wear with 90 days of no appliance in place, did not show histological signs of changes facilitating relapse, but, rather, had the same appearance as the 210-day experimental animal (Stöckli et al. 1971). In this study, corresponding anteroposterior changes in the occlusal relationship supported all of the histological interpretations. Stöckli and Willert (1971) concluded that (1) adaptive tissue changes in the temporomandibular joint of Macaca iris could be induced by mechanical stimuli, (2) transitional tissue response could be initiated shortly after anterior mandibular advancement, (3) the new condylar position demonstrated a high resistance against relapse and (4) the absence of any histopathologic symptoms revealed that during the growth period the temporomandibular joint had a high potential for compensating tissue adaptation mainly by physiologic processes.

Charlier, Petrovic and Herrmann-Stutzmann (1969) studied the effects of hyperpropulsion in young rat condylar cartilage. Eight litters of rat were used at 4 weeks old. Half of the rats in each litter wore a hyperpropulsion device, while the other half served as controls. After four weeks the rats were sacrificed and the mandibular condyles were sectioned and stained. The condyles of the experimental subjects showed the following characteristics when compared with controls: 1) the articular disc was significantly thicker, 2) the articular zone was distinctly larger and the cells were rounder, 3 ) the prechondroblastic zone was significantly elongated, due to increased cell proliferation, 4) the chondroblastic zone was elongated secondary to the increased activity of the prechondroblastic zone, 5) the angle constructed by a line drawn through the condyle to the inferior border of the mandible was 3 degrees larger in the treated animal, and 6) periosteal bone apposition on the posterior border and rear of the inferior border of the mandible was increased. Charlier, Petrovic and Herrmann-Stutzmann (1969) concluded that hyperpropulsion causes additional growth of condylar cartilage by stimulating the cells in the prechondroblastic zone, and that there is a causal relationship between the intensity of condylar growth and the amount of periosteal bone apposition on the posterior border and rear of the inferior border of the mandible. 
Petrovic (1972) evaluated the condyles of 28 male rats. The mandibles of each rat were forced into hyperpropulaion for 4 hours per day for periods of 1 week ( 2 animals), 2 weeks ( 2 animals), and 4 weeks ( 24 animals). The control group consisted of 28 male rats from the same litter. The following histological modifications were evident in the experimental animals compared to the control group: (1) the articular meniscus and prechondroblastic zone both showed an increase in vertical thickness following one week of experimentation, (2) the cells were more voluminous and the nuclei were lightly stained, which indicated a functional stimulation, (3) a thickening of the chondroblasic zone was hardly evident at 2 weeks, but was quite visible after 4 weeks. This change was thus secondary to an increase in the number of prechondroblasts that later differentiated into chondroblasts, and (4) the mandibular angle increased 3 degrees due to increased apposition of bone on the posterior border of the ascending ramus. Petrovic (1972) suggests that orthopedic devices work on condylar growth by stimulating or inhibiting the cellular proliferation in the prechondroblastic zone.

McNamara (1973) investigated the nature of intrinsic musculoskeletal adaptations resulting from experimental alteration of the orofacial environment. The mandibles of Macaca mulatta were anteriorly positioned during functional movements at four defined stages of maturation. Specific skeletal, dental and neuromuscular adaptations were studied and interrelated using serial electromyography, serial cephalometric radiography with metallic implants, and microscopic analysis. Two time periods were studied. During a 13-week control period, normal growth data were obtained from the four age groups. During the 13-week experimental period, specific neuromuscular and skeletal alterations were identified. The induced changes in the oral environment altered the postural activity in the muscles of mastication and, presumably, the postural position of the mandible. The superior head of the lateral pterygoid muscle gradually increased in activity and appeared to function as a principal forward positioner of the mandible. This activity decreased or disappeared by the conclusion of the study. At the end of the experimental period, ten of the twelve experimental monkeys had experienced and anteroposterior change in molar relationship. However, no single process could be identified as the sole cause of any effective alteration in maxillomandibular relationship at any age level. Mandibular skeletal adaptations were seen primarily in the infant and juvenile animals. Both the extent and direction of growth at the condyle were altered in the experimental animals. A significantly increased growth rate tended to occur during the first three months with a peak occurring in the second month. At four months, the growth rates of the experimental animals were not significantly different from that of the controls. Note that the maximum rate of condylar growth occurred during the second month. Maximum adaptive neuromuscular activity appeared just prior to or during this time.

Dentition changes in the mandible were seen mainly in the adolescent and adult animals. After 13 weeks, the animals were sacrificed and all condyles were analyzed histologically. Little evidence of physiological or pathological response to induced protrusive function was seen. These histological findings are consistent with past studies that suggest the adult temporomandibular joint is stable and resistant while the growing articulation is responsive to functional changes. 
According to McNamara (1973), a chronologic correlation exists between the occurrence and disappearance of altered neuromuscular function and skeletal balance. As skeletal balance was restored through specific structural adaptations, compensatory muscle function was reduced. Also, the nature and extent of skeletal and dental adaptations depended on the level of maturation of the animal.

McNamara, Connelly and McBride (1975) repeated the above experiment in growing juvenile animals to study the histologic response of the temporomandibular joint. Fourteen juvenile Macaca mulatta between the ages of 18 and 24 months were used. Seven of the animals were experimental animals, while the other seven served as controls. One experimental and one control animal were sacrificed at 2 weeks, 4 weeks, 6 weeks, 8 weeks, 10 weeks, 12 weeks, and 24 weeks following appliance cementation. The joints of 8 untreated juvenile rhesus monkeys that had been previously sectioned and prepared were also used as controls in this study. Histological adaptive changes could be identified in the condylar cartilage two weeks after appliance cementation. There was a hypertrophy and a hyperplasia of the prechondroblastic and chondroblastic layer of the condylar cartilage, especially along the posterior border of the condyle. New bone was also deposited along the anterior surface of the postglenoid spine, a reversal of the normal pattern. At a higher magnification, increased proliferation of the condylar cartilage was again observed and the thickness of the chondroblastic zone was two to three times as wide as in the control animals. At four weeks, the thickness of the condylar cartilage was still increased, particularly along the posterior border of the condyle. At higher magnification, an obvious hypertrophy of the chondrocytes in the chondroblastic layer was evident along with new bone formation in the zone of endochondral ossification. At six weeks, the maximum response of the condylar cartilage to functional change was noted. A generalized proliferation of the condylar cartilage, which was five to six times as thick as the control dimension, was seen. By ten weeks, all evidence of adaptation was removed, presumably by normally occurring remodeling of the joint. The proliferation of the condylar cartilage was no longer evident and the rapid bone deposition may have been secondarily remodeled. Condylar remodeling was essentially completed in the 24week animal. The condyle at this stage could not be differentiated morphologically from the condyles of the control group.

According to McNamara, Connelly and McBride (1975), specific adaptations occur within the temporomandibular joint of young rhesus monkeys as a result of forward positioning of the mandible, promoted by altered neuromuscular function. The condylar response was apparent as early as two weeks following the appliance placement, and reached its maximum at six weeks. However, the structural changes in the condyle were temporary in nature. By ten to twelve weeks, rapid secondary remodeling of the condyle clearly accounted for the return to the normal morphology of the joint.

These findings are consistent with those of Stöckli and Willert (1971), who documented temporomandibular adaptations on a histologic level in a related study. McNamara, Connelly, and McBride (1975) hypothesized that an increase in muscle function is followed by an adaptive response in the condylar cartilage, which 
subsequently results in the deposition of new bone in the condylar head. After structural balance has been restored through various adaptive processes, the proliferation of the condylar cartilage is reduced and a gradual lessening of the rate of bone deposition ensues. This reconstruction of skeletal balance also eliminated altered muscle function, and thus, there is a gradual return to the original patterns of muscle activity.

McNamara, Hinton and Hoffman (1982) performed a histologic analysis of temporomandibular joint adaptations to protrusive function in young adult rhesus monkeys. Their major objective was to determine whether the adaptive changes observed in younger animals could be induced in mature animals. Twelve young adult female rhesus monkeys wore a functional protrusive appliance for periods ranging from 2 to 24 weeks. Histological analysis of the joints demonstrated that 6 of the experimental animals exhibited a tissue response that was qualitatively similar to that found in juvenile monkeys and was not related to the duration of treatment. Three adult experimental animals developed crossbites, and three animals that functioned anteriorly showed little or no condylar response. McNamara, Hinton, and Hoffman (1982) concluded that while some adaptive capability may still exist in the temporomandibular joints of young adults, the potential magnitude of the joint response is limited and highly variable in occurrence.

McNamara and Bryan (1987) experimented on Macaca mulatta and studied the long-term mandibular adaptations to protrusive function. Their objective was to evaluate whether the mandible could be stimulated to grow longer than it would have without treatment and whether the treated mandible was longer at the end of the growth period than it would have been without experimental intervention. Twenty-three male juvenile rhesus monkeys were used. In 11 experimental animals protrusive functional appliances were placed and mandibular adaptations were monitored cephalometrically. Twelve animals served as controls. Following 48 weeks of treatment significant increases were seen in condylar growth and overall mandibular length. Following the 144-week treatment period, the mandibles of the experimental animals were 5 to $6 \mathrm{~mm}$ longer than those of the control animals. According to McNamara and Bryan (1987), in rhesus monkeys the growth of the mandible can be increased to such an extent that the adult mandible is greater in overall length than it would have been without experimental intervention. The hypothesis that there is a genetically predetermined length of the mandible is not supported by the results of this study.

Does an orthopedic appliance only change the direction of growth or do they also modulate the rate and amount of growth? Is the length of the mandible predetermined? Petrovic, Stutzmann and Gasson (1981) carried out an investigation to answer these controversial questions. Their results indicate that orthopedic appliances that place the rat mandible in a forward position increase both the amount and rate of condylar cartilage growth; the mandible becomes longer than that of controls. With time, during the growth period, the sagittal deviation decreases through the additional forward growth of the mandible. The supplementary growth rate of the condylar cartilage and the additional lengthening of the mandible also decrease. Periodic increases in the thickness of the propulsion of the appliance resulted in a new increase in lateral pterygoid activity and, consequently, a new increase in the rate and amount of condylar cartilage growth ensued. 
No relapse was observed when the appliance was removed after the completion of growth. When the appliance was removed before growth was completed, no significant relapse was evident if a good intercuspation had been achieved during treatment. If a good intercuspation had not been achieved, an increased or decreased condylar growth rate occurred until a state of intercuspal stability was established. The findings of this study indicate that there is no genetically predetermined length of the mandible.

The results of Petrovic, Stutzmann and Oudet (1975) in rats, of Stöckli and Willert (1971) in Macaca irus, and McNamara, Connelly and McBride (1975) in Macaca mulata have clearly shown that structural adaptation can be induced in the temporomandibular joints of young, growing animals as a response to altered function. Specific differences exist in the typical anatomy of the human and monkey temporomandibular joints (McNamara, Connelly and McBride 1975). However, according to McNamara, Connelly and McBride (1975), despite the specific differences, the general structure and function of the temporomandibular joint region of the rhesus monkey is similar to that found in man. If responses occur in the temporomandibular joints of such distinct species as rat and monkeys, it is reasonable that similar responses would occur in man.

\section{Class II Correction with the MARA}

A number of functional appliances have been designed to alter the mandibular position relative to the maxilla. Such appliances alter the mandibular position in both the anteroposterior and vertical planes, resulting in both orthopedic and orthodontic changes (Bishara 1989). The mandibular anterior repositioning appliance, or MARA, is one such functional appliance (Figure 2-1).

The MARA is a tooth-borne functional appliance (Pangrazio-Kulbersh et al. 2003) created by Douglass Toll of Germany and improved upon with the collaboration of Jim Eckhard of Manhattan Beach, California, Ormco and the Allesee Orthodontic Appliance Laboratory. The current design was completed in 1995, at which time use of the appliance began its use in clinical treatment (Allen-Nobel 2002).

In a study by Pangrazio-Kulbersh et al. in 2003, 30 Class II patients treated with the MARA were evaluated for anterior, posterior and vertical skeletal and dental changes. The patient group, including twelve boys with a mean age of 11.2 years and eighteen girls with a mean age of 11.3 years, were treated with the MARA for an average of 10.7 months. Lateral cephalometric radiographs were taken prior to starting treatment and six weeks following completion of the MARA treatment. The treatment group was then compared to a control of 21 untreated Class II patients, including eight boys and thirteen girls. The control group was obtained from the Michigan Elementary and Secondary School Growth Study for whom records, including longitudinal cephalograms were available for the ages studied. In addition the patients treated with the MARA were compared to Fränkel and Herbst groups that had previously been reported. 


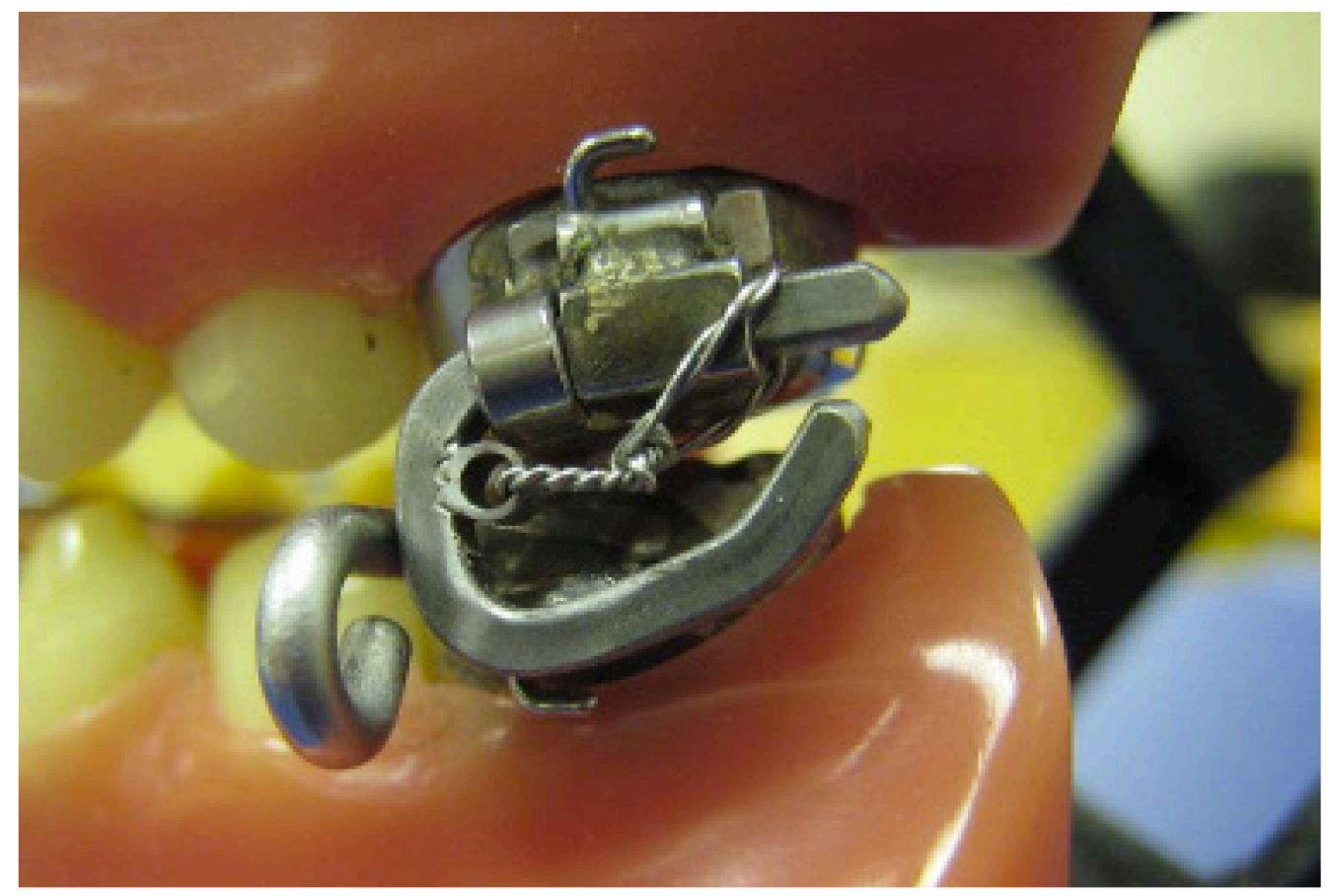

Figure 2-1. Lateral view of the MARA. 
The results of the study showed the MARA produced appreciable skeletal and dental treatment effects. The MARA group demonstrated an average of $1.1 \mathrm{~mm}$ of maxillary first molar distal movement. This is in comparison with the control group that showed a mesial maxillary first molar migration of $1.3 \mathrm{~mm}$. It was also seen that MARA treatment limits eruption of the maxillary first molar. When measured from the Frankfort horizontal, the maxillary first molar of the treatment group averaged an inferior movement of only $0.1 \mathrm{~mm}$ per year, in comparison with an inferior movement of $0.9 \mathrm{~mm}$ in the control group (Pangrazio-Kulbersh et al. 2003).

The MARA group showed increase forward movement of the mandibular dentition with a mesial movement of $1.2 \mathrm{~mm}$ at the first molar and $0.6 \mathrm{~mm}$ at the central incisor. The changes in the control group averaged only $0.5 \mathrm{~mm}$ for the mandibular first molar, and a lingual movement of $0.4 \mathrm{~mm}$ for the lower central incisor. IMPA increased $3.9^{\circ}$ for the treatment group, but only $0.3^{\circ}$ for the control group. Mandibular length increases $4.8 \mathrm{~mm}$ from Condylion to Gnathion in the MARA group, compared to $2.1 \mathrm{~mm}$ in the control. In the MARA group the chin point (Pogonion to Nasion-perpendicular) shifted anteriorly $2.3 \mathrm{~mm}$, and only $0.3 \mathrm{~mm}$ in the control. An ANB angle decrease of $1.4 \mathrm{~mm}$ was also seen in the treatment group, with a $0.1 \mathrm{~mm}$ decrease in the untreated control. Posterior facial height increased $4.0 \mathrm{~mm}$ in the MARA group, compared to a 1.3 $\mathrm{mm}$ increase in the control. Anterior facial height similarly increased more than the control, with respective increases of $2.5 \mathrm{~mm}$ and $1.0 \mathrm{~mm}$. This study found no change in mandibular plane angle between the two groups (Pangrazio-Kulbersh et al. 2003).

In addition, Pangrazio-Kulbersh et al., found the MARA to produce no skeletal effect on the maxilla. The MARA did, however, produce an average distal movement of $1.1 \mathrm{~mm}$ for the maxillary first molar. The resulting distal molar movement is largely responsible for the dental correction of the Class II malocclusion. The MARA treatment group had an average increase in mandibular length of $2.7 \mathrm{~mm}$, and a SNB increase of $1.0^{\circ}$. The chin point was seen to move anteriorly $2.0 \mathrm{~mm}$ in the MARA group while ANB decreased $1.3^{\circ}$ due to forward movement of B point. Also in the MARA group, the lower anterior facial height increased $2.5 \mathrm{~mm}$, and the posterior facial height increased $4.0 \mathrm{~mm}$. The authors felt the increase in posterior facial height in the treatment group was due to the molar crowns on the MARA causing the condyle to be positioned in a more inferior position in the glenoid fossa. This inferior position thus stimulates growth of the condyle in a superior-posterior direction. The resulting skeletal changes suggest the MARA can be effective in treating Class II skeletal discrepancies by increasing the mandibular length, without an anteroposterior orthopedic effect on the maxilla (Pangrazio- Kulbersh et al. 2003).

Siara-Olds et al. (2010) investigated the long-term dentoskeletal changes associated with the MARA and other functional appliances. The retrospective study examined 80 patients with similar Class II skeletal characteristics, divided evenly among 4 functional appliance treatments, the Bionator, Herbst, Twin Block, and MARA. A group of 21 children from the Michigan and Denver Growth studies were used as untreated controls (Siara-Olds et al. 2010). 
The MARA group exhibited a combination of skeletal and dentalveolar changes that were stable over time. Treatment results included flaring of the maxillary and mandibular incisors, a decrease in SNA, restrained maxillary growth, a steepening of the occlusal plane, and an increase in mandibular length of $0.94 \mathrm{~mm}$ per year. The MARA restraint of maxillary growth is in contrast to the 2003 study of Pangrazio-Kulbersh. However, the net effect of restrained maxillary growth, combined with increased mandibular growth, provides the desired anteroposterior correction of the maxillomandibular relationship in the treatment Class II patients.

\section{The Pharynx}

The pharynx is a funnel-shaped musculofibrous tubular passage, which is compressed in an anterioposterior direction. Its roof is situated immediately below the cranial base; while the inferior limits continues into the esophagus. The posterior wall lies immediately anterior to the bodies of the cranial six cervical vertebrae (Morris 1953). The anterior wall is incomplete, as the nasal cavities open into the upper part, and the oral cavity opens into the middle part of the pharynx. The lower portion of the pharynx serves as entrance into the larynx. According to the communication with the three cavities the pharynx is arbitrarily subdivided into three parts: the nasal pharynx, oral pharynx, and laryngeal pharynx (Sicher 1952).

The nasal pharynx belongs functionally to the respiratory system, and is bound by various walls. The roof, or fornix, combined with the posterior wall form a continuous arched wall that extends anteriorly from the base of the nasal septum to the caudal border of the anterior arch of the atlas. The anterior wall of the nasal pharynx is composed of the two nasal choanae. The floor is a posterior continuation of the floor of the nasal fossae formed by the pharyngeal surface of the soft palate. The floor becomes incomplete dorsally and presents as a narrow opening between the nasal and oral pharynx, the pharyngeal isthmus (Morris 1953).

The oral pharynx is not only a passage for air to travel to the respiratory system, but a common passageway in which food reaches the digestive system. The oral pharynx is a continuous passage from the posterior of the oral cavity cranially with the nasal pharynx, and caudally with the laryngeal pharynx. The posterior wall is related to the vertebral column, generally extending from the second to fourth cervical vertebra. The anterior wall is deficient at the opening to the oral cavity, but caudally is formed by the root of the tongue. Laterally the oral pharynx is bound by soft tissue and muscular components of the tube shaped structure. Caudally, near the level of the hyoid bone, the oral pharynx is continuous with the laryngeal pharynx (Gray 1948).

The laryngeal pharynx is the caudal portion of the pharynx and is continuous caudally with the esophagus near the level of the sixth cervical vertebra. This portion of the pharynx is wide cranially and narrow caudally. Its posterior wall is continuous with that of the oral pharynx and is related to the fifth and sixth cervical vertebrae. The lateral walls are composed of soft tissue and muscular structures, many of which are attached to 
the hyoid bone. The epiglottis occupies the cranial portion of this region, caudal to which is the superior aperture of the larynx (Morris 1953).

\section{Treatment Effects on Pharyngeal Airway}

Previous studies of the effects of orthodontic treatment on the pharyngeal airway consist of studies performed primarily using 2-dimensional cephalometric analysis. A 2011 study by Restrepo et al. evaluated the changes in the airway dimensions of class II retrognathic children who received treatment with either Klammt or Bionator II. The sample consisted of 50 lateral cephalograms of class II retrognathic patients in a prepubertal stage, before and after the use of a functional treatment for 1 year. When the measurements before and after treatment were compared, a statistically significant increase in the airway dimensions was found at the space where the adenoid tissue was located. The only airway dimensions found to have increased after treatment with functional appliances were the ones located at the nasopharynx.

Hänggi et al. (2008) compared the changes in pharyngeal airway volume of growing children to a group of children who had received activator-headgear Class II treatment. The experimental group consisted of 32 patients, 16 males and 16 females, who had received at least nine months of combined activator-headgear treatment, followed by full fixed orthodontic treatment. This group was compared with a control group that had received only minor orthodontic treatment. Hänggi et al. used pretreatment (mean age of 10.4 years), post-treatment (mean age of 14.5 years), and long term follow up (mean age of 22.1 years) lateral cephalograms to analyze the pharyngeal airway. Body height measurements were also collected to evaluate somatic growth patterns. The authors found significant growth differences between the two groups. The treatment group showed a greater increase in the pharyngeal area and length as well as an increase in the distance between the tongue and posterior pharyngeal wall. Hänggi et al. (2008) found in their study that orthodontic therapy has the potential to increase pharyngeal airway dimensions.

A study similar by Kirjavainen et al. (2007) used cephalograms to assess the changes in pharyngeal airway dimensions following cervical headgear treatment of Class II division 1 malocclusions. The study examined the pre and post-treatment lateral cephalograms of forty Class II division 1 patients treated using a cervical-pull headgear as the only treatment appliance. The data collected from the cephalometric evaluations of the Class II patients was then compared to cross-sectional data of 80 age matched Class I patients. Kirjavainen et al. (2007) found the Class II patients to possess wider nasopharyngeal spaces and narrower oral and hypopharyngeal spaces when compared to the Class I controls pretreatment. It was also found that the treatment of the Class II malocclusion resulted in a widening in the retropalatal area. No significant changes were seen in the oral and hypopharynx (Kirjavainen et al. 2007).

The studies that currently exist on the effects of Class II correction on the

pharyngeal airway have been accomplished using linear 2-dimensional cephalometric 
analysis. With the advancement of imaging technologies, and the development of conebeam computed tomography, it is now possible to analyze the airway volumetrically. In a study by Aboudara et al. (2009), these two imaging techniques were compared by using them to evaluate the size of the nasopharyngeal airway in 35 adolescent subjects. Volumetric measurement errors were found to range from 0 to 5\% when compared to the known volumes using calibration phantoms. Aboudara et al. (2009) also found a high correlation between the pharyngeal airway area and volume; the larger the area, the larger the volume. This study did however show large volumetric variability for airways seen to be relatively similar on lateral cephalometric examination. It was concluded, "the cone-beam 3-dimensional scan is a simple and effective method to accurately analyze the airway" (Aboudara et al. 2009).

\section{Cone-beam Computed Tomography}

Cone-beam computed tomography (CBCT) scanners are based on volumetric tomography using a 2-dimensional extended digital array to provide an area detector in combination with a 3-dimensional x-ray beam (Scarfe et al. 2006). CBCT images are collected using a single $360^{\circ}$ scan of the patient from which a series of basis projection images are acquired (Graber 2005). Using this "projection data", proprietary software programs apply sophisticated algorithms to generate a 3-dimensional volumetric data set. This software allows images to be reconstructed in 3 orthogonal planes: sagittal, axial, and coronal (Scarfe et al. 2006). CBCT imaging provides many advantages compared to traditional CT imaging, and is currently being used in numerous aspects of dentistry, including implant planning, surgical assessment of pathology, TMJ assessment, as well as its use in orthodontics to assess growth and development (Scarfe et al. 2006).

CBCT uses a single rotational scanning by an x-ray source and a reciprocating $\mathrm{x}-$ ray detector to facilitate acquisition of many single basis images, each slightly offset in beam-geometry rotation (Farman, et al. 2006). This raw image data can then be studied in various proprietary software programs to produce real-time advanced image display modes. These modes include linear curved, and oblique multiplanar reformation (MPR) sections perpendicular to the axial slices (Farman, et al. 2006). Currently there are multiple methods to reconstruct cephalometric radiographs from CBCT scans. These methods allow the practitioner to utilize the over 75 years worth of previous cephalometric orthodontic knowledge that has been obtained through previous studies. With the ability to reconstruct traditional cephalograms, existing cephalometric databases can be used for orthodontic treatment projections.

Farman et al. reported the ray-sum method as a way to simulate lateral cephalometric images from CBCT data sets. This method uses volumetric data to reconstruct a "virtual cephalogram". The image that is produced has uniform magnification because voxel resolution is isotropic, or equal in all 3 dimensions (Farman, et al. 2006). The fact that these reconstructed images are free from magnification must be taken into consideration when they are used in comparison with conventional cephalogram containing various amounts of magnification. 


\section{Cone-beam Computed Tomography Accuracy}

A study by Moshiri et al. (2007), examined the accuracy of ray-sum derived cephalograms compared with traditional cephalograms and anatomical truth. In this study a sample of 23 dry human skulls were used, upon which 15 anatomical landmarks were identified. 9 linear measurements, commonly used in cephalometric analysis, were measured on the skulls to serve as the anatomical truth. CBCT images were acquired using the i-CAT system with a single 360-degree, 20-second scan, comprising 306 basis images. Lateral cephalogram images were constructed from the scan using the ray-sum method with a voxel size of $0.4 \mathrm{~mm}$. Conventional digital lateral cephalograms were acquired using a Quint Sectograph with the photostimulable phosphor system. Linear measurements on all cephalograms were made by importing the images into Dolphin Imagining software. The results of the study showed the CBCT-derived 2-dimensional lateral cephalograms proved to be more accurate than conventional lateral cephalograms for most linear measurements calculated in the sagittal plane (Moshiri, et al. 2007).

In a study of the accuracy and reliability of linear cephalometric measurements derived from CBCT scans, Berco et al. (2009) compared measurements taken from CBCT scans of a dry human skull, to measurements of the skull itself. Seventeen landmarks were identified on the skull, each being labeled with a $0.5 \mathrm{~mm}$ diameter stainless steel ball bearing fixed with adhesive. Twenty-nine linear measurements were made directly on the skull and compared with the same measurements made on CBCT scans obtained using an i-CAT scan of 20 seconds with a $0.4 \mathrm{~mm}$ voxel size. All measurements for comparison were made by 2 different operators on 4 separate occasions. Method errors were found in the $\mathrm{x}, \mathrm{y}$, and z-axes of $0.19,0.21$, and $0.19 \mathrm{~mm}$ respectively. A mean measurement error was determined to be $-0.01 \mathrm{~mm}$. All measurement errors were found to be below the known voxel size and clinically insignificant. The authors concluded from this study that the i-CAT CBCT unit that was used allowed for clinically accurate and reliable 3D linear measurements, "with accuracy limited in part to voxel size and method error" (Berco et al., 2009).

In a study to determine the effect of CBCT voxel size on the accuracy of linear measurements, Damstra et al. (2010) used 10 dry human mandibles. 12 landmarks were identified upon which glass sphere markers were attached. The mandibles were scanned in three different sessions, using $0.40 \mathrm{~mm}$ and $0.25 \mathrm{~mm}$ voxel size resolutions. 25 linear measurements between the glass sphere landmarks were obtained on the CBCT images. These linear measurements were then compared to the anatomic truth obtained through direct measurement on the mandibles using a digital caliper. The results showed the intraclass correlation coefficients between the anatomical truth measurements and the measurements of the CBCT images of both voxel sizes studied to be greater than 0.99 . The correlation coefficient showed all the measurements derived from the CBCT scans to be accurate. The authors also found no difference in accuracy between the 0.40 and $0.25 \mathrm{~mm}$ voxel size groups, indicating that a increased voxel resolution did not result in greater accuracy of linear measurements (Damstra et al., 2010). 
The previously discussed studies have demonstrated that CBCT technology is capable of reproducing accurate and reliable two-dimensional images. However, it is this technology's three-dimensional capabilities that are of interest. It allows the segmentation and visualization of three-dimensional craniofacial structures including hollow structures such as the airway, which allows the transition of orthodontic analysis from lengths and angles to volumes and surface areas (El et al. 2010). Currently few studies exist that examine the reliability and accuracy of measurements in three dimensions.

Included in the existing studies that have attempted to assess the accuracy and reliability of measurements in three dimensions using CBCT is a study by El et al. (2010). The aim of their study was to compare the reliability and accuracy of 3 commercially available viewers for measuring upper airway volumes. The study examined CBCT images obtained from a Hitachi CB Mercuray Scanner (Hitachi Medical Systems America, Twinsburg, Ohio) of 30 randomly selected patients. The viewers included in the study were Dolphin3D (version 11, Dolphin Imaging \& Management Solutions, Chatsworth, Calif), InVivo-Dental (version 4.0.70, Anatomage, San Jose, Calif), and OnDemand3D (version 1.0.1.8407), CyberMed, Seoul, Korea). The commercial views were compared against a custom-written program called OrthoSegment (OS). The OS program was used as the gold standard for comparison, after having shown to be highly accurate in a previous study. The study found the reliability to be high for all of the programs. The highest correlation found with the OS program was the Dolphin3D measurement of the oropharynx volume, and the InVivoDental measurement of the nasal passage volume. High correlation was found for all programs (El et al. 2010). El et al. (2010) concluded that the 3 commercially available views are highly reliable in their airway volume calculations.

\section{Pharyngeal Analysis Using Cone-beam Computed Tomography}

The improvements in airway imaging capability provided by CBCT technology, according to Osorio et al. (2008), provide the "potential for an improved understanding of airway pathology and upper airway mechanics." The 2008 article by Osorio et al., discusses the ability of CBCT imaging to produce traditional skeletal and soft tissue images, as well as to easily obtain linear and volumetric measurements. CBCT imaging allows reconstruction of three-dimensional images with excellent image quality for an extensive range of possibilities for upper airway examination and analysis.

Grauer et al. (2009) utilized this emerging technology in a study to assess the relationship of facial morphology with pharyngeal airway volume and shape. The study examined CBCT records of 62 non-growing patients, utilizing 3-dimensional virtual surface models to calculate airway volumes. The patients were grouped by anteroposterior jaw relationships (Class I, Class II, Class III), and vertical proportions. The study found a statistically significant relationship between the inferior airway volume and the anteroposterior skeletal relationships, but no differences in airway 
volumes related to vertical proportions. Skeletal Class II patients were seen to have reduced inferior airway volumes and greater projections of the tongue into the airway along the anterior wall of the pharynx. The shape of the airway of skeletal Class II patients, when viewed from the coronal plane, was narrower than either Class I or Class III subjects. Grauer et al. (2009) concluded that patients with varying anteroposterior jaw relationships have associated differences in airway shape and volume.

Kim et al. (2010) used CBCT imaging to analyze the 3-dimensional pharyngeal airway volume of 27 children to compare the airway volumes of children with retrognathic mandibles to those with normal craniofacial relationships. Lateral cephalograms were constructed from the CBCT scans for various cephalometric analysis, including ANB angles by which the subject were divided into 2 groups. A normal group consisted of patients with ANB angles between 2 and 5 degrees, and a retrognathic group with ANB angles greater 5 degrees. Kim et al. (2010) found a statistically significant difference in the total airway volume between the two skeletal patterns. However, no statistically significant differences were found between the two groups in cross-sectional area of the airway or in the various regions of the airway. This is in contrast to Grauer et al. (2009) who found volumetric differences isolated to the lower region of the pharynx. The mean total airway volume in retrognathic patients was significantly smaller than that of patients with a normal anteroposterior skeletal relationship (Kim et al. 2010).

El et al. (2011) also evaluated the airway volume for different dentofacial skeletal patterns using CBCT imaging. 140 patients were divided into 3 groups based on anteroposterior jaw relationships using the ANB angle measurements. The three groups represented were Class I patients with an ANB angle between 1 and 3 degrees, Class II patients with and ANB angle greater than 3 degrees, and Class III patients with an ANB angle less than 1 degree. El et al. (2011) found a significantly decreased oropharyngeal volume in the Class II patients when compared to Class I and Class III patients. Patients presenting with Class II skeletal patterns due to a retruded mandible, $\mathrm{SNB}<78^{\circ}$, were seen to have a statistically significant smaller airway volume than patients with an SNB angle greater than $78^{\circ}$. Class II patients in the study also had a statistically smaller nasal passage volume when compared with Class I subjects (El et al. 2011).

A study by Park et al. (2010) examined the volumetric, planar, and linear changes in the pharyngeal airway after mandibular setback surgery using CBCT imaging. The pharyngeal airways of 12 subjects who underwent mandibular setback surgery were assessed linearly and volumetrically using lateral cephalometric radiographs and CT images before surgery and 6 months after surgery. Linear analysis showed posterior movement of the soft palate, tongue, and hyoid bone following surgery. It was seen that the volume of the oropharynx slightly decreased after mandibular setback surgery, while the nasopharynx remained relatively constant. The authors found that although the structures around the mandible moved backward after mandibular setback surgery on linear analysis, airway capacity was maintained by a physiologic deformation in the shape of the airway. 


\section{The Straightwire Technique}

The straightwire orthodontic technique was developed by Lawrence Andrews based on his "Six Keys to Occlusion" (Andrews 1975). The Straightwire appliance consists of brackets with built in tip, torque, and in-out position. This bracket system allows the archwire to be straight when the teeth are in the correct positions, without any additional bends in the archwire. Andrews identified the ideal tooth positions of an orthodontic patient by studying 120 non-orthodontic study casts. These casts had teeth that were pleasing in appearance with the correct bite relationship, which in the view of Andrews, would not benefit from orthodontic treatment. A large number of orthodontically treated patients were also studied $(n=1,150)$. The patients who did not receive orthodontic treatment yet had ideal occlusion showed significant similarities in crown positions, while the treated patients did not. This study allowed Andrews to identify six keys to occlusion: 1) molar relationship, 2) crown angulations or mesiodistal tip, 3) labiolingul or buccolingual crown inclination, 4) rotations, 5) tight contacts, and 6) curve of Spee.

Treatment goals and guidelines identified by Andrews include: appliance simplicity, short treatment time, extraction of teeth should be avoided, if treatment plan will allow, and all records taken in central relation. Treatment goals and guidelines include ANB from 0 to 5 degrees, static occlusion that adheres to the six keys, and functional occlusion that is mutually protected (Andrews 1975). 


\section{CHAPTER 3. METHODOLOGY}

\section{Sample Description}

Subjects in the present study were collected from two private orthodontic practices (Jackson, TN, and Wichita, KS). Two cone-beam computed tomography images per person had been taken for various dental or orthodontic concerns unrelated to this retrospective project. Both pre-treatment and post-treatment orthodontic CBCT files were used from the selected orthodontic patients. The private practice CBCT scans were made on a Next Generation i-CAT ${ }^{\circledR}$ (Imaging Sciences, Hatfield, PA) with a grayscale resolution of 14 bits and voxel size of $0.4 \mathrm{~mm}$. The treatment group consists of scans obtained from the Wichita, KS practice. The control group consists of scans obtained from the practice in Jackson, TN.

A total of 70 selected subjects ( 36 males; 34 females) were analyzed in this study. The treatment group was composed of 38 subjects ( 15 females; 23 males) who were treated with the MARA and full orthodontic bonding. The control group included 32 subjects (19 females; 13 males) who were also fully banded and bonded, but Class II correction was achieved through Class II elastics. The patients included in the study were selected from an age range of 9 to 14 years. We limited the study to Class II, division 1 malocclusions by selecting subjects with a positive overjet of greater than or equal to $3.5 \mathrm{~mm}$ and an ANB angle of greater than 4. Subjects were phenotypically normal; no clefts or syndromes were included. Subjects were also eliminated from the study if they exhibited enlarged adenoid tissues, or other airway obstruction.

\section{Pharyngeal Analysis}

The pharynx was imaged from CBCT images $(n=140)$ of the head. The scans were oriented parallel to Frankfort Horizontal, with care taken to make measurements in the midsagittal plane. The midpoint between the upper central incisors was used as a midsagittal plane reference. Dolphin $3 \mathrm{D}^{\circledR}$ (Dolphin Imaging and Management Solutions, Chatsworth, CA) an orthodontic imaging and analysis software program was used to collect dimensional data. Version 11.5 was used, which employs an "airway" module. Images were imported as DICOM (Digital Imaging and Communications in Medicine) files into Dolphin $3 \mathrm{D}^{\circledR}$. The DICOM files were used to create a lateral cephalometric view from within Dolphin. Measurements were made by using a custom analysis within the Dolphin program.

\section{Volumetric Analysis}

The airway is easily distinguished from the surrounding tissues because of the large difference in x-ray attenuation between air in the pharynx and the high water content of the surrounding tissues (Hans 2011). The pharynx is divided into three regions 
(from superior to inferior): nasopharynx, oropharynx, and laryngopharynx (Drake et al. 2005). Due to the limited view of the laryngopharynx on the majority of the CBCT images, we did not measure the laryngopharynx.

The nasopharyngeal airway was measured by constructing a triangular area of interest (Park et al. 2010) (Figure 3-1) using these three planes:

1. Pt Plane: The plane passing through Pt (Pterygomaxillary fissure) and PNS.

2. PNS Plane: A horizontal line parallel to Frankfort Horizontal passing through Posterior Nasal Spine (PNS).

3. Pharyngeal Tonsil Plane: Soft tissue wall of the posterior nasopharynx.

The following three horizontal planes were used to construct a region of interest to surround the oropharynx and to divide the oropharyngeal airway into superior and inferior oropharyngeal regions.

1. PNS Plane: The horizontal line parallel to Frankfort Horizontal passing through Posterior Nasal Spine (PNS).

2. Soft Palate Plane: The horizontal line parallel to Frankfort Horizontal passing through $U$ point, which is the most inferior point on the soft palate at the uvular tip (Mazaheri 1994).

3. Epiglottis Plane: The horizontal line parallel with Frankfort Horizontal passing through Et, the most superior point (tip) of the epiglottis.

Once the airway was defined, the "sensitivity" slider tool in Dolphin, which allows the software to detect differences in grayscale resolution, was adjusted to best recognize the airway (sensitivity value of 45 ). The Dolphin $3 \mathrm{D}^{\circledR}$ module calculates the volume and the minimum cross-sectional area using segmentation and Dolphin's computer algorithm. This segmentation method has been shown to be superior to the manual slicing and manual tracing method (Yushkevich et al. 2006). The level of most constriction (minimum cross-sectional area) was recorded as well (Figure 3-2).

\section{Cephalometric Analysis}

Lateral cephalograms were constructed from the CBCT scans. A custom analysis was created with the help of Dolphin software technicians using version 11.5. This custom analysis was then used to make all measurements. The following list (in alphabetical order) provides descriptions all the anatomical landmarks used in this study. All minima and maxima assume the head is oriented according to Frankfort Horizontal (Table 3-1).

The following linear distances and angles were calculated for each constructed, non-magnified lateral cephalogram. This list (in alphabetical order) provides definitions of all measurements used in this study (Table 3-2). 


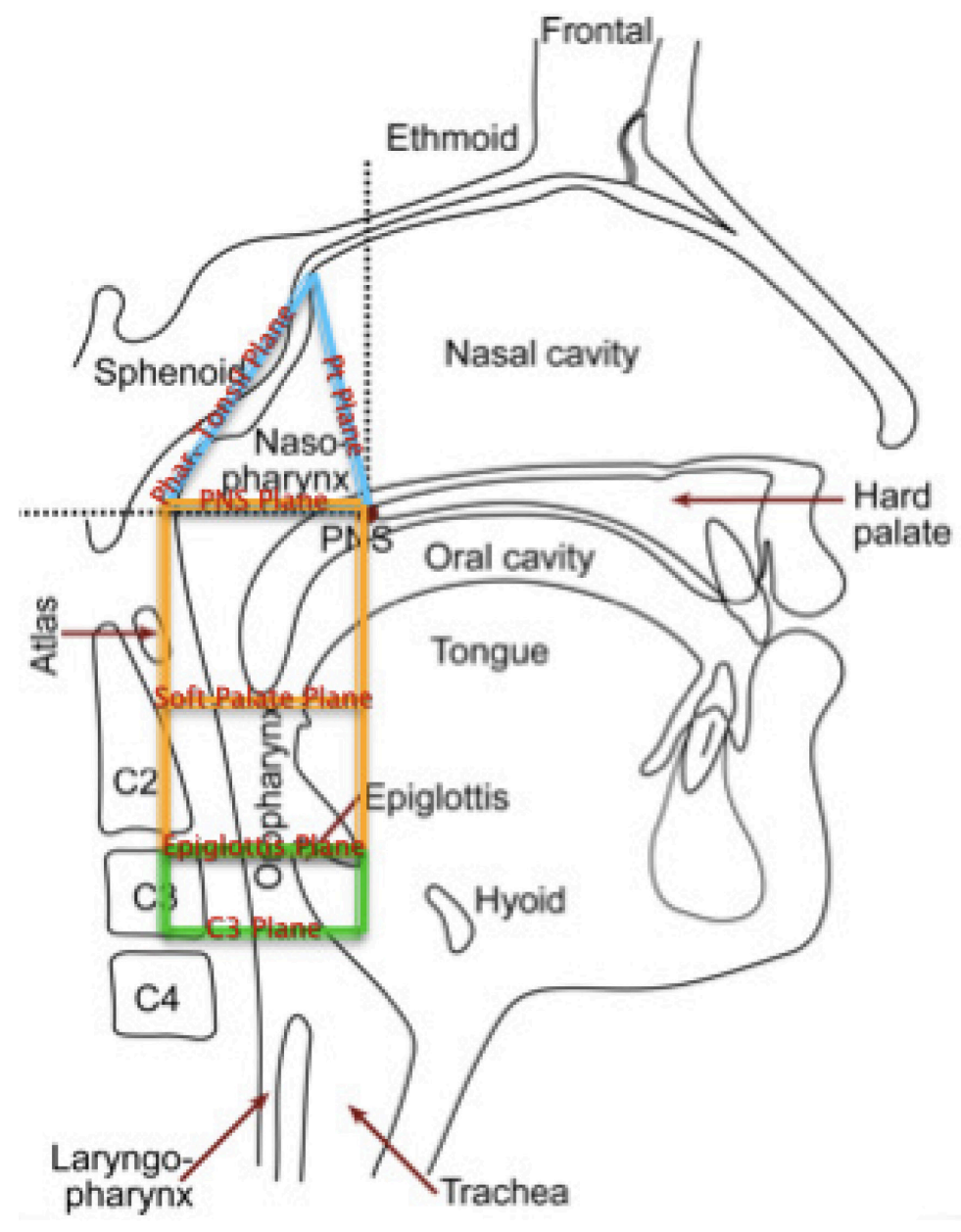

Figure 3-1. Sketch of lateral view of skull with skeletal and soft tissue landmarks identified and the airway segments delineated and defined.

Note: Figure produced in collaboration with co-resident Dr. Kyle D. Fagala and reproduced here with his permission. 


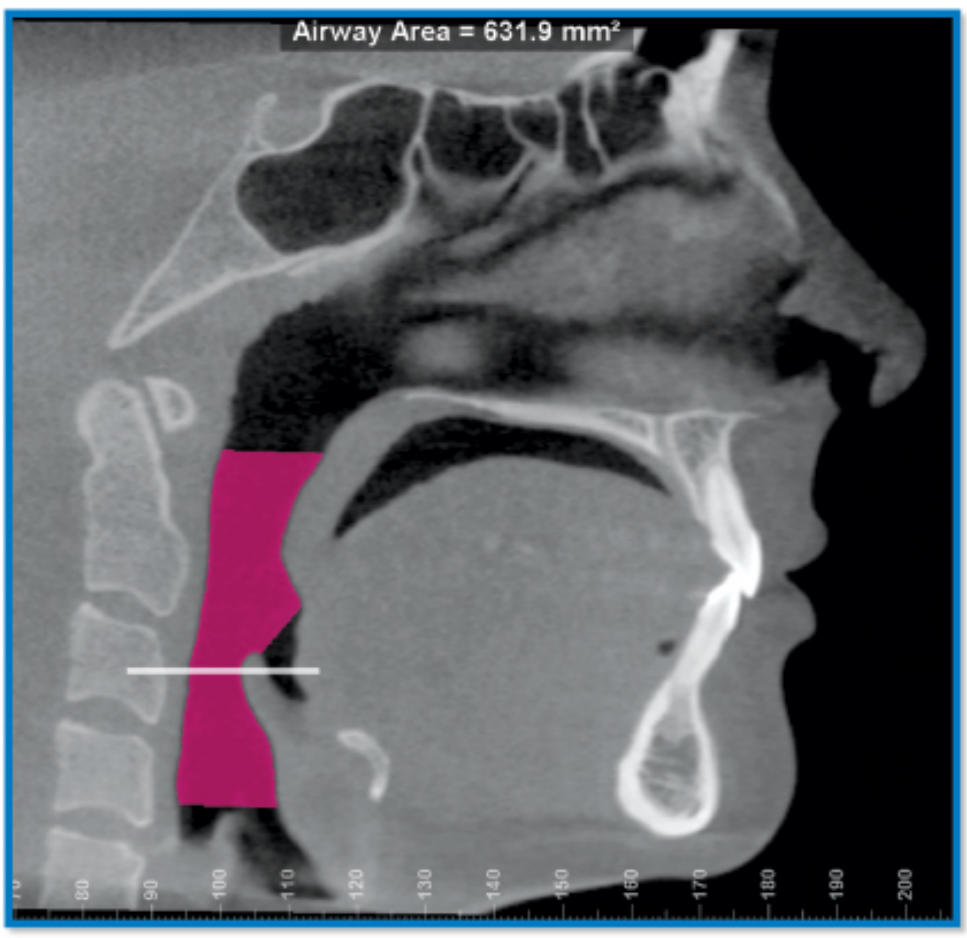

Figure 3-2. Two-dimensional rendering of the pharyngeal airway.

Note: Figure provided by Dr. Edward Harris March 11, 2011, and reproduced with his permission. 
Table 3-1. Cephalometric landmarks.

\begin{tabular}{|c|c|}
\hline Landmark & Definition \\
\hline A & $\begin{array}{l}\text { A Point (Subspinale): the most posterior point on the exterior } \\
\text { ventral curve of the maxilla between the anterior nasal spine and } \\
\text { Supradentale. }\end{array}$ \\
\hline $\mathrm{Aa}$ & $\begin{array}{l}\text { Anterior arch of the atlas: the most anterior point of the atlas } \\
\text { vertebrae. }\end{array}$ \\
\hline ANS & $\begin{array}{l}\text { Anterior nasal spine: the spinous process of the maxilla forming the } \\
\text { most anterior projection of the floor of the nasal cavity. }\end{array}$ \\
\hline B & $\begin{array}{l}\text { B Point (Supramentale): the most posterior point on the bony } \\
\text { curvature of the mandible between Infradentale and Pogonion. }\end{array}$ \\
\hline $\mathrm{Cd}$ & $\begin{array}{l}\text { Condylion: the most superior-posterior point on the curvature of the } \\
\text { capitulum of the condyle. }\end{array}$ \\
\hline Et & Tip of epiglottis: the most superior point of the epiglottis. \\
\hline $\mathrm{FH}$ & $\begin{array}{l}\text { Frankfort horizontal: a horizontal plane drawn from porion to } \\
\text { orbitale, with patient in natural head position. }\end{array}$ \\
\hline FOP & $\begin{array}{l}\text { Functional Occlusal Plane: a line drawn between the cusp tips of the } \\
\text { permanent first molars and the most mesial premolars (or deciduous } \\
\text { molars in mixed dentition). }\end{array}$ \\
\hline Go & $\begin{array}{l}\text { Gonion: the most posterior-inferior point on the gonial angle of the } \\
\text { mandible. }\end{array}$ \\
\hline Gn & $\begin{array}{l}\text { Gnathion (anatomic): the most anterior-inferior point of the } \\
\text { mandibular symphysis. }\end{array}$ \\
\hline $\mathrm{H}$ & $\begin{array}{l}\text { H Point: the most anterior and superior point on the hyoid bone } \\
\text { body. }\end{array}$ \\
\hline Ii & $\begin{array}{l}\text { Incision Inferius: the incisal tip of the most anterior mandibular } \\
\text { central incisor. }\end{array}$ \\
\hline Is & $\begin{array}{l}\text { Incision Superius: the incisal tip of the most anterior maxillary } \\
\text { central incisor. }\end{array}$ \\
\hline L6 & L6 mesial: the most mesial point on the lower first molar. \\
\hline M & M Point: the most posterior point of the mandibular symphysis. \\
\hline Me & Menton: the most inferior point on the mandibular symphysis. \\
\hline $\mathrm{Na}$ & $\begin{array}{l}\text { Nasion: the junction of the frontal nasal suture at the most posterior } \\
\text { point on the curvature at the bridge of the nose. }\end{array}$ \\
\hline Or & Orbitale: the most inferior point on lower margin of the bony orbit. \\
\hline $\mathrm{Pg}$ & $\begin{array}{l}\text { Pogonion: the most anterior point on the anterior contour of the } \\
\text { bony chin below B point and above Gnathion. }\end{array}$ \\
\hline Phw & $\begin{array}{l}\text { Posterior pharyngeal wall: point on the pharyngeal wall at the level } \\
\text { of the Psp (Posterior soft palate). }\end{array}$ \\
\hline PNS & $\begin{array}{l}\text { Posterior Nasal Spine: the spinous process formed by the most } \\
\text { posterior projection of the juncture of the palatine bones in the } \\
\text { midline of the roof of the oral cavity. }\end{array}$ \\
\hline
\end{tabular}


Table 3-1. (Continued).

\begin{tabular}{ll}
\hline \multicolumn{1}{c}{ Landmark } & \multicolumn{1}{c}{ Definition } \\
\hline Po & $\begin{array}{l}\text { Porion: the midpoint on the superior aspect of the rim of the } \\
\text { external auditory meatus. }\end{array}$ \\
Psp & $\begin{array}{l}\text { Posterior soft palate: the most superior-posterior point of the soft } \\
\text { palate. }\end{array}$ \\
Pt & $\begin{array}{l}\text { Pterygomaxillary fissure: the most superior-posterior point on the } \\
\text { average of the right and left outlines of the pterygomaxillary fissure. }\end{array}$ \\
Se & $\begin{array}{l}\text { Sella turcica: the center of the hypophyseal fossa, determined by } \\
\text { visual inspection. }\end{array}$ \\
$\mathrm{Se} \perp$ & $\begin{array}{l}\text { Sella-Vertical: the imaginary line passing through Sella, } \\
\text { perpendicular to Frankfort Horizontal plane. }\end{array}$ \\
$\mathrm{U} 6$ & U6 mesial: the most mesial point on the upper first molar. \\
\hline
\end{tabular}

Source: Table compiled in collaboration with co-resident Dr. Kyle D. Fagala and reproduced with his permission. 
Table 3-2. Linear (millimetric) dimensions and angles measured on the lateral cephalograms.

\begin{tabular}{|c|c|}
\hline Name & Description \\
\hline AFH & Anterior Facial Height: the linear distance from Nasion to Menton. \\
\hline ANB & $\begin{array}{l}\text { The inferior angle formed at the junction of the Nasion-A Point line } \\
\text { and the Nasion-B Point line. }\end{array}$ \\
\hline $\mathrm{AO}-\mathrm{BO}$ & $\begin{array}{l}\text { Wits Appraisal: the linear distance between two points along } \\
\text { Downs' occlusal plane obtained from the intersection of a } \\
\text { perpendicular line from point A and from point B to the occlusal } \\
\text { plane. }\end{array}$ \\
\hline Co-A & The linear distance from Condylion to A Point. \\
\hline Co-Gn & The linear distance from Condylion to Gnathion. \\
\hline FMA & $\begin{array}{l}\text { the anterior inferior-angle formed at the junction of the Frankfort } \\
\text { Horizontal plane and the mandibular plane. }\end{array}$ \\
\hline $\mathrm{H}$ to $\mathrm{FH}$ & the linear distance from $\mathrm{H}$ point to $\mathrm{FH}$, perpendicular to $\mathrm{FH}$. \\
\hline $\mathrm{Na}-\mathrm{Me}$ & the linear distance between Nasion and Menton. \\
\hline $\mathrm{Na} \perp-\mathrm{A}$ & $\begin{array}{l}\text { the linear distance from point A to Nasion when projected } \\
\text { perpendicular to the Frankfort Horizontal plane. }\end{array}$ \\
\hline $\mathrm{Na} \perp-\mathrm{B}$ & $\begin{array}{l}\text { the linear distance from point B to Nasion when projected } \\
\text { perpendicular to the Frankfort Horizontal plane. }\end{array}$ \\
\hline $\mathrm{Na} \perp-\mathrm{Pg}$ & $\begin{array}{l}\text { the linear distance from Pogonion to Nasion when projected } \\
\text { perpendicular to the Frankfort Horizontal plane. }\end{array}$ \\
\hline Psp-Phw & $\begin{array}{l}\text { Superior Airway Space: the linear distance from Psp to a point } \\
\text { directly posterior to Psp on the posterior pharyngeal wall, parallel to } \\
\text { FH. }\end{array}$ \\
\hline Se-Go & the linear distance from Sella to Gonion. \\
\hline $\mathrm{Se}-\mathrm{Me}$ & The linear distance from Sella to Menton. \\
\hline $\mathrm{Se}-\mathrm{Na}$ & The linear distance from Sella to Nasion. \\
\hline $\mathrm{Se} \perp-\mathrm{A}$ & $\begin{array}{l}\text { The linear distance from Sella to A point when projected } \\
\text { perpendicular to the Frankfort Horizontal plane. }\end{array}$ \\
\hline $\mathrm{Se} \perp-\mathrm{B}$ & $\begin{array}{l}\text { The linear distance from Sella to B point when projected } \\
\text { perpendicular to the Frankfort Horizontal plane. }\end{array}$ \\
\hline $\mathrm{Se} \perp-\mathrm{M}$ & $\begin{array}{l}\text { The linear distance from Sella to M Point when projected } \\
\text { perpendicular to the Frankfort Horizontal plane. }\end{array}$ \\
\hline $\mathrm{Se} \perp-\mathrm{Po}$ & $\begin{array}{l}\text { The linear distance from Sella to Porion when projected } \\
\text { perpendicular to the Frankfort Horizontal plane. }\end{array}$ \\
\hline SNA & $\begin{array}{l}\text { The posterior inferior angle formed at the junction of the Sella- } \\
\text { Nasion plane and the Nasion-A Point plane. }\end{array}$ \\
\hline
\end{tabular}


Table 3-2. (Continued).

\begin{tabular}{ll}
\hline \multicolumn{1}{c}{ Name } & \multicolumn{1}{c}{ Description } \\
\hline SNB & The posterior inferior angle formed at the junction of the Sella- \\
& $\begin{array}{l}\text { Nasion plane and the Nasion-B Point plane. } \\
\text { Angle formed by the intersection of a line from Se-Gn with the FH } \\
\text { plane. }\end{array}$ \\
\hline
\end{tabular}

Source: Table compiled in collaboration with co-resident Dr. Kyle D. Fagala, and reproduced with his permission. 
The cephalometric measurements from Table 3-2 are categorized in the following table (Table 3-3) by skeletal and dental measurements. Also included in the table is the purpose for each measurement in the cephalometric analysis.

\section{Class II Analysis}

Currently there are several methods used to identify Class II malocclusions, as well as the severity. It seems, however, that the most informative cephalometric measurement to the present analysis is the ANB angle. The ANB does have its shortcomings, as it depends primarily on angulation of the Sella-Nasion plane, a plane that is anatomically variable (Jacobson and Jacobson 2006). However, its usage is perhaps the most widespread and well understood by the orthodontic community. We compared the Sella-Nasion line to Frankfort Horizontal plane and eliminated cases with too large a discrepancy. We then included in the study patients with an ANB greater than 4 degrees.

\section{Error Calculation}

A total of $30 \mathrm{CBCT}$ scans were randomly selected and their cephalometric variables, as well as airway dimensions were re-measured by the same investigator following a wash-out period of several weeks after the initial measurements. The results of the original and re-measured groups were compared; a repeatability index was calculated (Dahlberg 1940). The remaining subjects were then analyzed according to the established protocol.

\section{Statistical Design}

Measurements were exported from Dolphin 3D ${ }^{\circledR}$ into a spreadsheet in Microsoft ${ }^{\circledR}$ Excel 2010 (Microsoft Corporation, Redmond, WA). The spreadsheet was used to combine patient information including demographic information (patient's age, sex, occlusion classification, and skeletal classification). The measurements then were transferred to the statistical package JMP ${ }^{\circledR} 10$ (SAS Institute Inc., Cary, NC). Descriptive statistics were computed, including arithmetic mean, standard deviation (sd), standard error of mean (sem), upper and lower $95 \%$ confidence limit $\left(\mathrm{L}_{1}, \mathrm{~L}_{2}\right)$, sample size $(\mathrm{n})$, sample variance $\left(\mathrm{s}^{2}\right)$, skewness $\left(\mathrm{g}_{1}\right)$, coefficient of variation $(\mathrm{CV})$, maximum value, median value, and minimal value. Some of the graphs were made using DeltaGraph 6.0 for Windows (Rockworks, Utah), but most were developed within the JMP 10 platform, especially using the GraphBuilder ${ }^{\odot}$ routine.

Analysis of variance (ANOVA) was used to simultaneously test variables for group differences. The ANOVA design allowed for simultaneously testing of an age difference (the covariate) while males and females were analyzed in tandem, controlling for sexual dimorphism. 
Table 3-3. A list of the variables measured from the lateral cephalometric images in the present study.

\begin{tabular}{|c|c|}
\hline Dimension & Variable \\
\hline & $\begin{array}{c}\text { Cranial Base } \\
\end{array}$ \\
\hline $\mathrm{Se}-\mathrm{Na}$ & Anterior Cranial Base Length (mm) \\
\hline \multirow{3}{*}{ Co-A } & Midface \\
\hline & Horizontal length of the midface $(\mathrm{mm})$ \\
\hline & Facial Height \\
\hline $\mathrm{Na}-\mathrm{Me}$ & Total Anterior Facial Height (mm) \\
\hline $\mathrm{PFH} / \mathrm{AFH}$ & Ratio of posterior facial height to anterior facial height \\
\hline Se-Go & Posterior Facial Height (mm) \\
\hline \multirow{4}{*}{$\begin{array}{l}\text { Na Perp-A } \\
\text { SNA } \\
\text { Se } \perp \text {-A }\end{array}$} & Maxillary Position \\
\hline & A-P positional change in the maxilla $(\mathrm{mm})$ \\
\hline & Positional change in the maxilla relative to anterior cranial base $\left(^{\circ}\right)$ \\
\hline & A-P positional change in the maxilla $(\mathrm{mm})$ \\
\hline \multirow{10}{*}{$\begin{array}{l}\text { Co-Go } \\
\text { Co-Gn } \\
\text { Go-Me } \\
\text { Na Perp-B } \\
\text { Na Perp-Pg } \\
\text { SNB } \\
\text { Se } \perp \text {-B } \\
\text { Se } \perp-M \\
\text { Y Axis }\end{array}$} & Mandibular Size and Position \\
\hline & Vertical Mandibular Ramus Length (mm) \\
\hline & Mandibular Length (mm) \\
\hline & Mandibular Body Length (mm) \\
\hline & A-P positional change in the mandible $(\mathrm{mm})$ \\
\hline & Protrusive growth of the chin $(\mathrm{mm})$ \\
\hline & Positional change in the mandible relative to anterior cranial base $\left({ }^{\circ}\right)$ \\
\hline & A-P positional change in the mandible $(\mathrm{mm})$ \\
\hline & A-P positional change in the mandible $(\mathrm{mm})$ \\
\hline & Rotation of the mandible $\left(^{\circ}\right)$ \\
\hline \multirow{5}{*}{$\begin{array}{l}\text { ANB } \\
\text { AO-BO } \\
\text { FMA } \\
\text { Na A-Pg }\end{array}$} & Maxillomandibular Relationships \\
\hline & A-P relationship of the maxilla-mandible $\left(^{\circ}\right)$ \\
\hline & A-P relationship of the maxilla-mandible $(\mathrm{mm})$ \\
\hline & Maxillomandibular divergence $\left(^{\circ}\right)$ \\
\hline & Facial convexity $\left({ }^{\circ}\right)$ \\
\hline
\end{tabular}


Table 3-3. (Continued).

\begin{tabular}{|c|c|}
\hline Dimension & Variable \\
\hline & Dental Relationships \\
\hline FMIA & $\begin{array}{l}\text { Inclination of lower incisors relative to the Frankfort line. The distal } \\
\text { angle is measured. }\left({ }^{\circ}\right)\end{array}$ \\
\hline IMPA & Inclination of lower incisors relative to the mandibular plane $\left(^{\circ}\right)$ \\
\hline Overbite & Vertical overlap of the upper and lower central incisors (mm) \\
\hline Overjet & Horizontal overlap of the upper and lower central incisors (mm) \\
\hline U1-L1 & $\begin{array}{l}\text { Angular relationship between the maxillary and mandibular central } \\
\text { incisors }\left(^{\circ}\right)\end{array}$ \\
\hline U1-NA & Angulation of the maxillary central incisor to the maxilla $\left(^{\circ}\right)$ \\
\hline U1-NA mm & Position of the maxillary central incisor to the maxilla (mm) \\
\hline L1-NB & Angulation of the mandibular central incisor to the mandible $\left(^{\circ}\right)$ \\
\hline L1-NB mm & Position of the mandibular central incisor to the mandible $(\mathrm{mm})$ \\
\hline
\end{tabular}

Source: Table compiled in collaboration with co-resident Dr. Kyle D. Fagala, and reproduced with his permission. 
Box plots were produced to explore the data and to screen for outliers. Plots were generated for each tooth and grade combination. A box plot is a graphic technique in the family of descriptive statistics. It is a graphical display of the sample distribution that resembles a box with two lines or "whiskers" coming out the sides. The box can be drawn horizontally or vertically. The five vertical lines in each box plot denote 10, 25, 50,75 , and 90th percentiles. The ends of the box fall at the upper and the lower quartiles of the distribution, QU and QL, so the middle $50 \%$ of the cases (the median) falls within the QU-to-QL range of scores. Sample variability is shown by the length of the box. The line in the middle of the box represents the median of the distribution. The median is an estimate of the central tendency, and placement of the median suggests whether the data are skewed. If the median is closer to the upper quartile, the data are negatively skewed; if the median is closer to the lower quartile, they are positively skewed. Individual data points above and below the 10th and 90th percentile are denoted by symbols. Data points that fall outside the 10\% and 90\% are called outliers (Norman and Streiner 1994). 


\section{CHAPTER 4. RESULTS}

\section{Sample Statistics}

A total of 70 patients' orthodontic files (sets of CBCTs) were examined in this study. Cases were examined at the start and the end of comprehensive orthodontic treatment. All were American white adolescents between the ages of 10 and 15 years of age at the start of orthodontics (mean $=12.14$ years; $s d=1.97$ years; $n=70$ ). Of these, 38 were treated with Edgewise mechanics alone, while the other 32 were treated with a MARA in combination with Edgewise mechanics. There were 36 boys and 34 girls in the sample.

Using two-way ANOVA tests (treatment and patients' sex were the factors), neither the ages at the start nor end of treatment nor treatment duration differed significantly between the two treatment groups (Table 4-1). As shown in Table 4-2, treatment commenced around 12 years of age, so many of the patients would have been preadolescents. Treatment required about 2.2 years, with or without the MARA, so the end of treatment records were taken at around 14 to 15 years of age (mean $=14.31$ years; $\mathrm{sd}=1.17$ years; $\mathrm{n}=70$ cases).

Figure 4-1 displays a summary of the sample sizes by sex and orthodontic office (Kansas or Tennessee). Again, as confirmed by the ANOVA tests in Table 4-1, none of the age differences by sex or site was statistically significant.

\section{Initial Records Examination}

At the initial records examination, each variable $(\mathrm{k}=44)$ was assessed statistically with a two-way factorial model with treatment (Edgewise-Alone or MARA+Edgewise) and sex of the patient (boy, girl). Of these (Appendix A), 7 exhibited a significant difference (Table 4-3), and all of these were differences between treatments (i.e., none of the variables exhibited a significant sex difference). Inspection of Table 4-3 shows that the statistically significant variables can be partitioned into two groups, (1) those measuring differences in incisor angulation and (2) those due to size of the mandible.

A difficulty with these data is that geographical site and orthodontic mechanics were completely confounded. That is, all of the cases treated with Edgewise mechanics alone were from the Tennessee site, and all of the MARA+Edgewise cases were treated the Kansas office. This confounding makes it difficult to distinguish between differences due to geography (Kansas, Tennessee) versus those attributable to treatment (Edgewise with or without a MARA). It would have been clearer if proportionate samples of each treatment had been collected from each orthodontic office.

At the initial examination, there was the opportunity to see the influences of the geographical differences (seemingly some unknown combination of genetic differences, 
Table 4-1. Results of two-way ANOVAs for age at examinations by patient's sex and source of the sample (Kansas or Tennessee), sexes pooled.

\begin{tabular}{lcccc}
\hline \multicolumn{1}{c}{ Source } & df & Sum of Squares & F Ratio & P Value \\
\hline & 1 & Age at Start of Treatment & & \\
Treatment & 1 & 3.06 & 2.11 & 0.1510 \\
Patient's Sex & 1 & 0.01 & 0.00 & 0.9510 \\
Treatment-x-Sex & 1 & 0.04 & 0.03 & 0.8712 \\
& & Age at End of Treatment & & \\
Treatment & 1 & 3.51 & 2.56 & 0.1145 \\
Patient's Sex & 1 & 0.07 & 0.05 & 0.8271 \\
Treatment-x-Sex & 1 & 0.40 & 0.29 & 0.5904 \\
& & & & \\
Treatment & 1 & 0.01 & 0.05 & 0.8159 \\
Patient's Sex & 1 & 0.11 & 0.41 & 0.5224 \\
Treatment-x-Sex & 1 & 0.69 & 2.72 & 0.1040 \\
\hline
\end{tabular}

Table 4-2. Descriptive statistics for the chronological ages of the samples at the examinations (years).

\begin{tabular}{lcc}
\hline \multicolumn{1}{c}{ Group } & Least Squares Mean & Standard Error \\
\hline Edgewise, Female & Age at Start of Treatment & \\
Edgewise, Male & 12.39 & 0.276 \\
MARA+, Female & 12.36 & 0.334 \\
MARA+, Male & 11.92 & 0.311 \\
& 11.98 & 0.251 \\
Edgewise, Female & Age at End of Treatment & \\
Edgewise, Male & 14.52 & 0.269 \\
MARA+, Female & 14.62 & 0.325 \\
MARA+, Male & 14.22 & 0.302 \\
& 14.00 & 0.244 \\
& & \\
Edgewise, Female & Duration of Treatment & 0.116 \\
Edgewise, Male & 2.13 & 0.140 \\
MARA+, Female & 2.26 & 0.130 \\
MARA+, Male & 2.31 & 0.105 \\
\hline
\end{tabular}




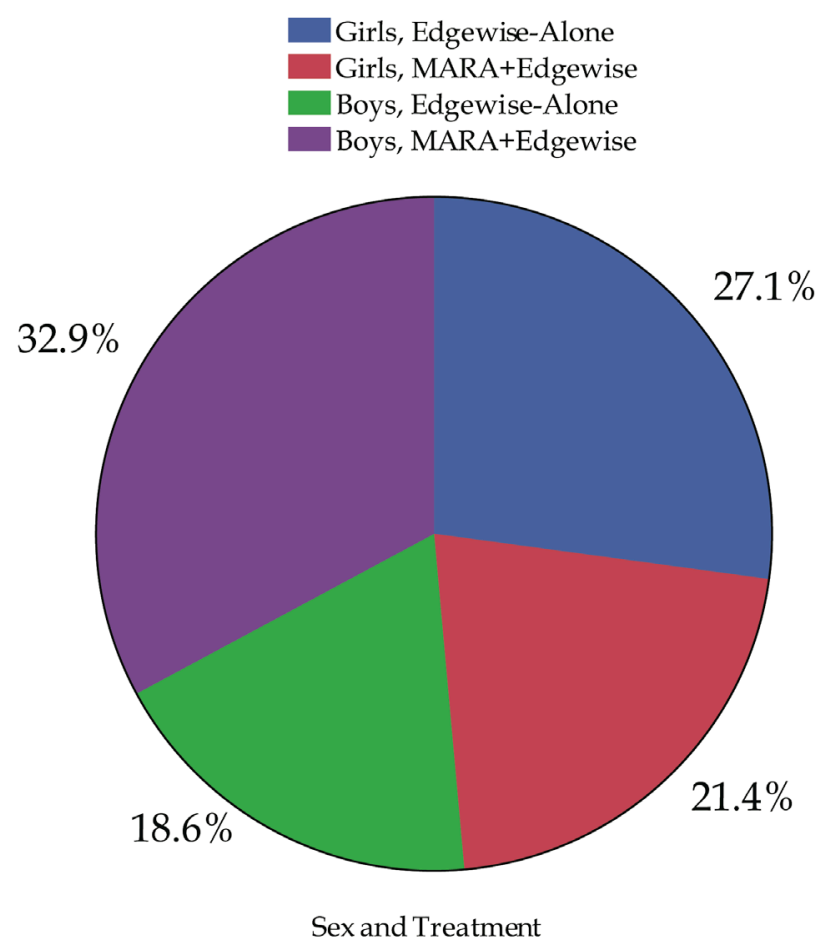

Figure 4-1. Percentages of the total sample by sex of the subject and geographical site.

Note: $(\mathrm{n}=70)$, Kansas $=$ MARA+Edgewise; Tennessee $=$ Edgewise-Alone . 
Table 4-3. Listing of the statistically significant differences by two-way ANOVA at the initial records examination.

\begin{tabular}{lcr}
\hline \multicolumn{1}{c}{ Source } & Effect & P-Value \\
\hline Interincisal angle & Treatment & 0.0044 \\
U1-Sella-Nasion & Treatment & 0.0108 \\
U1-NA $\left(^{\circ}\right)$ & Treatment & 0.0122 \\
U1-NA (mm) & Treatment & 0.0447 \\
Condylion-A-Point & Treatment & $<0.0001$ \\
Condylion-Gnathion & Treatment & 0.0010 \\
Gonion-Menton & Treatment & 0.0020 \\
Sella-Vertical-to-Pogonion & Treatment & $<0.0001$ \\
\hline
\end{tabular}


environmental differences, and differences in case selection), since no treatment has been delivered.

\section{In-treatment Changes}

Table 4-4 lists the statistically significant ANOVA tests from among Appendix $\mathbf{B}($ alpha $=0.05)$. In these two-way factorial tests there was a mixture of treatment (Edgewise mechanics with or without a MARA) and sex (boy, girl) effects. Inspection of this table shows, however, that there was only one significant treatment-by-sex interaction effect (incisor overbite). The nature of this single interaction effect is discussed first. These interactions are commonly not understood by clinicians.

An assumption of ANOVA models is that the effects are additive among all factors. Additivity means that the effects are equivalent between effects, so expectation here is that the effect of "sex" will be equivalent in both "treatments" (Edgewise mechanics with or without MARA). In fact, as graphed in Figure 4-2, there was a significant interaction effect $(\mathrm{P}=0.0249)$ for the variable overbite. The nature of the interaction (significant non-additivity) is described in this figure's legend.

An important feature in Table 4-4 is the absence of any airway (pharyngeal) variable, which confirms that there was no overriding difference or change in the airway dimensions during treatment. All of the significant differences involved skeletodental dimensions. Pharyngeal changes evidently have not been apparent (at least on twodimensional planar x-rays) so they have not been tested for in traditional cephalometric studies.

A key measure of maxillary protrusivenes is the cephalometric angle SNA. Treatment changes, by sample are graphed for SNA in Figure 4-3. There was effectively no change in the Edgewise+MARA sample, but SNA was reduced, on average, about two degrees in the Edgewise-alone sample.

The angle SNB also showed a significant treatment difference, but just barely so ( $\mathrm{P}=0.0424$, two-tail test). The SNB changes are graphed in Figure 4-4. The slight decrease in the Edgewise-alone sample coupled with the slight increase in the MARA+ sample produced a statistically significant difference between the two samples $(\mathrm{P}=$ 0.0424). This result offers weak support for the benefit of a MARA in enhancing the facial profile.

The FMA was seen to be significantly different between the two treatment groups, with the Edgewise group experiencing a significantly larger decrease (Figure 4-5).

Another related dental angle, Interincisal Angle, also achieved a significant difference between treatments (Figure 4-6), but this seems of little importance because its positioning is predominantly a function of the orthodontists' training and personal 
Table 4-4. Listing of the statistically significant variables as assessed from twoway ANOVAs.

\begin{tabular}{llr}
\hline Variable & Significant Effect & P-Value \\
\hline 1. SNA & Treatment & \\
2. SNB & Treatment & 0.0020 \\
3. FMA & Treatment & 0.0424 \\
4. IMPA & Treatment & 0.0020 \\
5. Interincisal angle & Treatment & 0.0007 \\
6. U1-SeNa & Sex & $<0.0001$ \\
7. L1-NB $\left(^{\circ}\right)$ & Treatment & 0.0441 \\
8. U1-NA $\left(^{\circ}\right)$ & Treatment & 0.0007 \\
9. U1-NA $\left(^{\circ}\right)$ & Sex & 0.0070 \\
10. Incisor overbite & Treatment-X-Sex & 0.0448 \\
11. Condylion-A & Treatment & 0.0249 \\
12. Condylion-A & Sex & 0.0345 \\
13. Condylion-Gnathion & Sex & 0.0054 \\
14. A-Na Perpendicular & Treatment & $<0.0001$ \\
15. Pogonion-Nasion-Perpendicular & Treatment & 0.0001 \\
16. Anterior Facial Height & Sex & $<0.0001$ \\
17. Posterior Facial Height & Sex & 0.0001 \\
18. Go-Menton & Sex & 0.0128 \\
19. Sella-Vertical-A & Treatment & 0.0018 \\
20. Sella-Vertical-A & Sex & 0.0101 \\
21. Sella-Vertical-B & Treatment & 0.0011 \\
22. Sella-Vertical-B & Sex & 0.0001 \\
23. Sella-Vertical-M & Treatment & 0.0034 \\
25. Sella-Vertical-M & Sex & $<0.0001$ \\
\hline
\end{tabular}




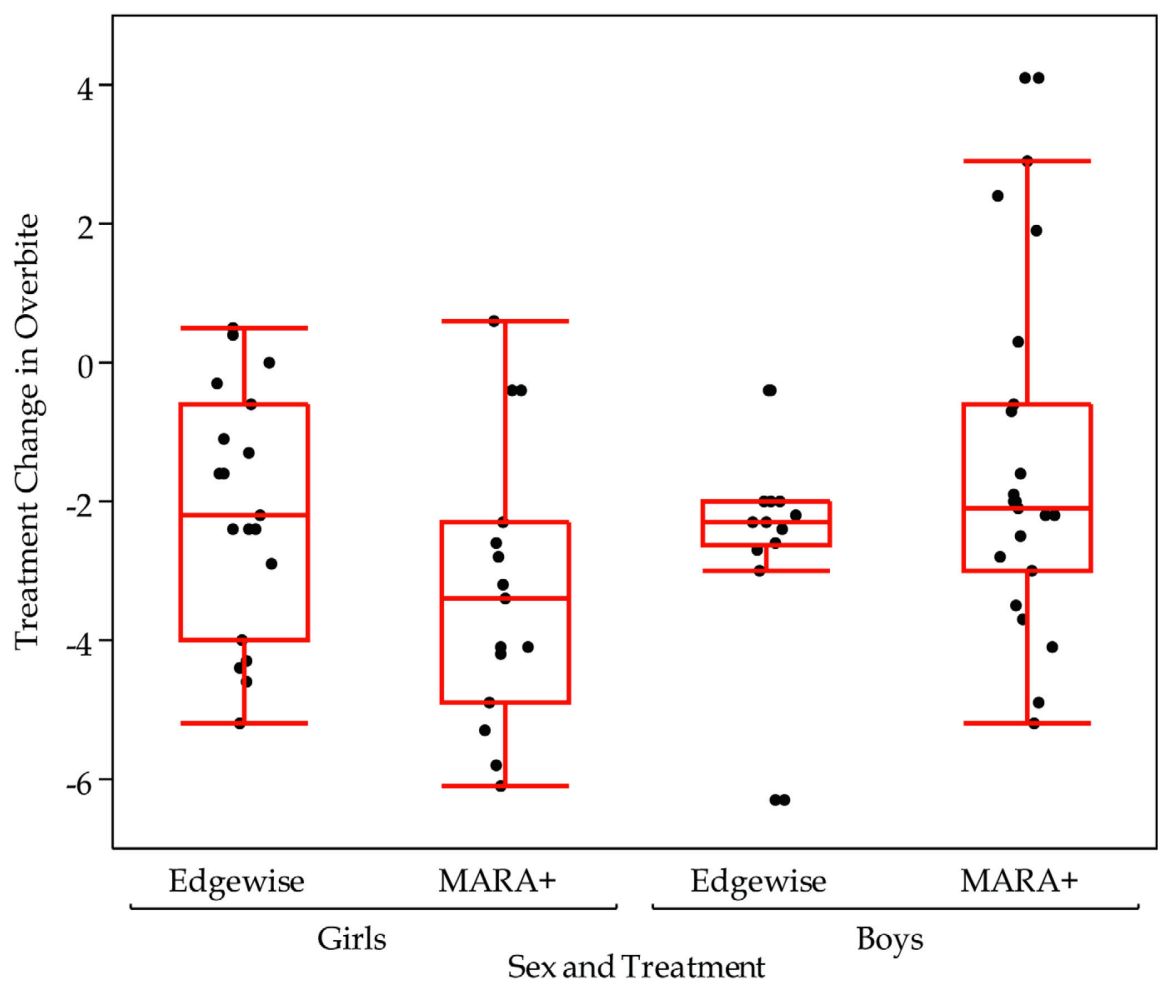

Figure 4-2. Box plots, by mechanics and sex, for the in-treatment changes in incisor overbite.

Notes: Recall that these are the amounts of treatment change, so in girls there was a greater median decrease in the Edgewise-alone sample. In boys, however, the two mechanics produced about the same median decreases in overbite. It is this difference in the treatment changes in the two different sexes that produced a statistically significant interaction effect. Also, it is noticeable how much more consistency (small variability) occurred in the Edgewise-alone sample of boys. 


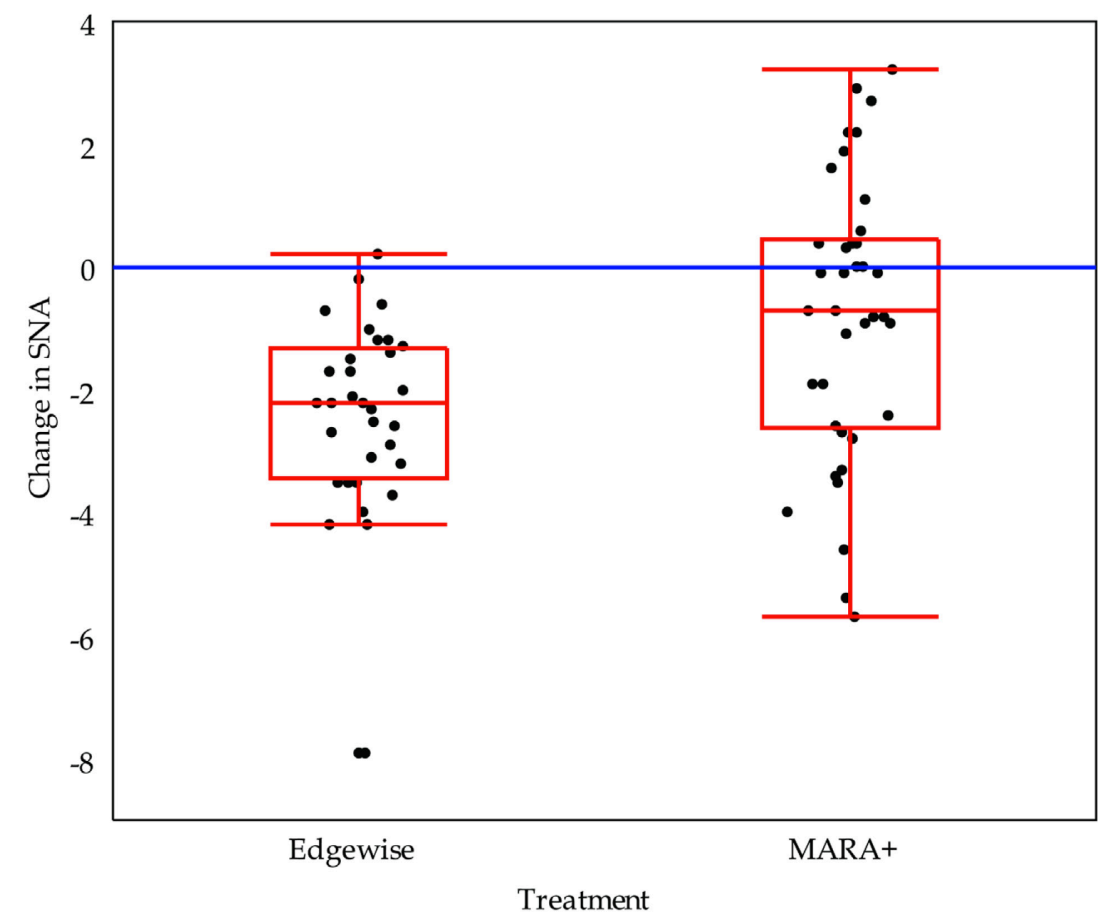

Figure 4-3. Box plots of the treatment changes in the angle SNA, by treatment.

Notes: "Edgewise" denotes cases that were treated by Edgewise mechanics alone (the Tennessee group), while "MARA+" are the cases that were treated with Edgewise mechanics plus a MARA (the Kansas sample). The blue horizontal line was set at zero (no change). 


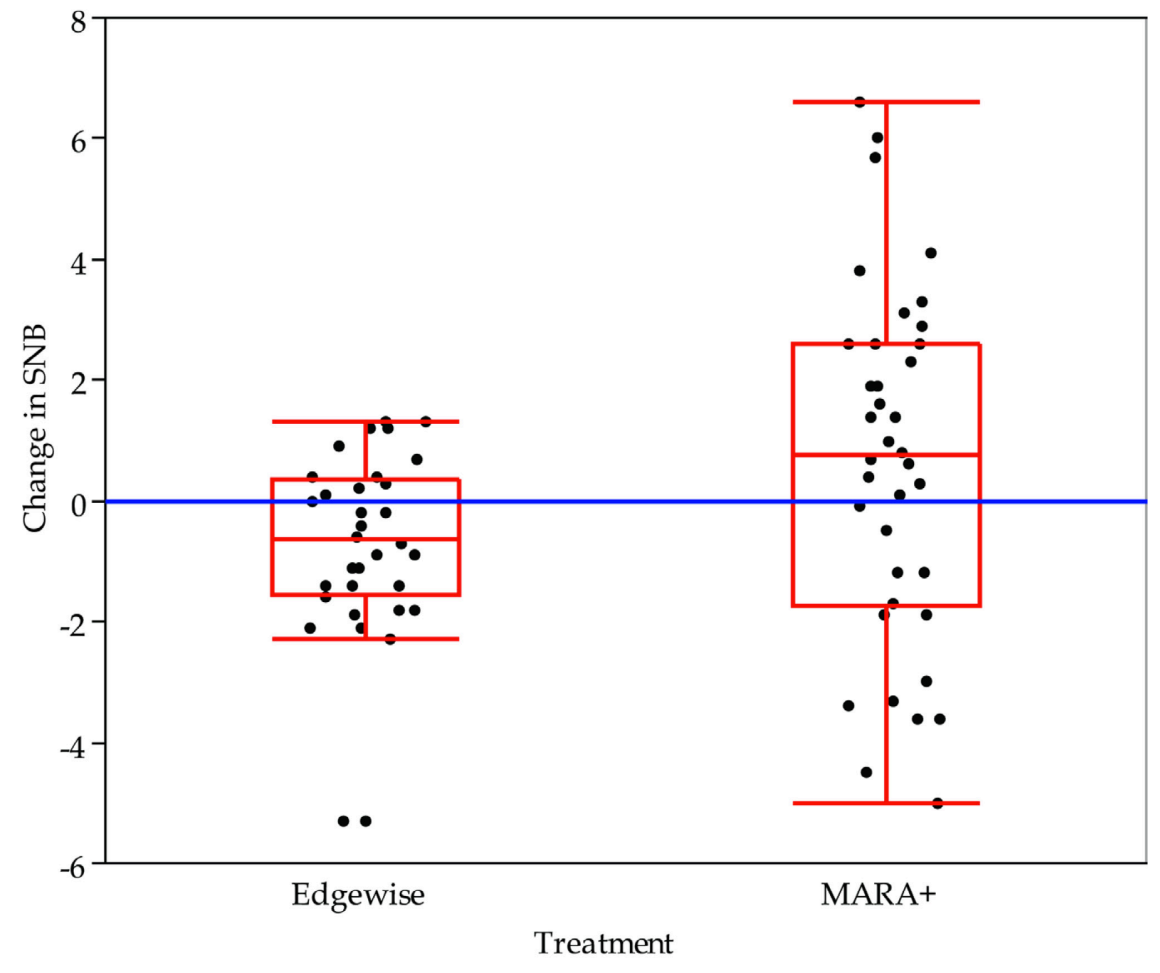

Figure 4-4. Box plots of the changes in the angle SNB.

Note: The median change in the Edgewise sample was a decrease of almost one degree, while in the MARA+ sample; SNB increased a little less than one degree. 


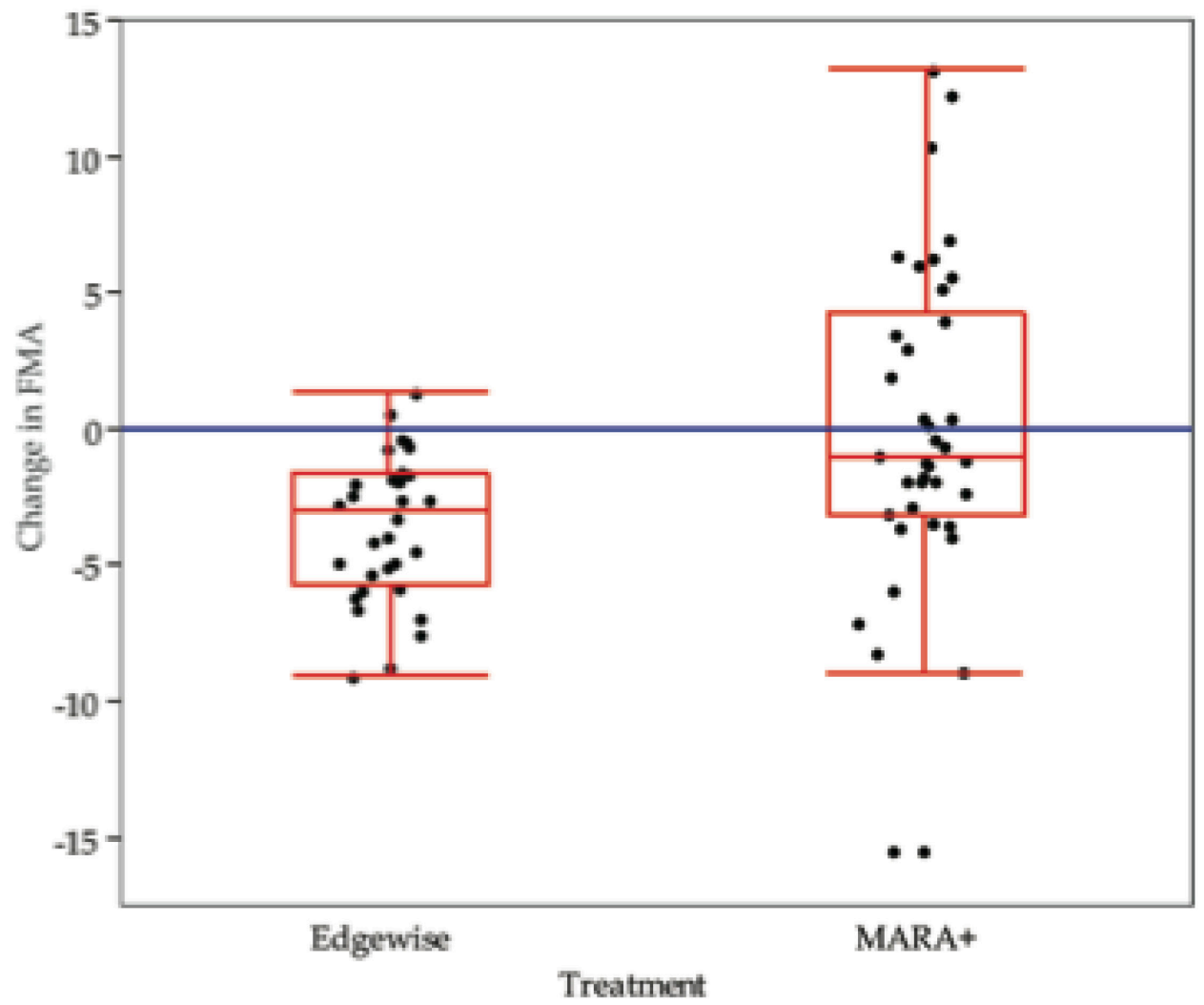

Figure 4-5. Box plots of the changes in FMA by treatment group.

Notes: Both groups exhibited an average reduction in FMA, but the median decrease was greater, at about 2 degrees, in the Edgewise-Alone sample. The blue horizontal line was drawn at zero (no change). 


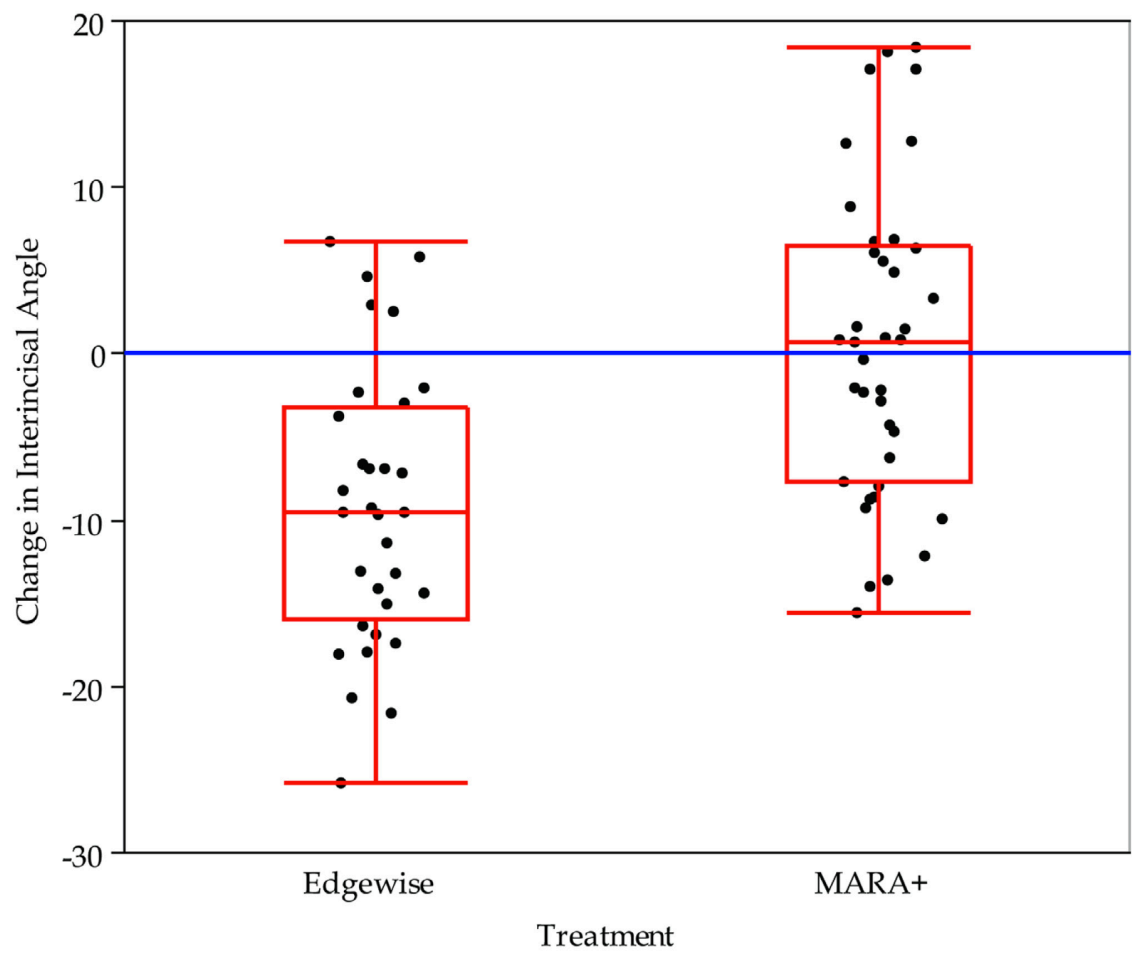

Figure 4-6. Box plots of the treatment differences in the Interincisal Angle.

Notes: There was little average change in the MARA+Edgrwise sample, but this angle was reduced almost 10 degrees on average in the Edgewise-Alone group. The blue horizontal line was drawn at zero (no change). 
preferences. The incisors in the Edgewise-alone group were more proclined than in the MARA+ sample during treatment (reductions in the angle) by roughly 10 degrees.

Changes in the millimetric distance of U1 to the Sella-Nasion line are graphed in Figure 4-7. Here there was a significant difference between the sexes but not between the treatment groups (Table 4-4).

The cephalometric angle U1 to the Sella-Nasion line experienced a significant sex difference during treatment (Figure 4-7). The difference here was highly significant statistically $(\mathrm{P}<0.0001)$. On the average, there was little change in the girls (median $=\mathrm{a}$ slight increase), but the average boy had the angle U1-SN increase by about 5 degrees during treatment. It would seem, then, that the orthodontists who treated these cases had a different expectation for the aesthetics of this angle in boys and girls.

\section{End of Treatment Comparisons}

There were eight significant variables at the start of treatment, but by the end of orthodontic treatment the number of significant variables (alpha $=0.05$; two-tailed tests) increased to 23 (Table 4-5). In these two-factor ANOVA tests, Treatment, Sex, or the Treatment-by-Sex Interaction could be statistically significant (alpha $=0.05$; two-tail), and Table 4-5 notes which were significant in the 23 significant tests of the 44 variables (Appendix C). In no case was the interaction effect significant, so the boys and girls responded comparably (fulfilling the assumption of additivity; Sokal and Rohlf 1995). Most of the tests disclosed treatment differences. In just one test was "Sex" the only significant factor (anterior facial height).

None of the pharyngeal variables was significantly different between treatments before treatment, but the measure of pharyngeal volume termed Airway 3 Volume (Inferior) became significantly different between samples by the end of treatment (Figure 4-8). This volume was smaller in MARA+Edgewise group. Least-squares mean for the airway in the Edgewise-alone sample was $4,722 \mathrm{~mm} 3$, while this mean was $3,742 \mathrm{~mm} 3$ in the MARA+Edgewise series. On the other hand, this volume also was smaller in the MARA+Edgewise group at the start of treatment, but not significantly so.

The Y-axis angle also differed at the end of treatment (Figure 4-9). The median angle at the end of treatment was 56 degrees in the Edgewise sample and 59 degree in the MARA+Edgewise sample. The Y-axis was measured as the inferior-anterior angle, so a smaller angle indicated a more-anterior, less steep growth axis in the Edgewise-alone sample.

The next significant ANOVA encountered was the mandibular plane angle, FMA (Figure 4-10). In keeping with the Y-axis, the FMA was lower in the Edgewise-alone sample. One suggestion is that this sample has a smaller FMA and is more forwardgrowing than in the MARA+Edgewise group. 


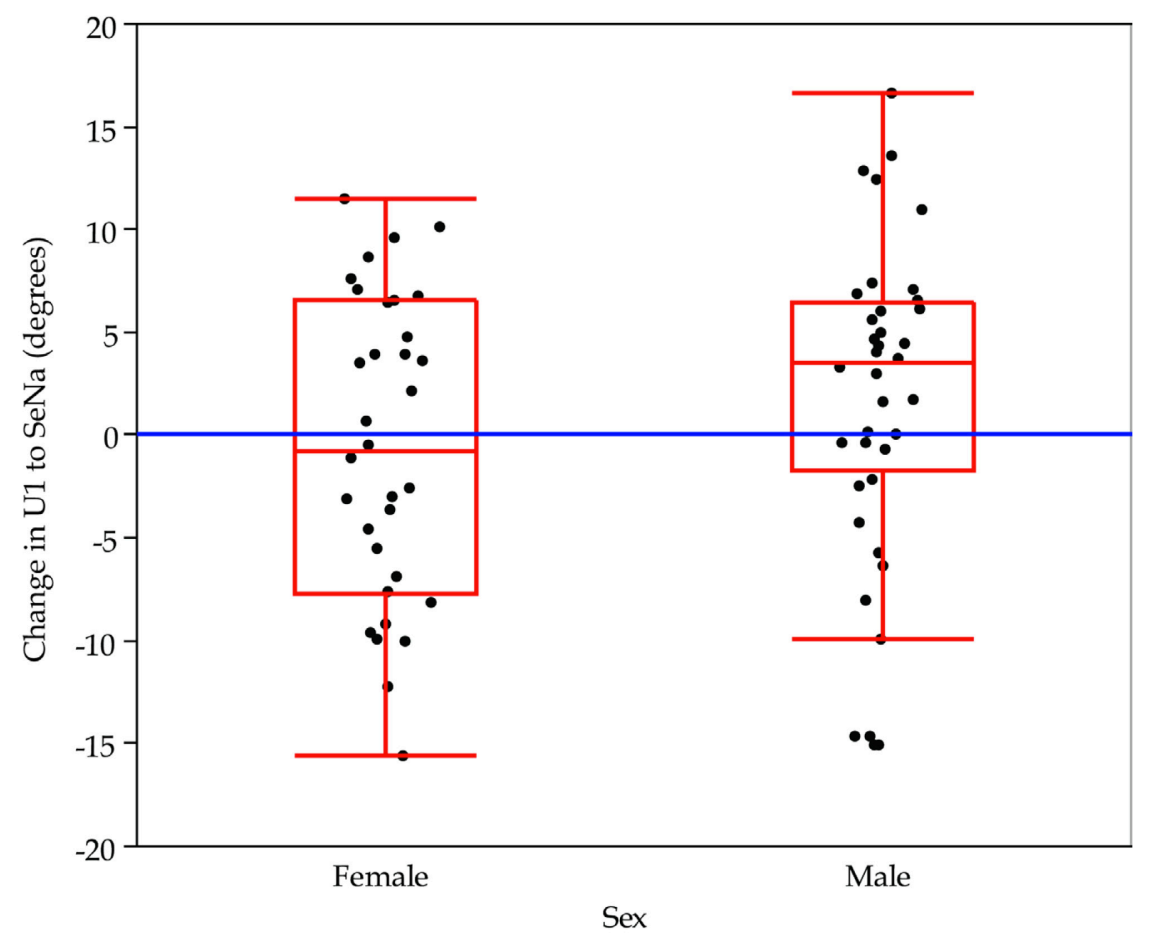

Figure 4-7. Box plots of the treatment changes in the dental angle U1 to the SellaNasion line, by sex.

Notes: There was no treatment change in this variable, but boys exhibited around a 5degree increase while girls exhibited a slight decrease. The blue horizontal line was drawn at zero (no change). 
Table 4-5. Listing of the 23 statistically significant variables found between the samples at the end of treatment and which factors attained significance.

\begin{tabular}{ll}
\hline Variable & Effect \\
\hline 1. Airway 3 Volume (Inferior) $\left(\mathrm{mm}^{3}\right)$ & Treatment \\
2. Y-Axis $\left(^{\circ}\right)$ & Treatment \\
3. FMA $\left(^{\circ}\right)$ & Treatment \\
4. IMPA $\left(^{\circ}\right)$ & Treatment \\
5. FMIA $\left(^{\circ}\right)$ & Treatment \\
6. Interincisal angle $\left(^{\circ}\right)$ & Treatment \\
7. U1-SeNa $\left(^{\circ}\right)$ & TX and Sex \\
8. L1-NB $\left(^{\circ}\right)$ & Treatment \\
9. L1-NB $(\mathrm{mm})$ & Treatment \\
10. U1-NA $\left(^{\circ}\right)$ & TX and Sex \\
11. Incisor Overjet & Treatment \\
12. Condylion-to-A Point $(\mathrm{mm})$ & TX and Sex \\
13. Condylion-to-Gnathion $(\mathrm{mm})$ & TX and Sex \\
14. A-to-Nasion Perpendicular & Treatment \\
15. Pogonion-to-Nasion Perpendicular $(\mathrm{mm})$ & Treatment \\
16. Molar Relationship (mm) & Treatment \\
17. Posterior Facial Height $(\mathrm{mm})$ & Treatment \\
18. Gonion-to-Menton (mm) & TX and Sex \\
19. Sella-Vertical-to-A Point $(\mathrm{mm})$ & TX and Sex \\
20. Sella-Vertical-to-B Point $(\mathrm{mm})$ & TX and Sex \\
21. Anterior Facial Height & Sex \\
22. Sella-Vertical-to-Pogonion $(\mathrm{mm})$ & Treatment \\
23. Sella-Vertical-to-M Point $(\mathrm{mm})$ & TX and Sex \\
\hline
\end{tabular}




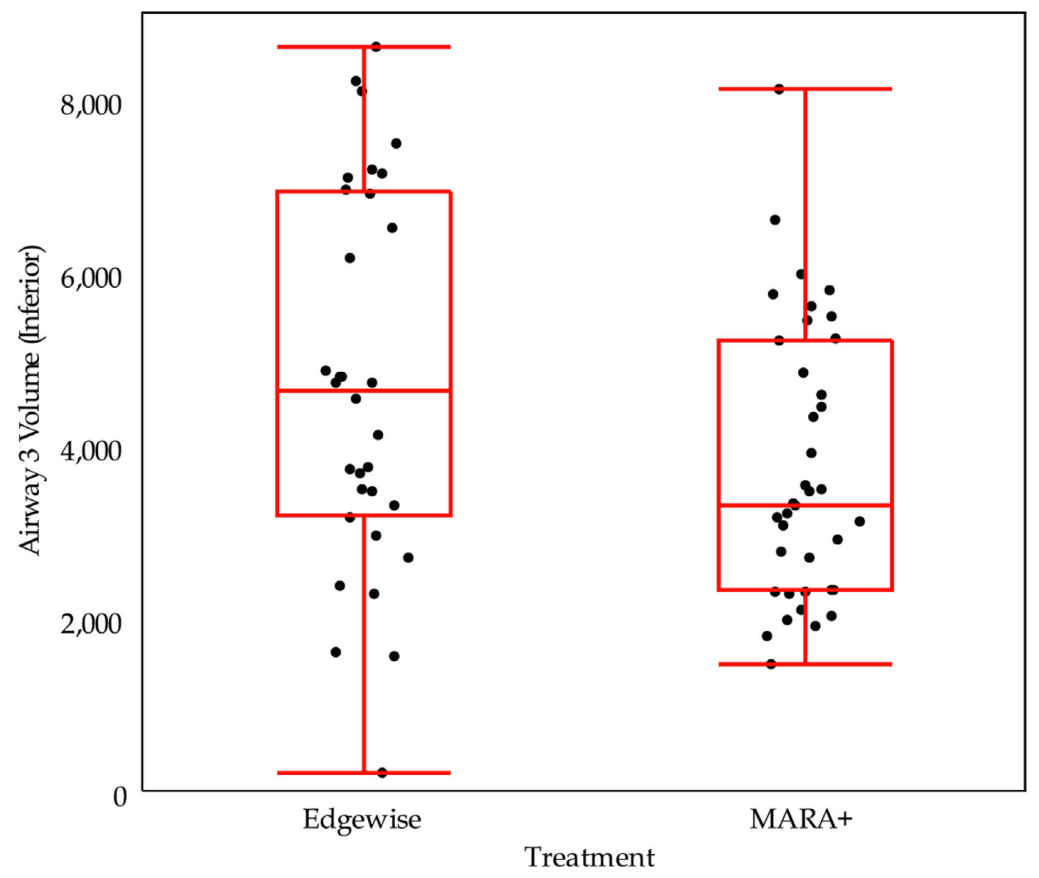

Figure 4-8. Box plots of the distributions of inferior pharyngeal volume $\left(\mathrm{mm}^{3}\right)$ between treatments evaluated at the end of treatment.

Notes: This also was termed pharyngeal volume 3. Edgewise refers to treatment with the Edgewise appliance alone $(n=32)$; MARA + refers to the combined use of the MARA and the Edgewise appliance $(\mathrm{n}=38)$. 


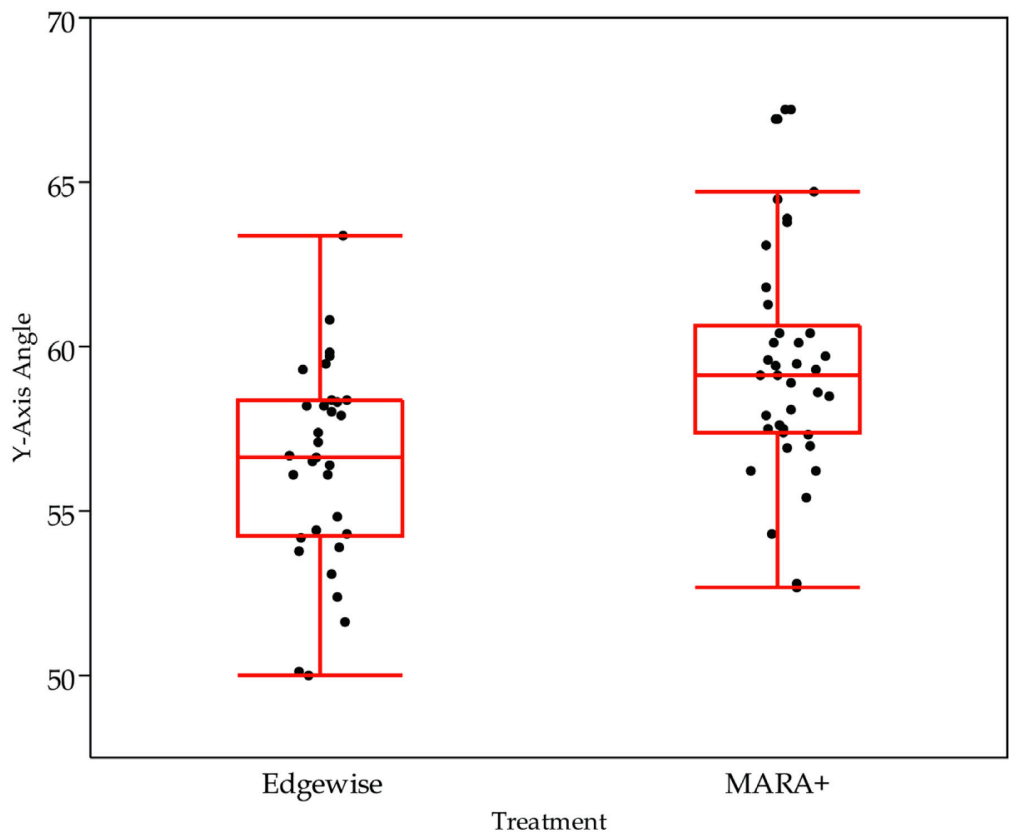

Figure 4-9. Box plots of the distributions of the Y-axis (degrees) between treatments evaluated at the end of treatment.

Note: Edgewise refers to treatment with the Edgewise appliance alone $(\mathrm{n}=32)$; MARA+ refers to the combined use of the MARA and the Edgewise appliance $(n=38)$. 


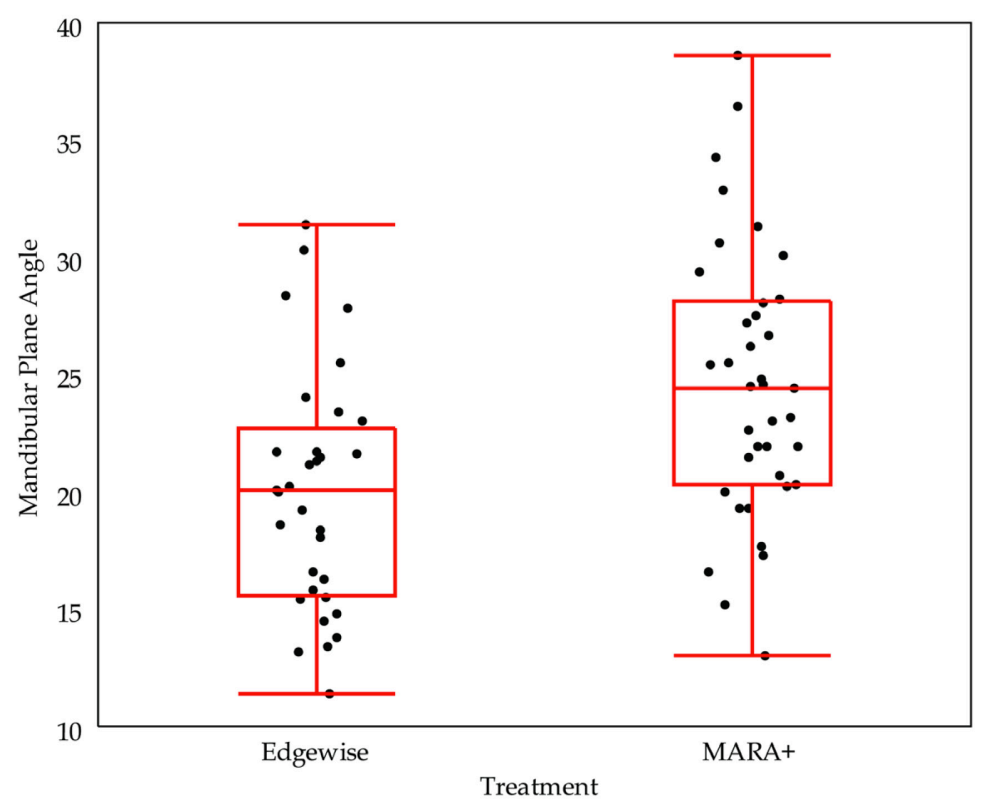

Figure 4-10. Box plots of the distributions of the angle FMA (degrees) between treatments evaluated at the end of treatment.

Note:Edgewise refers to treatment with the Edgewise appliance alone $(n=32)$; MARA+ refers to the combined use of the MARA and the Edgewise appliance $(n=38)$. 
IMPA was significantly larger (more proclination) in the Edgewise-alone sample. The mean at the end of treatment was 104 degrees in the Edgewise-alone sample, and 94.5 degrees in the MARA+Edgewise group (Figure 4-11). The angulation difference could be due to the individual preferences of the orthodontists and/or as an accommodation to the lower mandibular plane angle in the Edgewise-alone series - or both.

FMIA also was significant between treatments by the end of treatment (Figure 4-12). FMIA is an acronym for Frankfort Mandibular Incisor Angle, so the smaller mean in the Edgewise-alone sample shows that the lower incisor was more-proclined. At the end of treatment FMIA was 55.5 degrees $(\mathrm{sd}=6.07)$ in the Edgewise-alone series, while that in the MARA+Edgewise the mean was 61 degrees $(\mathrm{sd}=7.12)$. Again, the difference could be due to individual preferences, as an accommodation to other skeletodental differences, or some combination of the two.

Predictably, these incisor differences (IMPA, FMIA) resulted in the interincisal angle differing as well (Figure 4-13). This angle was significantly smaller in the Edgewise-only group. The mean Interincisal Angle at the posttreatment examination was 116 degrees $(\mathrm{sd}=7.04)$ in the Edgewise-only group, and 133 degrees in the MARA+Edgewise $(\mathrm{sd}=9.41)$ series.

These differences in incisor angulations extended to others (U1-Sella-Nasion, L1NB distance, and L1-NB angulation). The angle U1-to-Sella-Nasion was significantly smaller in the Edgewise-alone treatment (Figure 4-14). The mean was 107 degrees ( $\mathrm{sd}=$ $5.75)$ in the Edgewise group and 100 degrees $(\mathrm{sd}=6.91)$ in the MARA+Edgewise group.

The L1-to-NB angle differed at the end of treatment, but this result is different in that L1-NB was one of the few variables where the ANOVA table showed that both "Treatment" and "Sex" were statistically significant (Figure 4-15). In both treatments, males were finished with the lower incisors more upright (larger L1-NB angle) than in the girls. The treatment difference occurred because the angle was significantly larger in the Edgewise-alone series (Figure 4-15). The sex difference was a bit larger in the MARA+Edgewise group.

Figure 4-16 shows the millemetric difference between treatment groups for L1NB. There was a significant difference between treatment groups with the Edgewise group increasing nearly 1 millimeter more in this linear measurement.

Another significant dental angle by the end of treatment was U1 to the NA line (Figure 4-17). Both treatment and sex were significant effects because this angle was larger in the Edgewise-Alone sample, and it tended to be larger in boys than girls (Table 4-6).

The mean values for final U1 to NA measurements are listed in Table 4-6. It would seem that these final positions of the incisors were effectively under control of the 


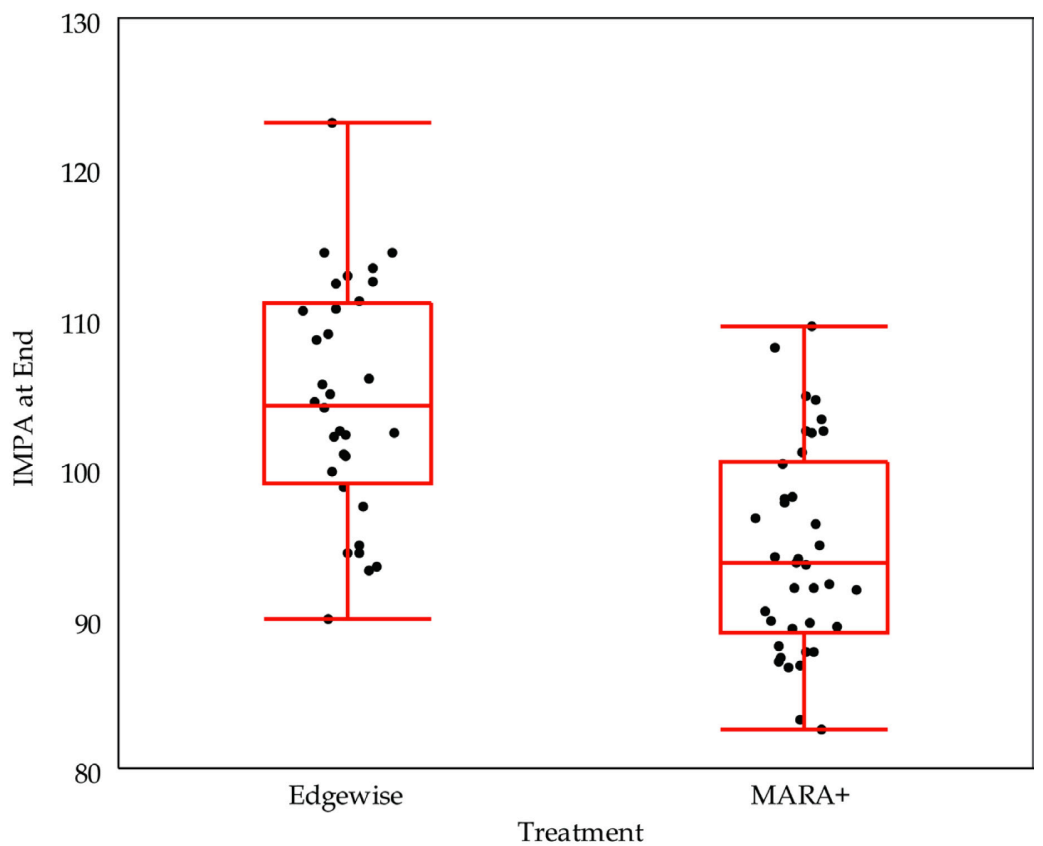

Figure 4-11. Box plots of the distributions of the angle IMPA (degrees) between treatments evaluated at the end of treatment.

Note: Edgewise refers to treatment with the Edgewise appliance alone $(n=32)$; MARA+ refers to the combined use of the MARA and the Edgewise appliance $(n=38)$. 


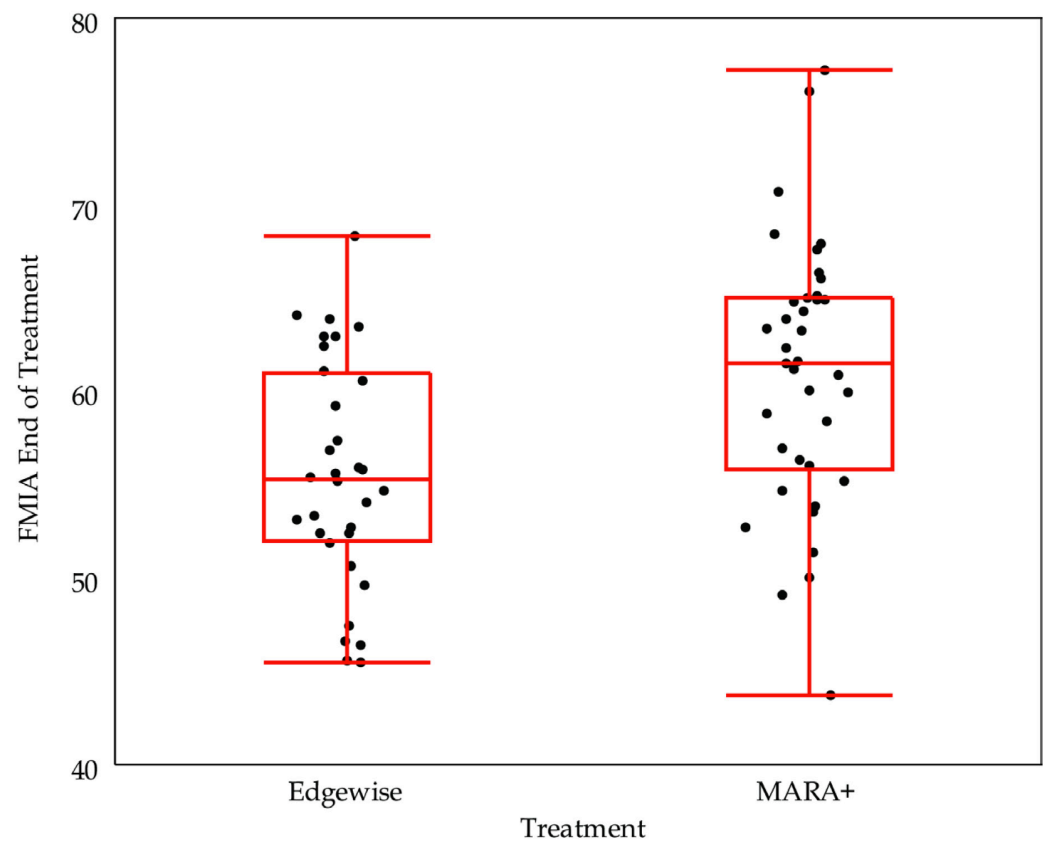

Figure 4-12. Box plots of the distributions of the angle FMIA (degrees) between treatments evaluated at the end of treatment. 


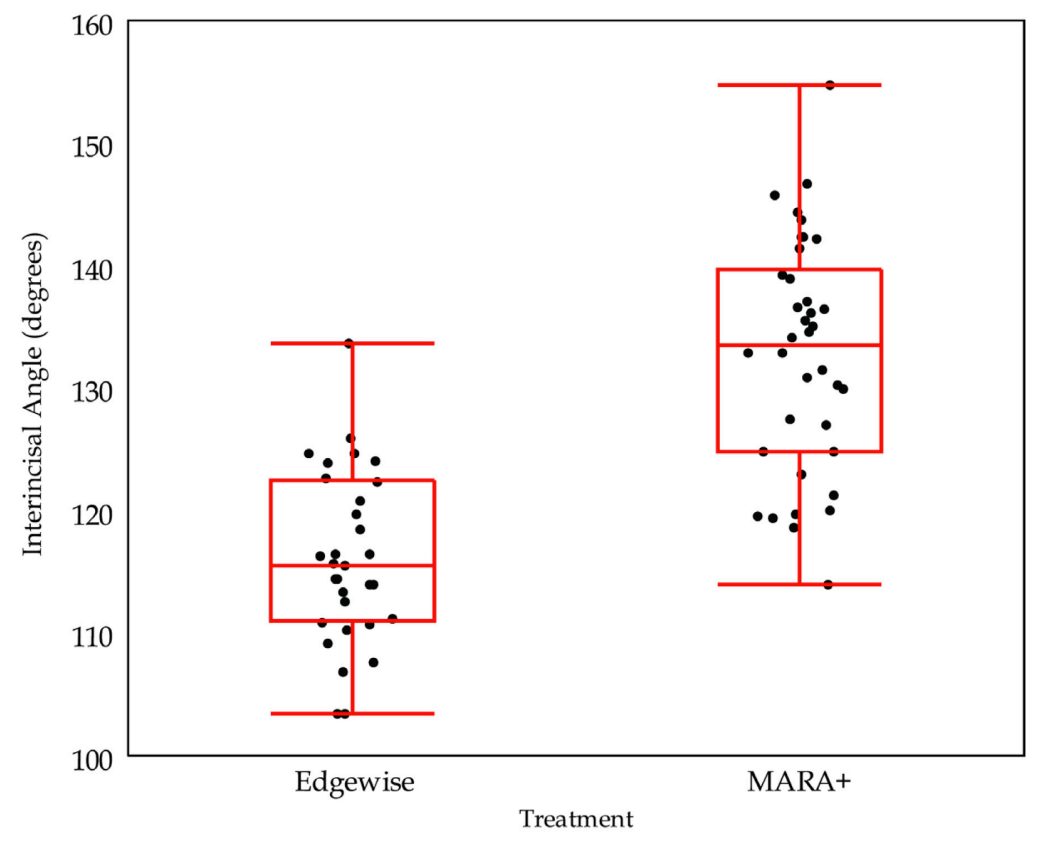

Figure 4-13. Box plots of the distributions of the Interincisal Angle (degrees) between treatments evaluated at the end of treatment. 


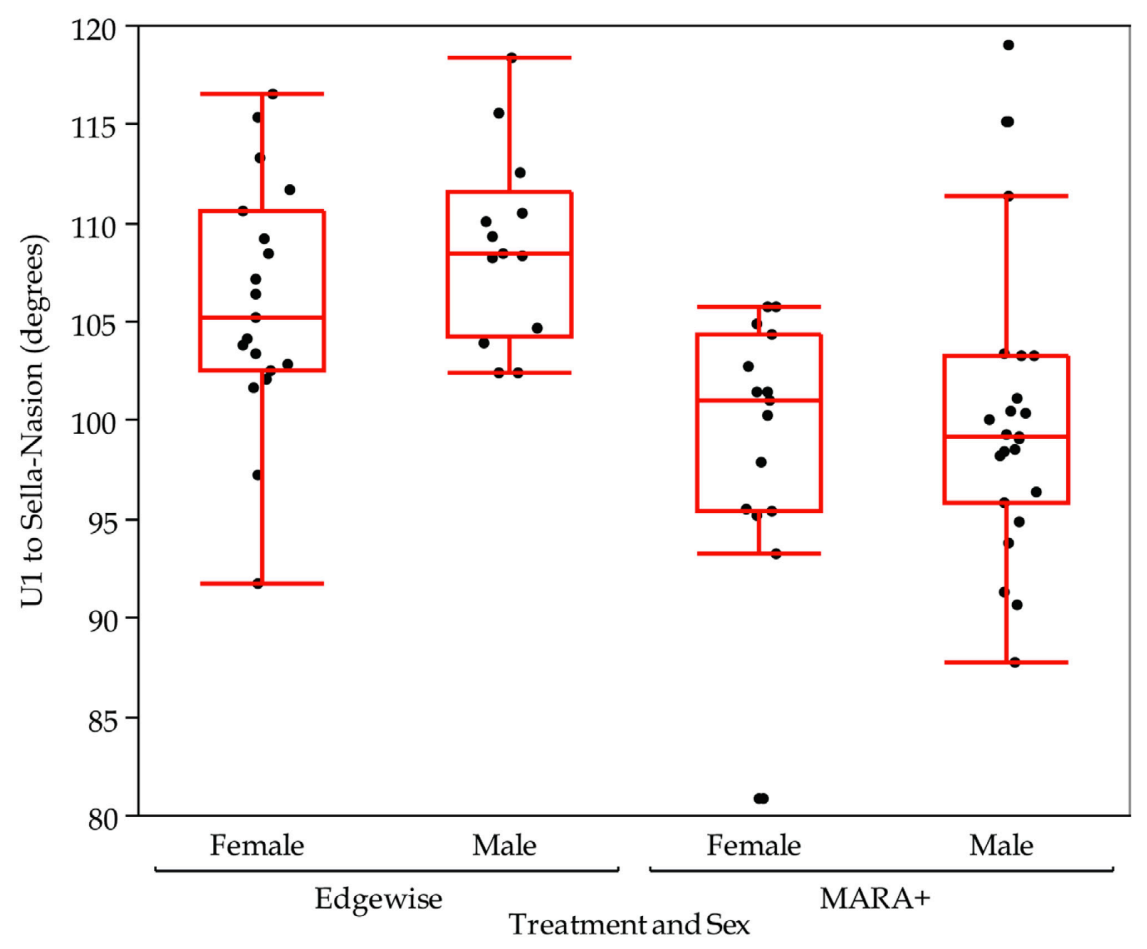

Figure 4-14. Box plots of the distributions of the U1-Sella-Nasion angle (degrees) between treatments and between sexes evaluated at the end of treatment. 


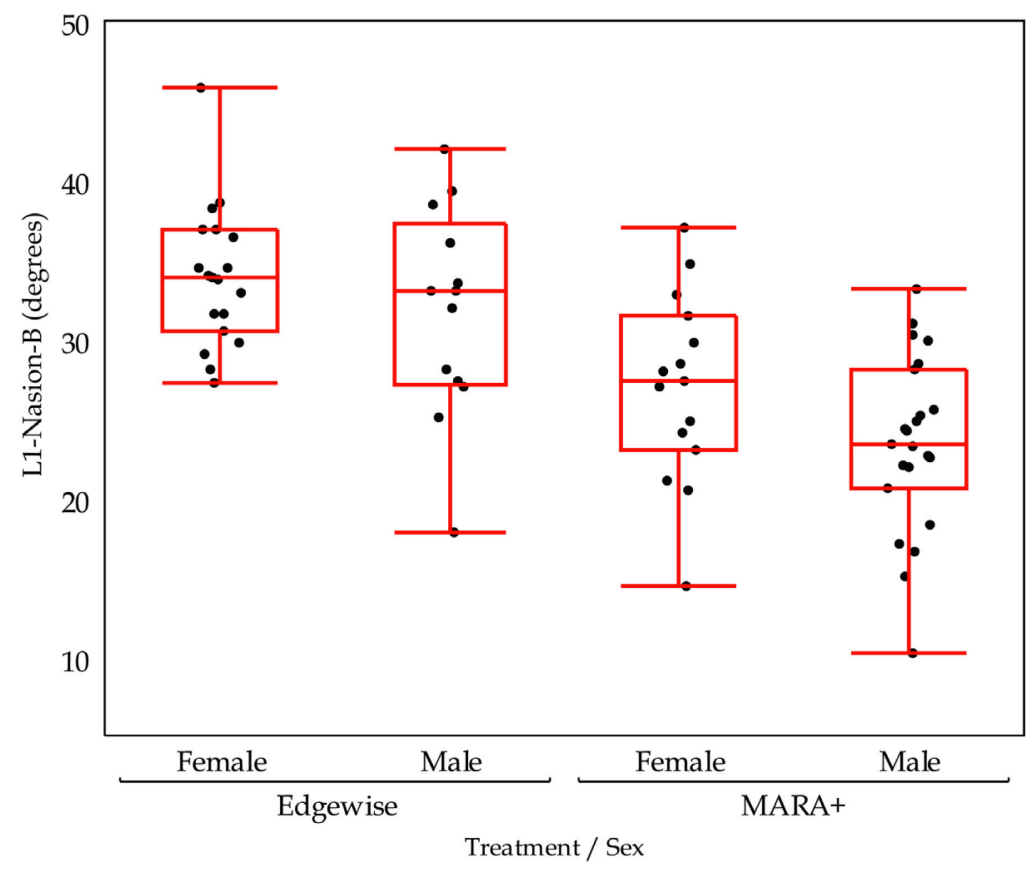

Figure 4-15. Box plots of the distributions of the L1-Nasion-B angle (degrees) between treatments evaluated at the end of treatment. 


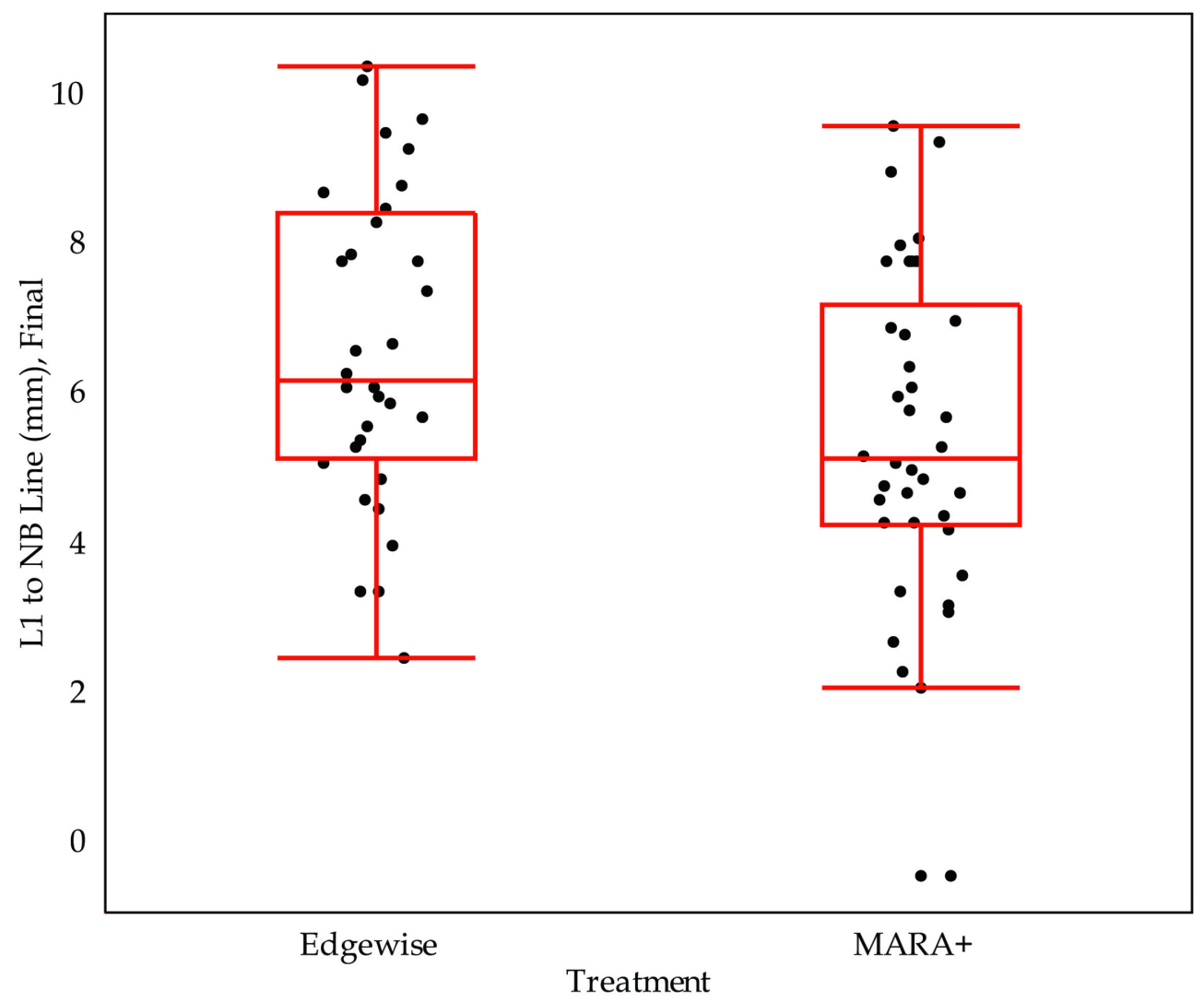

Figure 4-16. Box plots of the distributions of the L1-Nasion-B distance (millimeters) between treatments at the end of treatment.

Note: This dental distance was, on the average, larger in the Edgewise-alone (Tennessee) group. 


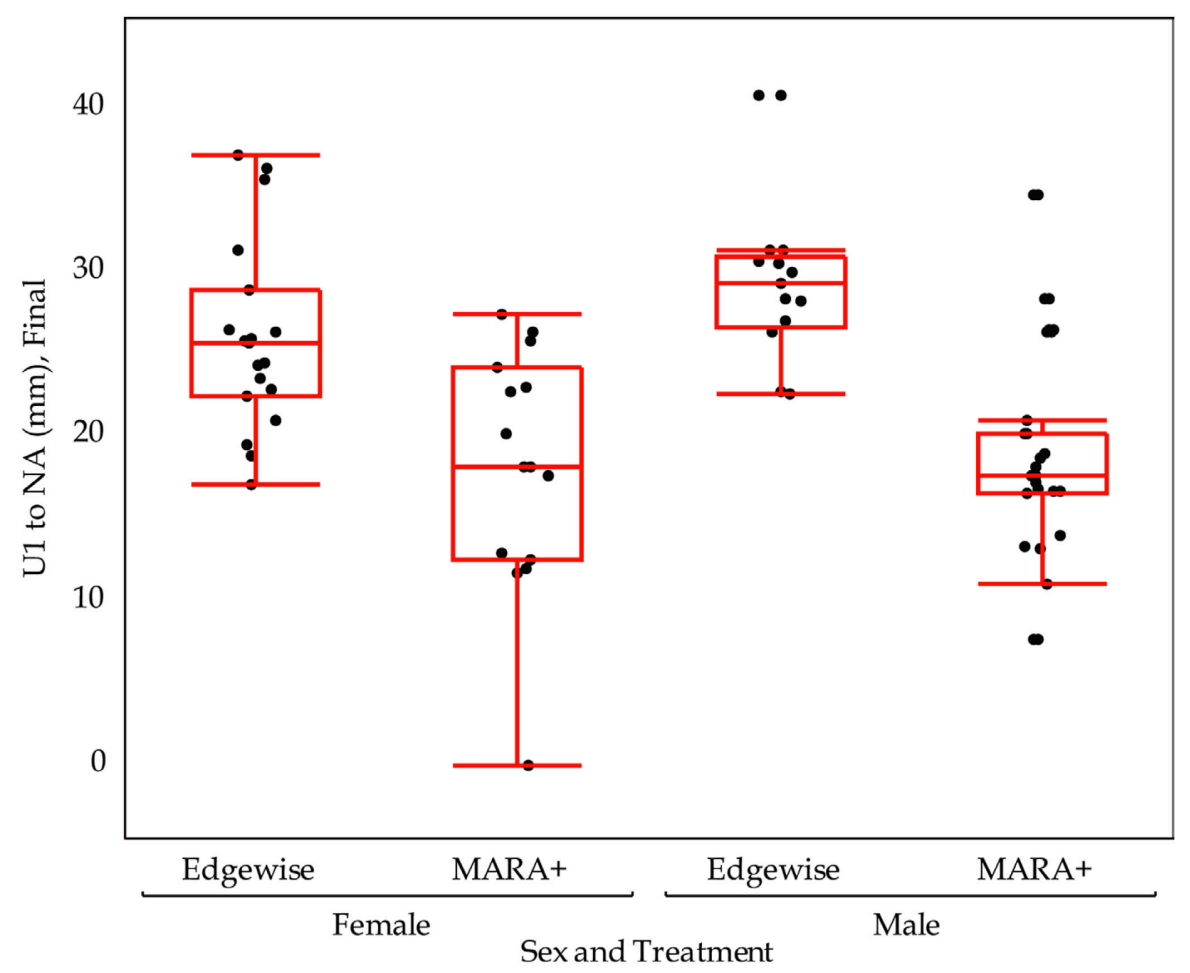

Figure 4-17. Box plots of the distributions of the $U 1$ to the Nasion-A line (degrees) between treatments and between sexes evaluated at the end of treatment.

Note: The upper central incisor was more proclined in the Edgewise-Alone sample within each sex, and girls tended to be more proclined than boys.

Table 4-6. Descriptive statistics for U1 to NA (degrees) at the end of treatment.

\begin{tabular}{lcc}
\hline \multicolumn{1}{c}{ Group } & Mean & Sd \\
\hline Edgewise, Females & 25.5 & 5.8 \\
Edgewise, Males & 28.7 & 4.6 \\
MARA+, Females & 17.7 & 7.4 \\
MARA+, Males & 18.2 & 5.9 \\
\hline
\end{tabular}


orthodontists, so, while these differences are real, they pertain more to practitioner preferences rather than limitations of the mechanics.

Given the systematic differences in tooth angulation just reviewed, it is not surprising that incisor overjet also differed significantly between sites by the end of treatment (Figure 4-18). The average millimetric difference between treatments was not great, but it was generally greater in the MARA+Edgewise sample. The final mean was $2.6 \mathrm{~mm}(\mathrm{sd}=0.78)$ in the Edgewise-Alone (Tennessee) group, but a bit larger in the in the Kansas (MARA+Edgewise) sample $(\bar{x}=3.3 \mathrm{~mm}$; sd $=1.01)$.

The next statistically significant variable at the end of treatment (Table 4-5) was the mandibular distance from Condylion to A Point (Figure 4-19). This variable was interesting because it was a dimension that was different between both treatments and sexes. As suggested by other comparisons, this measure of mandibular size was larger in the Edgewise-Alone (Tennessee) sample. This is true when comparing the least-squares means adjusted for sex and site differences (not just the raw means plotted in these graphs). The suggestion is that mandibular size differed between sites (Kansas, Tennessee) even after adjusting for the patient's chronological age.

The measure of mandibular size, Condylion-to-Gnathion also differed by both treatment and sex (Figure 4-20). This measure of mandibular size was significantly larger in the Tennessee sample, and, within each sample (Tennessee, Kansas), Condylion-to-Gnathion was significantly larger in boys than girls. This latter difference is a common when comparing adolescents and adults where the steroid-mediated effects of puberty are evident (e.g., Riolo et al. 1975).

The measure of maxillary size A-to-Nasion-Perpendicular was significantly different by treatment at the final records (Figure 4-21). This coincides with the general theme of the Tennessee sample having larger facial dimensions than those from Kansas, which is seemingly a geographical difference (population variation) independent of orthodontic treatment.

A standard cephalometric measure of mandibular size is Pogonion to NasionPerpendicular. This is can be viewed as a measure of chin prominence (Pogonion) relative to Nasion. There was a significant difference in this measure at the end of treatment (but not a significant sex difference). Figure 4-22 shows that Pogonion to Nasion-Perpendicular was larger in the Edgewise-Alone (Tennessee) sample.

Sagittal molar relationship is a common measure of relationships between the permanent first molars (e.g., Baume et al. 1973; Harris and Corruccini 2008). Conventionally, Class II relationships are assigned negative values (distoclusion), while the less common Class III cases (mesoclusion) are assigned positive values.

By the end of treatment, the average molar relationship in the Edgewise-Alone (Tennessee) sample was $-1.15 \mathrm{~mm}(\mathrm{sd}=1.1 \mathrm{~mm})$, and in the MARA+Edgewise sample 


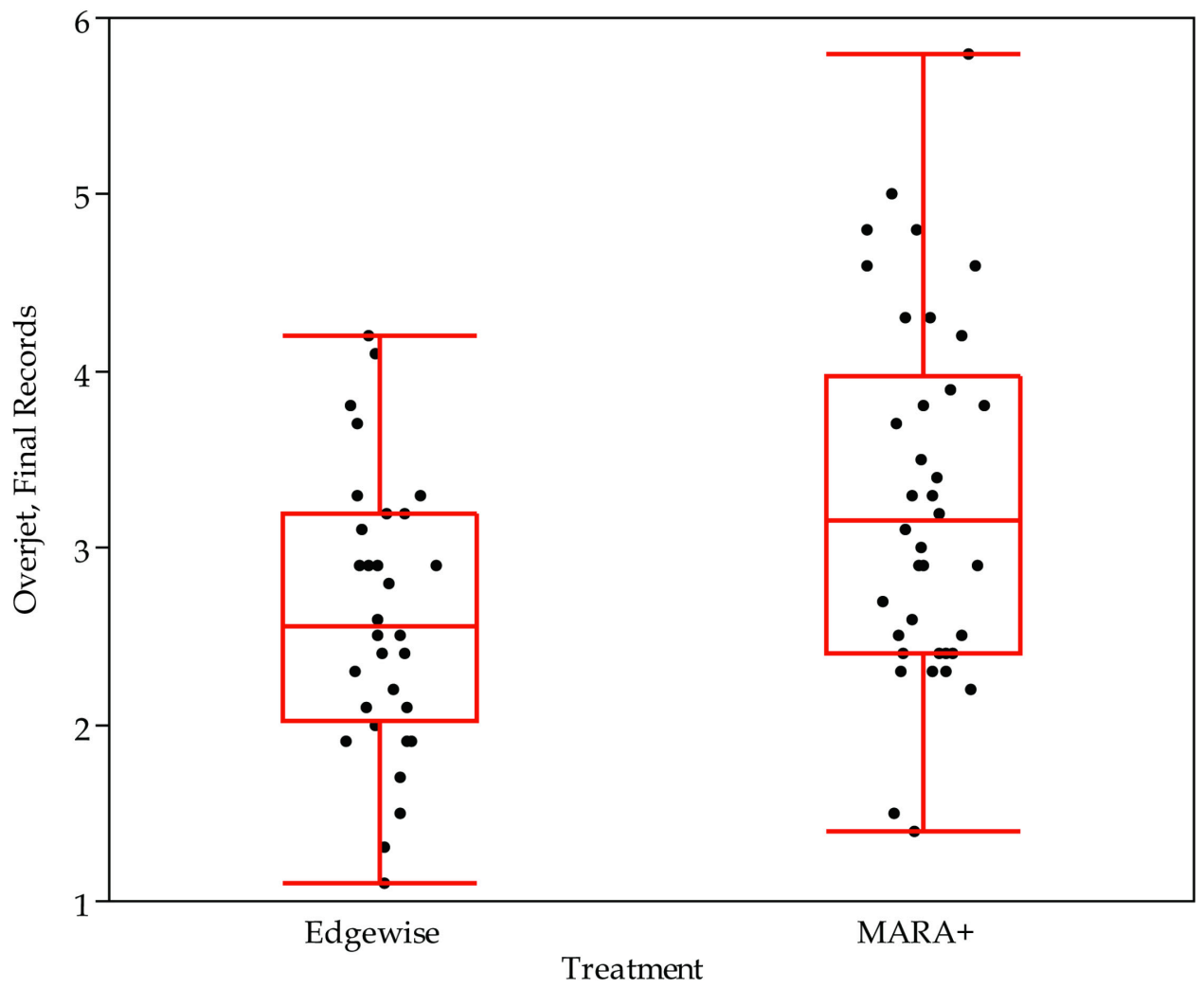

Figure 4-18. Box plots of the distributions of incisor Overjet (millimeters) between treatments at the end of treatment.

Note: Overjet was significantly greater in the MARA+Edgewise series. 


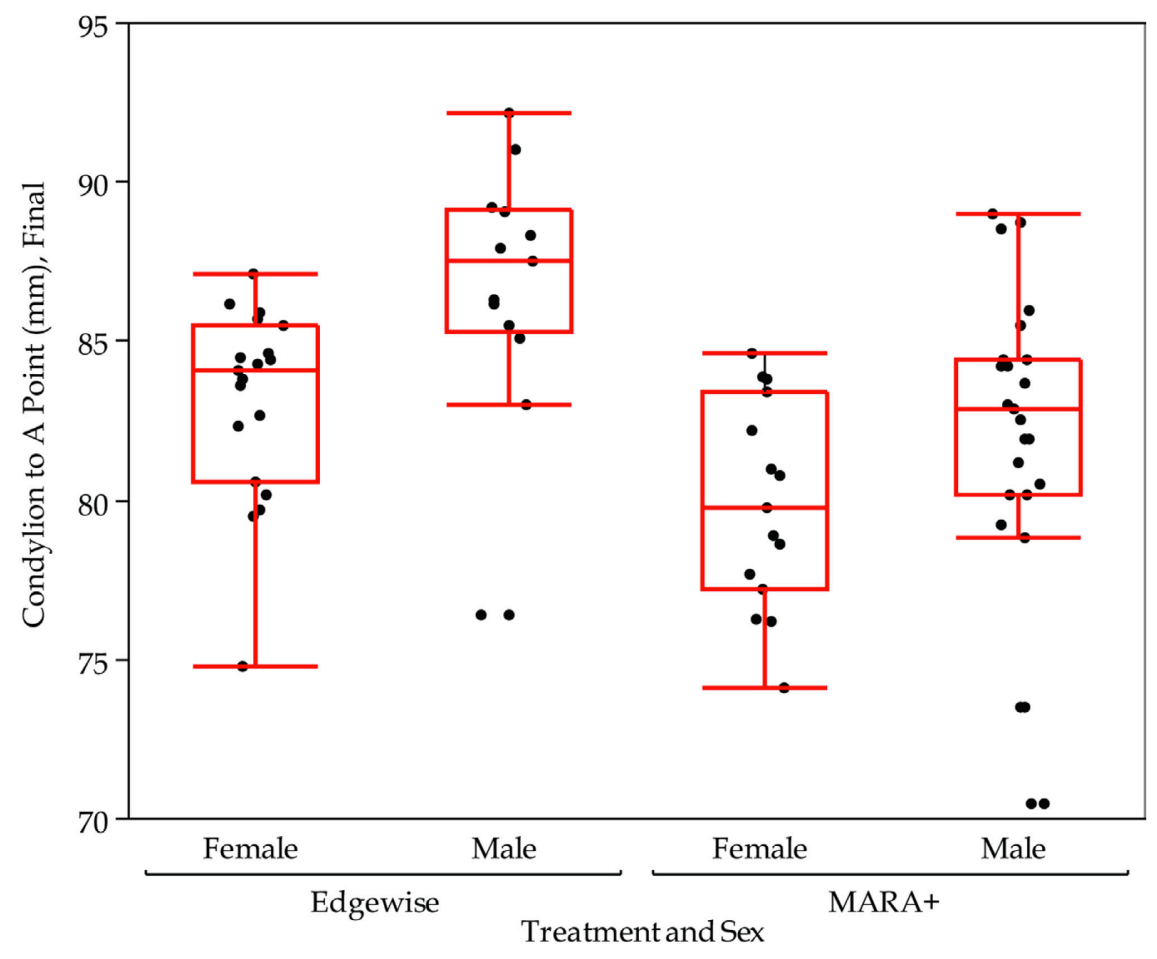

Figure 4-19. Box plots of the distributions of Condylion-to-A Point length at the end of treatment, by treatment and sex.

Notes: This measure of maxillary depth was shorter in the MARA+Edgewise sample. It also was shorter in females than males within each treatment. 


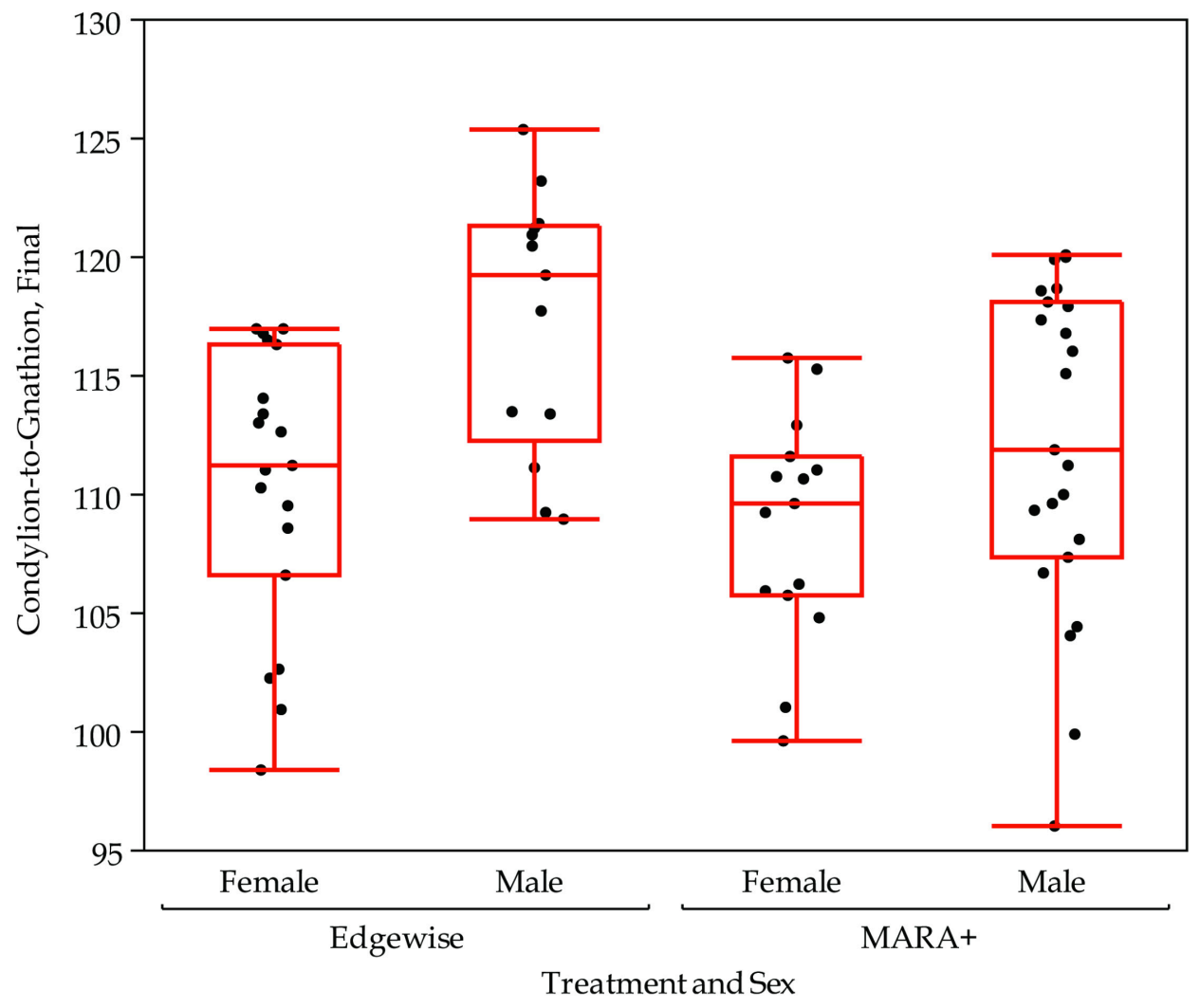

Figure 4-20. Box plots of the distributions of Condylion-to-Gnathion distance at the final records, by treatment and sex.

Notes: This mandibular length was significantly larger in the Edgewise-Alone (Tennessee) sample than in the MARA+Edgewise (Kansas) group. Within each treatment, boys had a significantly larger mandible. 


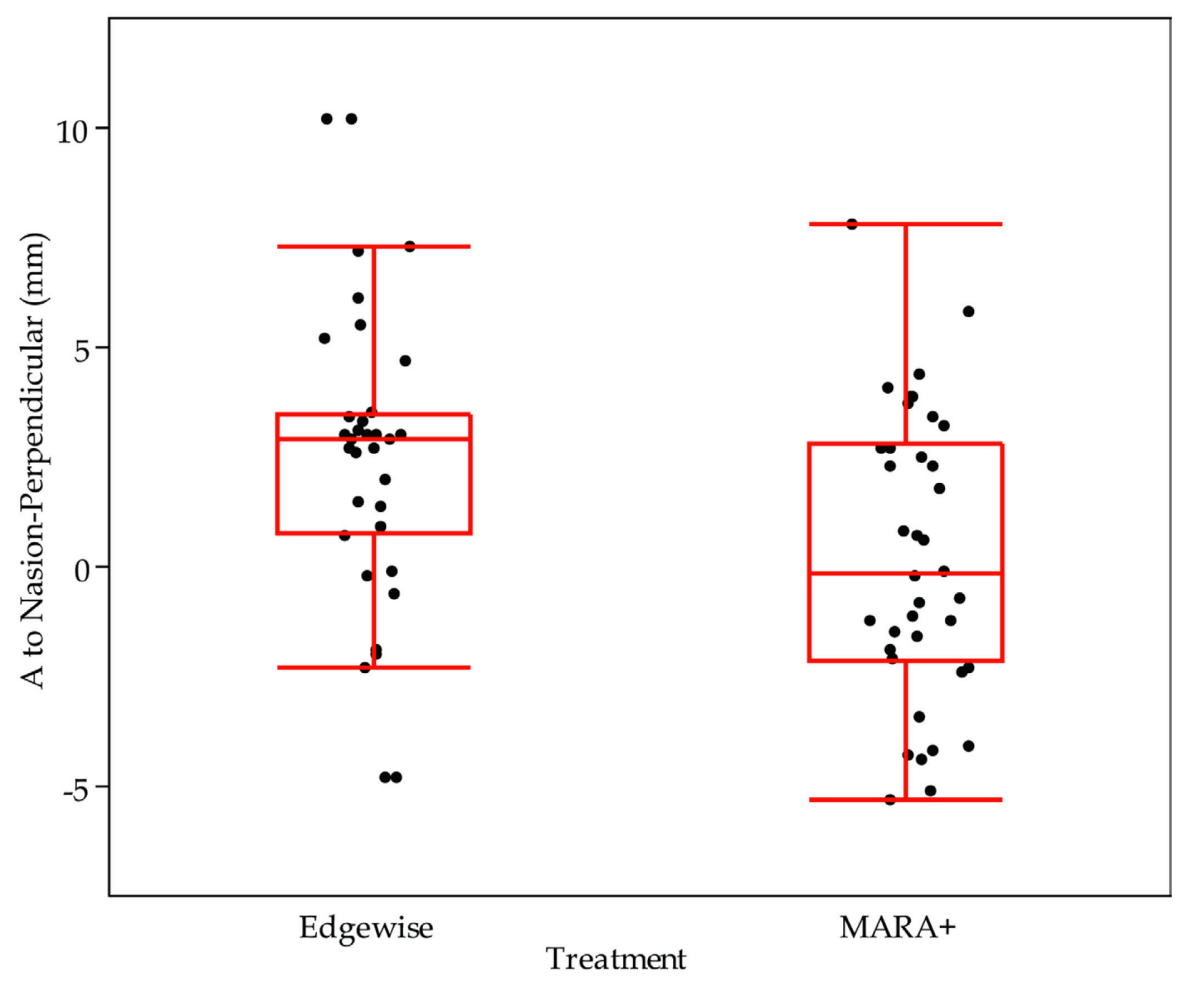

Figure 4-21. Box plots of the distributions of the distance A-to-NasionPerpendicular at the final records, by treatment and sex.

Note: This measure of maxillary depth was significantly longer in the Edgewise-Alone (Tennessee) sample. 


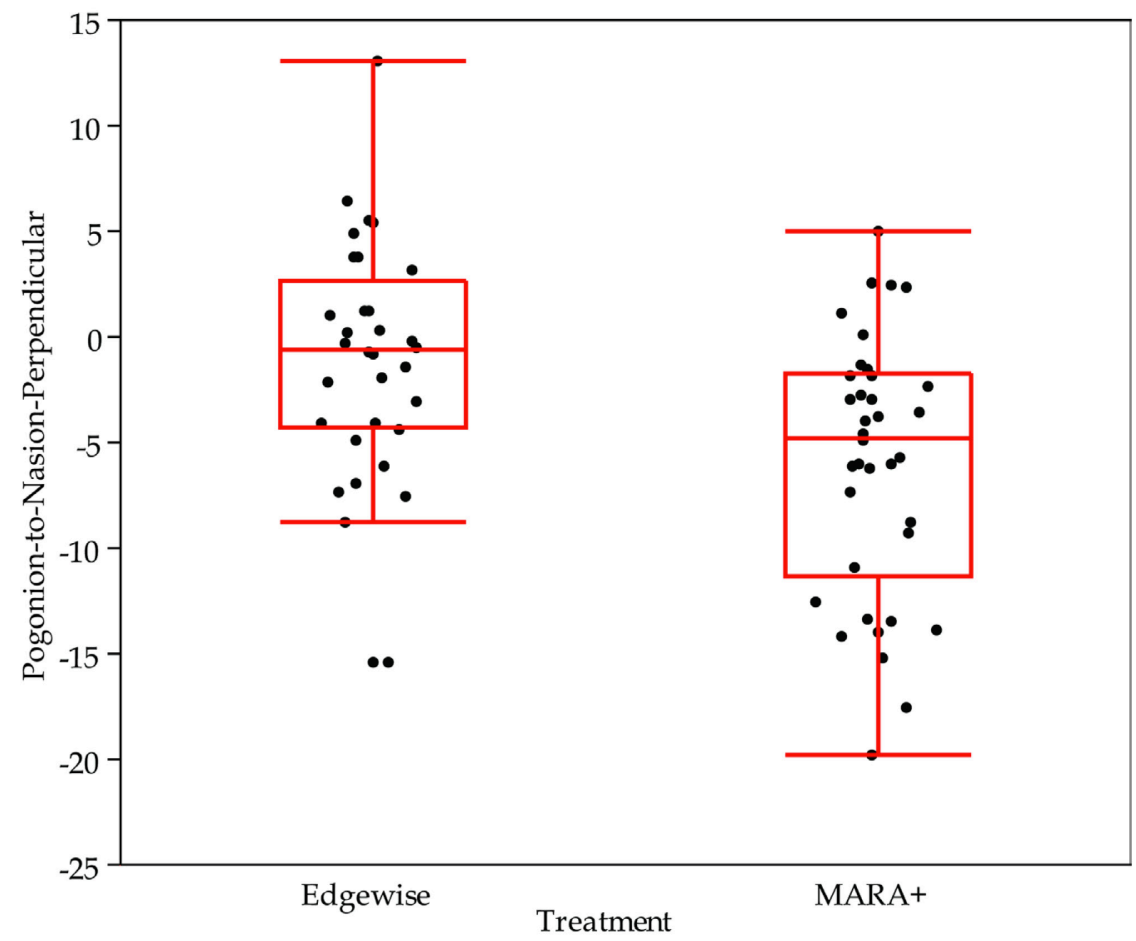

Figure 4-22. Box plots of the distributions of the distance Pogonion-to-NasionPerpendicular at the final records, by treatment and sex.

Note: This measure of mandibular depth was significantly longer in the Edgewise-Alone (Tennessee) sample. 
the mean was close to zero ( $\overline{\mathrm{X}}=-0.2 ; \mathrm{sd}=0.98 \mathrm{~mm}$ ), a highly significant difference (Figure 4-23).

Posterior Facial Height differed significantly by sex (but not treatment) when the final records were taken (Figure 4-24). Boys had a significantly greater mean. The mean was $74.4 \mathrm{~mm}(\mathrm{sd}=4.4)$ in girls, and $77.6 \mathrm{~mm}$ in boys $(\mathrm{sd}=6.0)$.

Corpus length (Gonion-to-Menton) is a large part of mandibular size, and, indeed (Figure 4-25), Gonion-to-Menton was significantly different between the sexes by the end of treatment. In the females, the mean was $74.4 \mathrm{~mm}(\mathrm{se}=0.89)$ at the end of treatment, while the mean in males was $77.6 \mathrm{~mm}(\mathrm{se}=0.90)$. Gonion-to-Menton also was significantly different between treatments; with a longer mean size in the EdgewiseAlone sample $(\bar{x}=76.2$; se $=0.93)$ compared to the MARA+Edgewise (Kansas) sample $(\bar{x}=75.9 \mathrm{~mm}$; se $=0.86)$. Again, though, these geographical differences existed before treatment, so there is virtually no evidence here that treatment affected growth.

Just as the mandible was larger in the Tennessee sample, so the maxilla also was larger. This is because the two jaws need to couple and because the faces are proportionate between samples (Enlow 1975). This is shown in Figure 4-26, where Sella-Vertical to A Point at the end of treatment is graphed. Here again, both treatment and sex were statistically significant by ANOVA test.

The two horizontal (anterposterior) dimensions Sella-Vertical to Points A and B both differed significantly by the end of treatment (Figures 4-26 and 4-27). Again, the Tennessee sample was longer than the Kansas sample, and boys were bigger than girls.

Anterior Facial Height was significantly different between the sexes by the end of orthodontic treatment (Figure 4-28). There was no geographical difference, however. The mean AFH length was $109.0 \mathrm{~mm}(\mathrm{sd}=5.6 \mathrm{~mm})$ in girls at the end of treatment, and $113.3 \mathrm{~mm}(\mathrm{sd}=7.1)$ in the average boy, a $4 \%$ difference.

Several dimensions show that the Tennessee (Edgewise-Alone) sample was a bit larger. This geographical difference was reiterated with the dimension Sella-Vertical to Pogonion (Figure 4-29). This measure was significantly larger in the Tennessee versus the Kansas sample. Mean size was $23.8 \mathrm{~mm}(\mathrm{sd}=2.8)$ in the Kansas sample, and 20.7 $\mathrm{mm}(\mathrm{sd}=2.7 \mathrm{~mm})$ in the Kansas sample.

The 23rd and last statistically significant difference encountered at the end of treatment was Sella-Vertical to M Point (Figure 4-30). M Point is the distal-most (most dorsal) point on the convexity of the outer cortical plate of the mandibular symphysis. This seems to be a region of little remodeling, so $\mathrm{M}$ seems to be a stable region for cephalometric superimposition. Sella-Vertical to M measures the amount of horizontal jaw growth. 


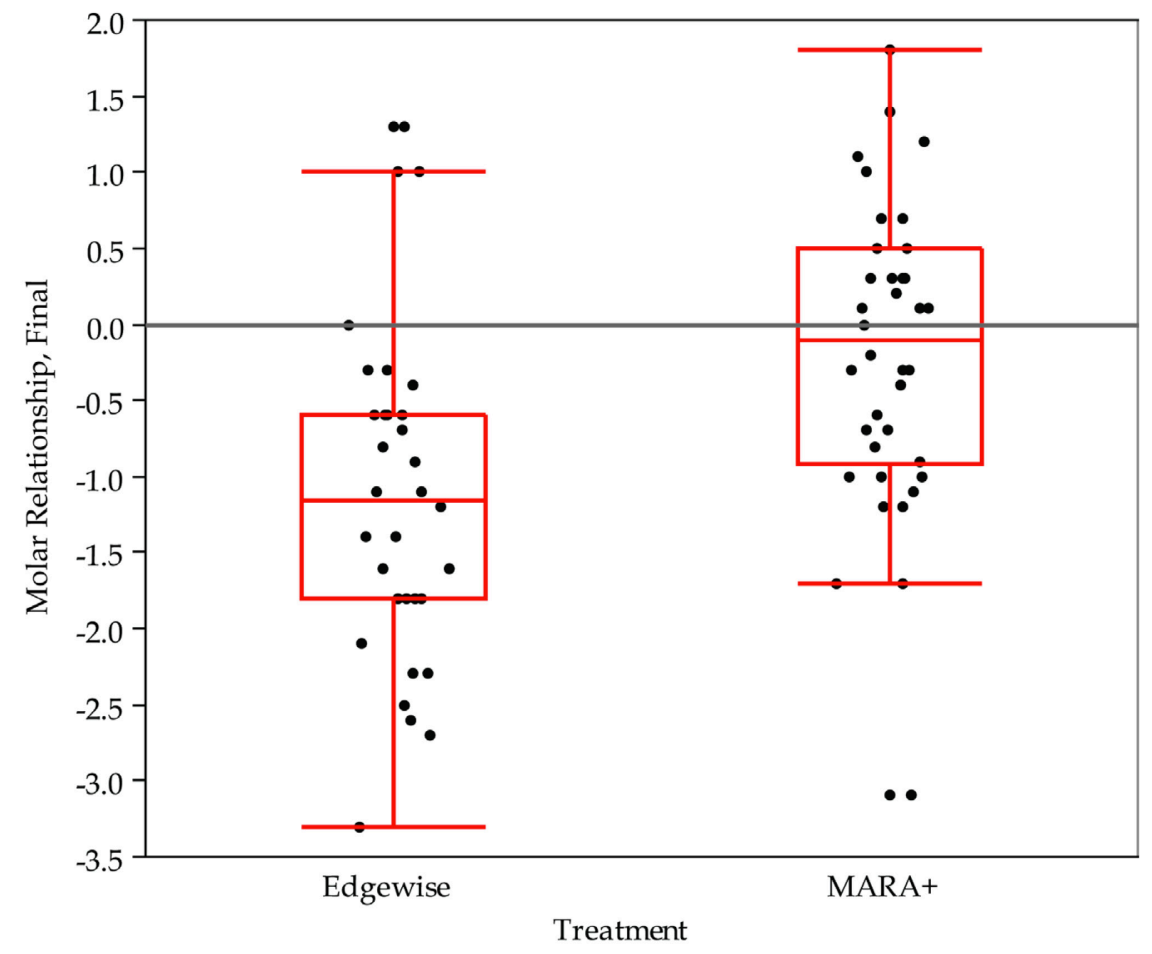

Figure 4-23. Box plots of the distributions of Molar Relationship at the final records, by treatment.

Notes: Given the manner the measurements were taken, the Edgewise-Alone sample was finished to a slight Class II relationship (median $\sim-1.2 \mathrm{~mm}$ ), while the median in the MARA+Edgewise was close to zero. A horizontal line was drawn across the graph at zero. 


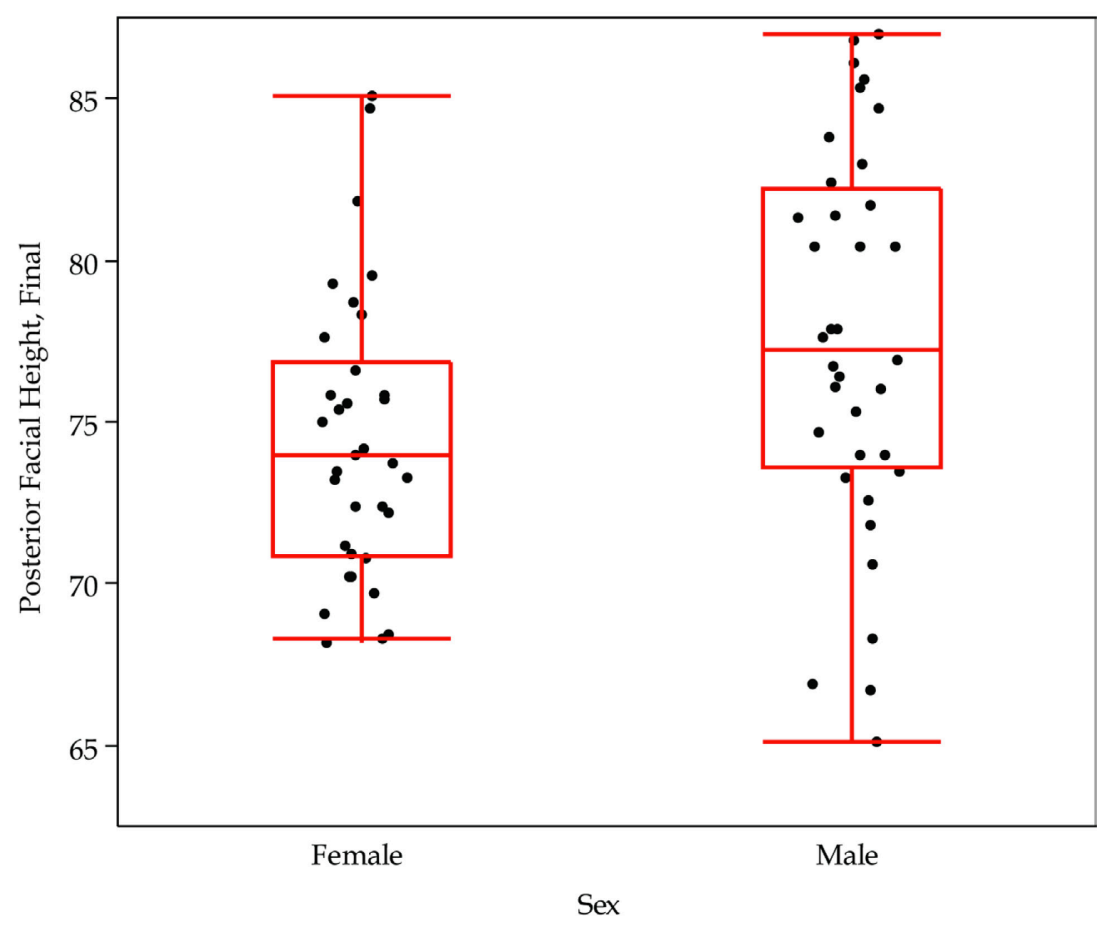

Figure 4-24. Box plots of the distributions of Posterior Facial Height $(\mathrm{mm})$ at the final records examination, by sex.

Note: PFH was significantly larger in boys than girls, though there was considerable overlap between treatments to the point that the mechanics employed was not a significant factor. 


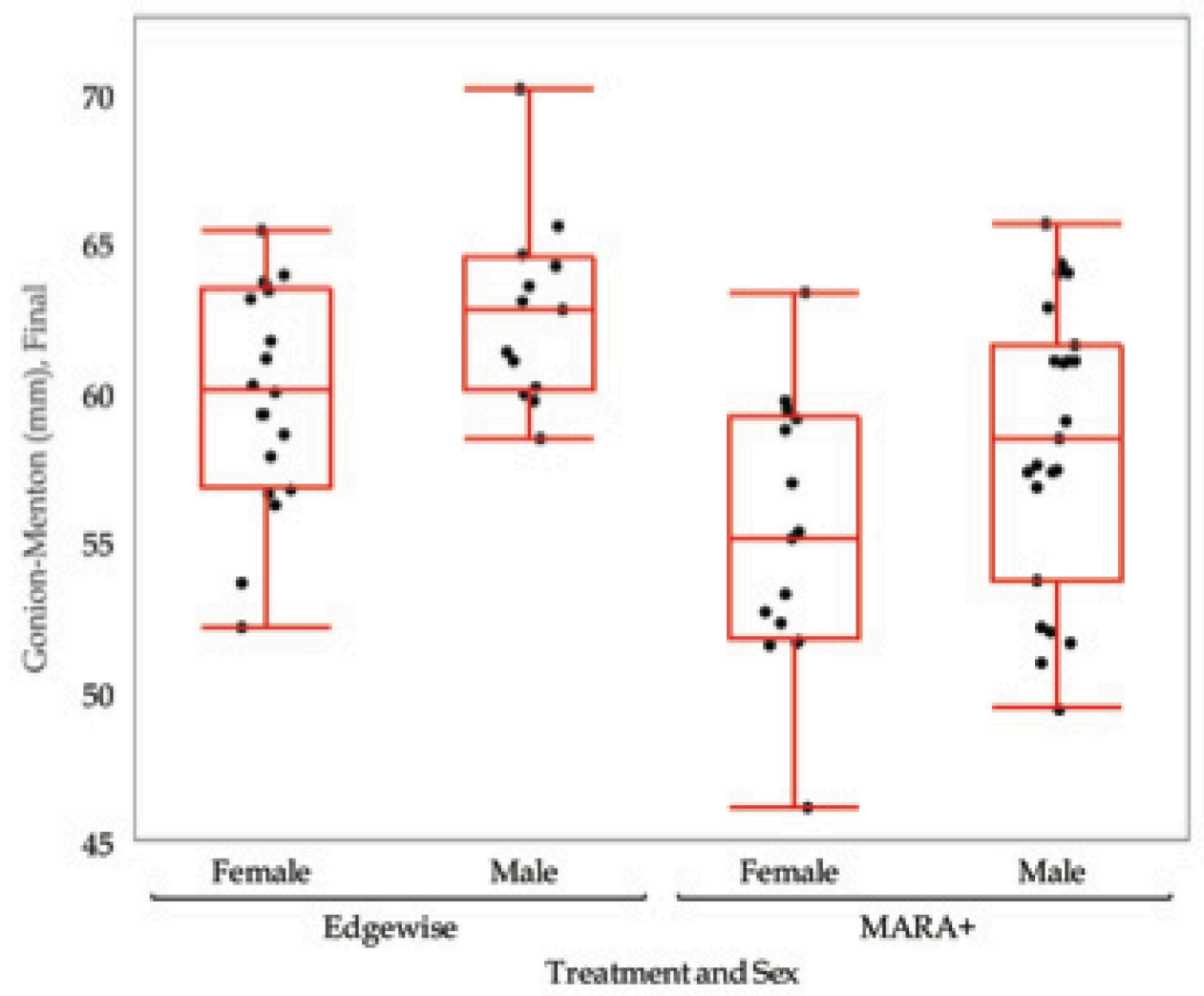

Figure 4-25. Box plots of the distributions of Gonion-Menton at the final records, by treatment.

Note: This measure of corpus length was significantly shorter in the MARA+Edgewise group, and, within treatments, boys had a significantly longer corpus length than the girls. 


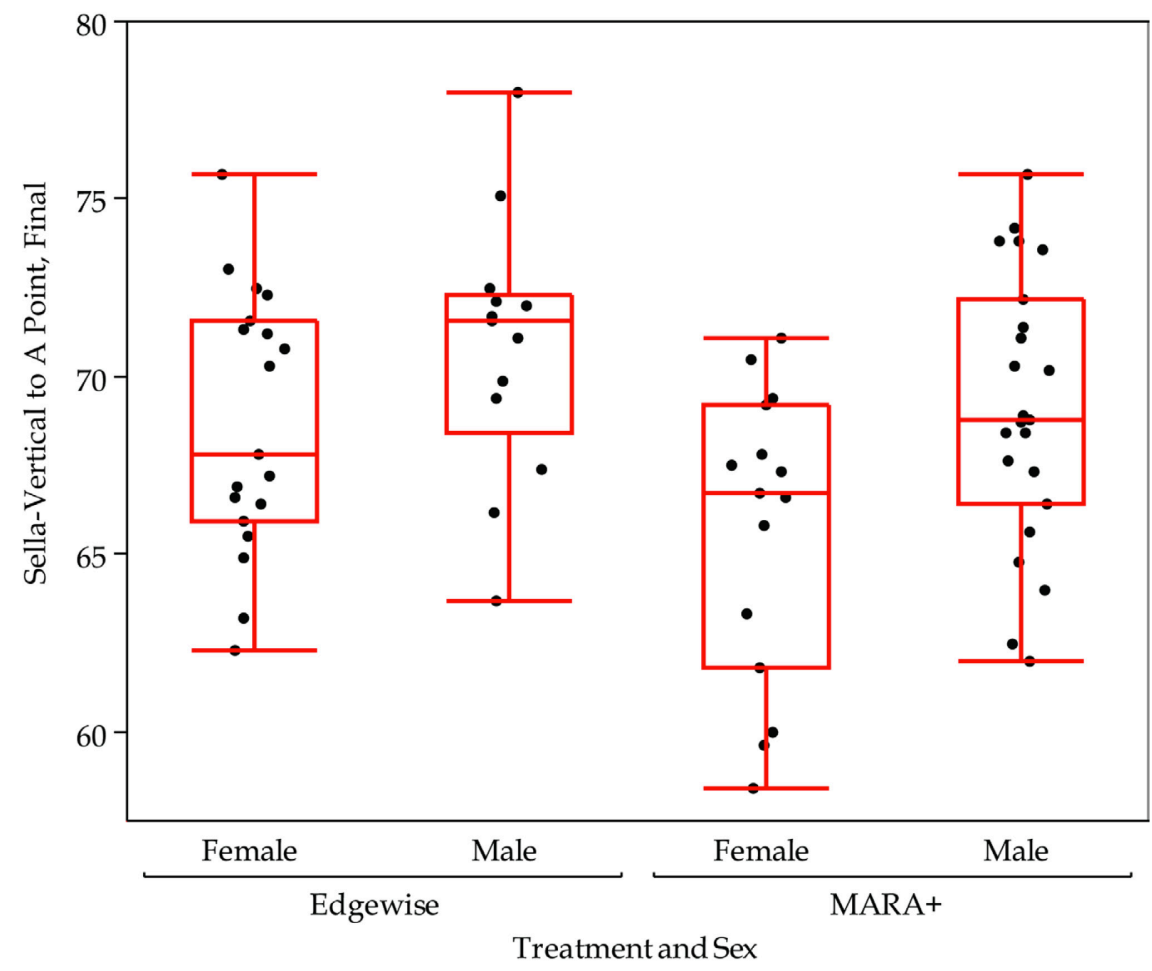

Figure 4-26. Box plots of the distributions of Sella-Vertical to A Point at the final records, by treatment.

Note: The distance was greater in the Edgewise-Alone sample, and, within each treatment, boys had significantly larger dimensions than girls. 


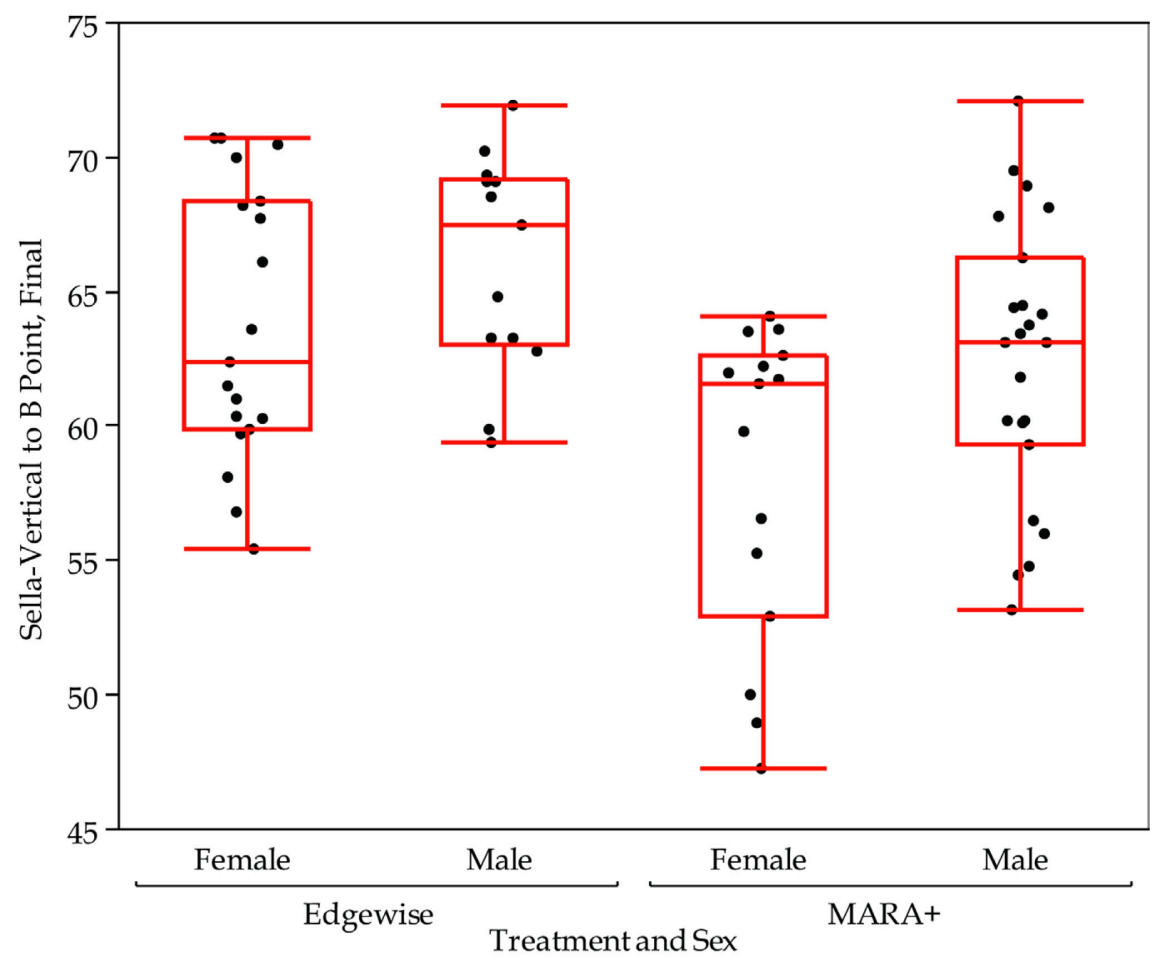

Figure 4-27. Box plots of the distributions of Sella-Vertical to B Point at the final records, by treatment.

Note: The distance was greater in the Edgewise-Alone sample, and, within each treatment, boys had significantly larger dimensions than girls. 


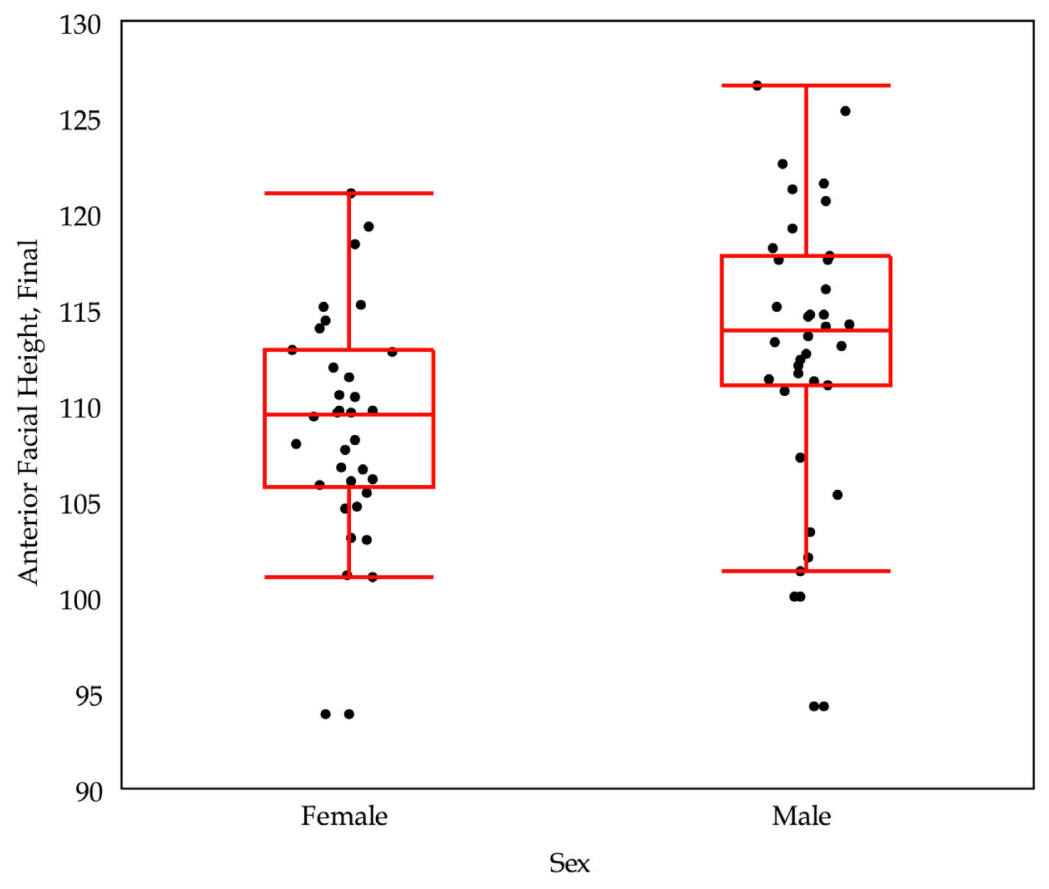

Figure 4-28. Box plots of the distributions of Anterior Facial Height (AFH) at the final records, by treatment.

Note: This was the only variable analyzed at the end of treatment that exhibited a significant difference by sex without also showing a significant treatment effect. 


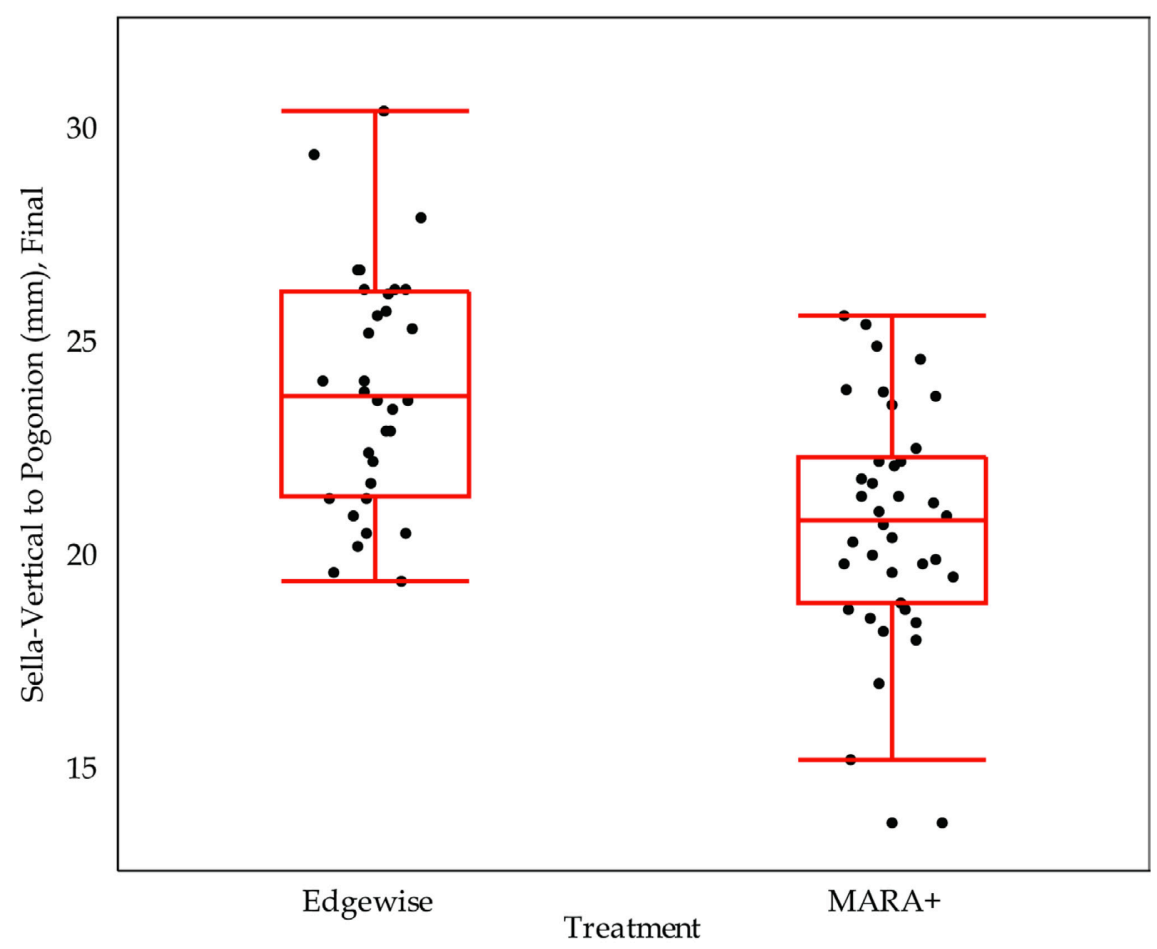

Figure 4-29. Box plots of the distributions of Sella-Vertical to Pogonion at the final records, by treatment.

Note: This mandibular measure of jaw length was significantly longer in the EdgewiseAlone sample, but there was no statistically significant sex difference. 


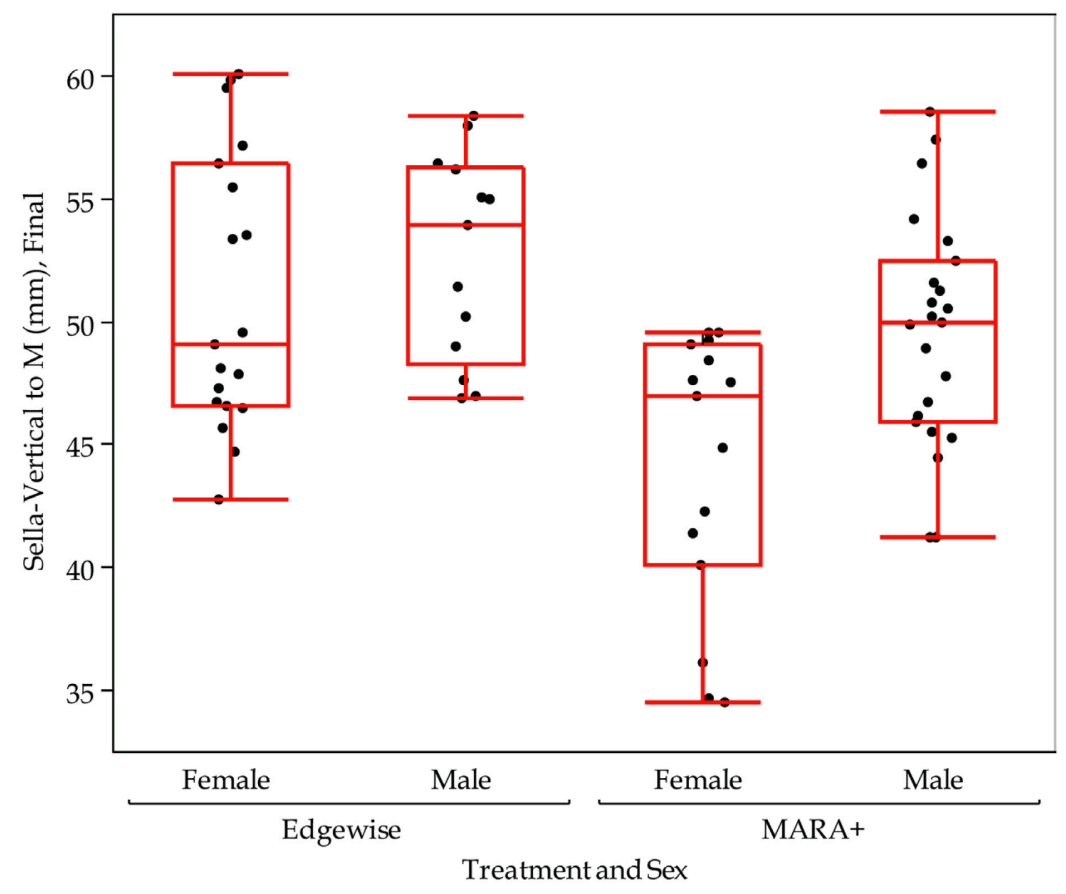

Figure 4-30. Box plots of the distributions of Sella-Vertical to M Point at the final records, by treatment.

Note: This mandibular measure of jaw length was significantly longer in the EdgewiseAlone sample, and, within each treatment, length was significantly longer in boys than girls. 


\section{Intraobserver Reliability}

It is impossible for repeated measurements of the same object to be identical. Differences are due in part to human (operator) differences in landmark selection, personal definitions of the variable - that can change over time - and the level of precision (significant digits) recorded (Houston 1983; Houston et al. 1986). Another component of the repeatability differences is the measuring instrument. All have some fixed level of digits, beyond which they are not reliable, and machines (calipers, computers) do not always measure consistently or equally precisely in all planes of space. Instrument errors actually can be viewed as coming from two sources, random error and systematic error. Random error occurs because our system of measurements is limited to fixed increments. Systematic errors occur because there is a problem with the instrument. As examples, readings from a computer program where the screen setting is distorted or not at the correct screen resolution will produce false values. If calipers have been bent, they will yield systematically larger or smaller values than the correct ones (e.g., Harris and Smith 2009).

It is valuable to quantify the extent of intraobserver reliability (termed Technical Error of Measurement, TEM) because TEM shows the opportunity for imprecision. It is hoped that repeated measurements will be precise and accurate. Precision (repeatability, reproducibility) is a measure of how consistent (close together) measurements are of the same object. Vierira and Corrente (2011, p 488) stated: "By definition, repeatability is the closeness of agreement between successive readings obtained by the same method on the same material and under the same condition (same operator, same apparatus, same setting and same time)."

How close a given measurement is to the true value can be defined as accuracy. According to the target analogy (Figure 4-31) measurements can be accurate but not precise. Or, they can be precise but not accurate. For TEM to be small, the goal is for the measurements to be both precise and accurate. TEM less than the supposed intergroup differences are not influenced by non-biological TEM effects.

A quantity's true value can be hard to determine, but the larger the sample size, the closer we can get to the true size (Winer et al 1990).

\section{Systematic Error}

One possibility is that the second set of measurements was systematically different from the first, perhaps because the operator's opinion of where a landmark was located had changed during the interim. Matched (paired) t-tests were used to test for this (two-tail tests). 

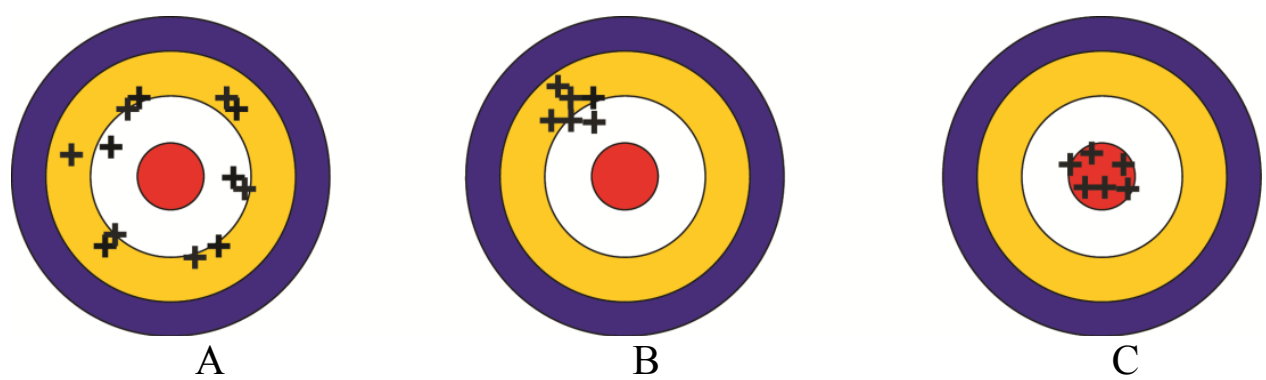

\section{Figure 4-31. Precision and accuracy.}

Notes: The "bull's eye" metaphor illustrates the concepts of accuracy and precision. (A) Demonstrates accuracy; the center of the bull's eye (the true value) is surrounded. The mean of the measurements is close to the actual value. These measurements have low repeatability, however, because of their scatter and individual departures from the true value. (B) Demonstrates precision; all measurements are equidistant form the true value, but they are close together. (C) Demonstrates accuracy and precision; the measurements are not only close to the true value, but also close to one another. Modified with permission. Harris, EF, Smith, RN. Accounting for measurement error: A critical but often overlooked process. Arch Oral Biol 2009, 54, Supplement 1:107-17. 


\section{Random Error}

The Dahlberg statistic (Dahlberg 1940) is used to calculate for random error. It is calculated for each variable as

$$
d=\sqrt{\frac{\sum_{i=1}^{n}\left(x_{1 i}-x_{2 i}\right)^{2}}{2 n}}
$$

where $\mathrm{X}_{1 \mathrm{i}}$ and $\mathrm{X}_{2 \mathrm{i}}$ are the two measurements for subject i. and $\mathrm{n}$ is the number of replicated (pairs of) subjects (Dahlberg 1940; Knapp 1992). All differences are squared to make them positive. This measure accounts for the standard error of the measurement difference, it is not the mean difference of the measurement error as sometimes claimed (Altman and Bland 1983; Bland and Altman 1996, 1999, 2003).

Considerable reliance is placed on the Dahlberg statistic, however, the arguments of Vierira and Corrente (2011) must be considered. They point out that the Dahlberg statistic holds true only when the readings are (1) independent, (2) identically distributed random variables, and (3) the average of the differences between readings are on average zero.

The present study recorded 44 craniofacial variables per subject plus identifying information (sex, Class, examination dates and ages). After a considerable wash-out period, 15 of the 70 cases were selected at random and re-measured without recourse to results of the first measurement session. Two sorts of repeatability were analyzed, a systematic measure (assessed by paired t tests) and a random measure (quantified by the commonly-applied Dahlberg statistic).

Of the 44 variables examined, most were non-significant by paired t test (Appendix D). T tests (comparing two means) only evaluate systematic differences; one group mean is systematically larger or smaller than the other. Appendix E lists just the Dahlberg statistic for the 44 dimensions. Seventeen of these 44 dimensions did achieve statistical significance and these have been abstracted and are listed in Table 4-7 (alpha = 0.05 ). It is annoying hat so many of the variables differed systematically between sessions.

The Dahlberg statistic also was calculated for each variable (Table 4-8), which is a measure of the dispersion of the measurements across repetitions (e.g., Bland and Altman 1986). 
Table 4-7. Descriptive statistics for the statistically significant differences between measurement sessions (alpha $=\mathbf{0 . 0 5})$.

\begin{tabular}{lrrrr}
\hline \multicolumn{1}{c}{ Variable } & Session 2 & Session 1 & Difference & Probability \\
\hline AFH & 112.33 & 105.73 & 6.60 & $<0.0001$ \\
Airway 1 Area & 300.44 & 210.07 & 90.37 & 0.0002 \\
Airway 1 Volume & $7,308.40$ & $5,415.08$ & $1,893.32$ & 0.0010 \\
Airway 1+2 Area & 628.93 & 531.97 & 96.95 & 0.0427 \\
ANB & 4.91 & 5.57 & -0.65 & 0.0144 \\
Condylion-Gnathion & 112.99 & 107.55 & 5.43 & $<0.0001$ \\
Facial Convexity & 8.34 & 10.40 & -2.06 & 0.0062 \\
Gonion-Menton & 60.14 & 57.88 & 2.26 & 0.0067 \\
L1-Nasion-B (mm) & 6.89 & 5.15 & 1.73 & 0.0021 \\
Mesial Molar Relation & -0.44 & 1.41 & -1.85 & $<0.0001$ \\
Overbite & 1.34 & 4.63 & -3.29 & $<0.0001$ \\
Overjet & 2.79 & 5.75 & -2.96 & $<0.0001$ \\
PFH & 76.35 & 70.19 & 6.17 & $<0.0001$ \\
Sella-vertical-A & 68.71 & 66.68 & 2.03 & 0.0009 \\
Sella-vertical-B & 61.37 & 58.57 & 2.80 & 0.0058 \\
Sella-vertical-M & 47.98 & 45.07 & 2.91 & 0.0054 \\
\hline
\end{tabular}


Table 4-8. Dahlberg statistic calculated for the remeasurement subset of the sample $(n=15$ pairs $)$.

\begin{tabular}{|c|c|}
\hline Variable & Dahlberg Statistic \\
\hline $\mathrm{AFH}$ & 5.18 \\
\hline Airway 1 Area (Naso) & 79.92 \\
\hline Airway 1 Volume (Naso) & $1,800.33$ \\
\hline Airway $1+2$ Area & 133.95 \\
\hline Airway 1+2 Volume & $4,309.26$ \\
\hline Airway $1+2+3$ Area & 166.63 \\
\hline Airway 1+2+3 Volume & $5,563.76$ \\
\hline Airway 2 Area (Superior) & 80.88 \\
\hline Airway 2 Volume (Superior) & $2,998.78$ \\
\hline Airway 3 Area (Inferior) & 66.52 \\
\hline Airway 3 Volume (Inferior) & $1,620.16$ \\
\hline A-Nasion-Perpendicular & 1.26 \\
\hline ANB & 0.77 \\
\hline B-Nasion-Perpendicular & 1.07 \\
\hline Co-A & 2.30 \\
\hline Co-Gn & 4.45 \\
\hline Convexity & 2.24 \\
\hline FMA & 1.88 \\
\hline FMIA & 5.92 \\
\hline Go-Me & 2.47 \\
\hline IMPA & 6.62 \\
\hline Interincisal & 8.79 \\
\hline L1-NB $\left(^{\circ}\right)$ & 6.23 \\
\hline L1-NB (mm) & 1.73 \\
\hline Mesial Molar Relation & 1.54 \\
\hline Minimum Constriction & 66.30 \\
\hline Overbite & 2.54 \\
\hline Overjet & 2.37 \\
\hline PFH & 4.90 \\
\hline Pg-Na Perp & 2.99 \\
\hline SellaV-A & 1.92 \\
\hline SellaV-B & 3.02 \\
\hline SellaV-M & 3.11 \\
\hline SellaV-Pogonion & 1.05 \\
\hline SNA & 1.36 \\
\hline SNB & 1.08 \\
\hline Sup Airway Space & 1.81 \\
\hline Total Airway & $5,574.32$ \\
\hline U1-NA $\left(^{\circ}\right)$ & 4.19 \\
\hline U1-NA (mm) & 4.64 \\
\hline U1-SN & 3.85 \\
\hline U1-SN & 3.85 \\
\hline
\end{tabular}


Table 4-8. (Continued).

\begin{tabular}{lc}
\hline \multicolumn{1}{c}{ Variable } & Dahlberg Statistic \\
\hline Wits (AOBO) discrepancy & 1.43 \\
Y-Axis & 1.37 \\
\hline
\end{tabular}




\section{CHAPTER 5. DISCUSSION}

Orthodontics is an unusual field in that much of the treatment is done through a combination of scientific diagnosis and subjective esthetic ideals. Throughout the history the specialty of orthodontics there have been numerous "hot button" issues with regard to orthodontic treatment planning. One such issue, which has been debated continuously to this day, is the extraction debate. This debate is multifaceted, involving relationships between tooth and arch alignment, crowding, occlusion and treatment outcome esthetics. Both sides of the argument have used available dental literature to support their treatment planning methods and ideals. By way of this debate, and through the advancement of dental imaging technologies, a section of dental professionals have promoted the inclusion of pharyngeal airway analysis into orthodontic treatment planning and diagnosis. These practitioners contend that the airway must be considered in orthodontic treatment planning due to the unsubstantiated theory that certain orthodontic mechanics, primarily extraction mechanics, may produce an impingement on the airway space. The airway reduction, it has been claimed, may lead to a host of potential issues, from headaches and developmental delays, to most importantly obstructive sleep apnea.

The pharyngeal airway volume is of concern to the orthodontist due to the prevalence of obstructive sleep apnea syndrome (OSAS); a disorder caused by obstruction of the upper airway. Young et al., estimate that two percent of women and four percent of men in the middle-aged workforce meet the criteria for sleep apnea syndrome. If orthodontic treatment modalities exist that positively or negatively affect the pharyngeal airway volume, this can play a significant role in the orthodontist's diagnosis and treatment planning of a given patient.

The purpose of the present study was to use cone beam computed tomography (CBCT) technology to compare volumetric pharyngeal airway changes between two different orthodontic treatment modalities. The study examined differences in pharyngeal airway changes between treatment with the MARA and with conventional Edgewise appliances with Class II elastics. The goal of this CBCT study was to identify any increased airway benefit obtained from the use of the MARA in the treatment of subjects with skeletal Class II malocclusions.

The theory behind the present investigation was that advancing the mandible using a functional appliance could potentially increase the pharyngeal airway volume. By positioning the mandible forward the associated musculature and soft tissue would be hyperpropulsed as well, thus increasing the airway volume. In fact, an oral appliance used to position the mandible forward has been shown to be an effective technique for treating mild to moderate obstructive sleep apnea (Lowe 2012) by enlarging the airway. One must be careful directly applying this to the current study, however, as sleep apnea is studied in patients who are asleep and in a supine position. Our patients were awake and upright during scanning, with images being captured without a standard tongue position. Also, and most importantly, sleep apnea is multifactorial and largely correlated to BMI 
(body mass index) and neck circumference as well as pharyngeal flaccidity (Banno et al., 2007), none of which was assessed in the present study.

Currently studies are available that have used CBCT to examine pharyngeal airway volume in association with a specific mandibular position. Hong, et al., examined the pharyngeal airway volume in adult Class III patients compared with those of Class I patients. The study of 60 patients (31 Class IIIs, and 29 Class Is) identified a significantly larger upper pharyngeal airway volume in the patients with a protrusive mandible. That study also found significant correlations between volume and measurements characterizing the anterior position of the mandible.

Park et al. (2010) studied 12 subjects who underwent mandibular setback surgery to assess pharyngeal volumetric changes. A statistically non-significant decrease was found in oropharyngeal volume on both 2-D and 3-D analysis of images taken before surgery and 6 months after surgery. The volume of the nasopharynx, however, was relatively unchanged. This finding suggests that deformation occurs to maintain airway patency following mandibular setback surgery. It may also suggest nasopharyngeal volume is independent of mandibular positioning. The results of this study should be assessed with reservation due to the small sample size and possible statistical anomalies.

Grauer et al. (2009) used this emerging CBCT technology to assess the relationship of facial morphology with pharyngeal airway volume and shape. The study examined records of 62 non-growing patients, utilizing 3-dimensional virtual surface models to calculate airway volumes. The patients were grouped by anteroposterior jaw relationships (Class I, Class II, Class III), and vertical proportions. The study found a statistically significant relationship between the inferior airway volume and the anteroposterior skeletal relationships, but no differences in airway volumes related to vertical proportions. Skeletal Class II patients were seen to have reduced inferior airway volumes and greater projections of the tongue into the airway along the anterior wall of the pharynx. The shape of the airway of skeletal Class II patients, when viewed in the coronal plane, was narrower than either Class I or Class III subjects. Grauer et al. (2009) concluded that patients with varying anteroposterior jaw relationships have associated differences in airway shape and volume.

Kim et al. (2010) examined the airways of 27 children (mean age 11 years). The ANB angle was used to separate the patients into two groups. These authors found statistically significant differences between numerous cephalometric measurements, including Pogonion to Nasion-perpendicular distance, ANB angle, height of the posterior nasal plane, mandibular body length, and facial convexity. Importantly, it was found that the total airway volume was significantly smaller in the Class II subjects. Though likely caused by a type II statistical error due to small sample sizes, no significant difference was found between the two groups when the total airway area was sectioned into 4 sub regions.

Based on the results from these studies, one could conclude that there is some correlation between the position of the mandible and the pharyngeal volume. With this 
background we attempted to identify differences that may exist due to different treatment mechanics used to treat Class II malocclusions. Does using a functional appliance for correcting a Class II malocclusion provide a benefit such that it increases the airway significantly more than correction using more conventional dentoaveolar mechanics? Our study found that it does not. In fact, we found no significant difference in pharyngeal airway volume during or after treatment between the two treatment modalities that would suggest beneficial airway expansion when using the MARA appliance. The only significant difference identified between the two treatment groups regarding the airway was a difference in the volume of the inferior pharyngeal segment at the end of treatment. This significance, however, was in favor of the conventional mechanics group, as it was a smaller airway section was seen in the MARA group $\left(3,742 \mathrm{~mm}^{2}\right.$ versus $4722 \mathrm{~mm}^{2}$ ).

The results regarding the airway would not be in disagreement with the literature on the subject if viewed in the broad context in which these previous studies were done. Both of our sample groups were treated to correct a Class II malocclusion, meaning both groups by Angle's Classification were the same at the beginning of treatment (all Class II) and the same at the end of treatment (all Class I). The differences in treatment, despite some of them being statistically significant, were not large enough to produce significantly different airway volumes.

We tried to eliminate as many confounding factors as possible. The age at the beginning of treatment and the treatment duration for both groups were not statistically different. The same set of inclusion criteria was applied to both groups. Both sites used the same i-CAT CBCT machine, with the same settings and exposure time. One confounding factor, however, could not be eliminated due to the constraints of the data. The samples were from two different geographical locations, and treated by different practitioners. Based on the assessment of the initial records there were eight significant findings on which the groups differed. Included here is a difference in initial mandibular length, with the Tennessee sample possessing longer mandibles. This could be due to a myriad of factors not limited to geographical influences, population genetics, or simply case selection.

Another potential shortcoming of the current study was the difficulty in consistently measuring the airway and its divisions. Despite being as systematic as possible, significant differences were identified during our repeat measures. The difficulty in measuring the airway is nearly unavoidable due to the anatomic variability of the pharynx. When making measurements and dividing the airway into segments, divisions are made based on soft tissue landmarks as well as hard tissue landmarks. Of particular difficulty is dividing the oropharynx in three dimensions based on a soft tissue landmark of the soft palate. A landmark that can be variable not only anatomically, but also based on whether the patient is swallowing. Also, positions of the identifiable landmarks differ while moving mediolaterally through slices of the pharynx. An attempt was made to measure each patient in the midsagital plane based on the midline of the maxillary incisors. 
An important source of variability was the selected separation density between the soft tissues on the nasopharynx and the volume of the interior of the nasopharynx itself. The Dolphin software (like many such programs) leaves it to the operator to choose a setting that optimally distinguishes between these two anatomic units with similar Hounsfield units, which is the attenuation of X-rays by materials (tissues). Hounsfield units (HU) are a linear scale of x-ray attenuation, which differs by material. This is done in the Dolphin program by adjusting a "slider" (radiodensity) that discriminates between the fluid (largely air) within the pharynx contrasted with the fluid (largely water) of the pharyngeal tissues themselves. The attenuation of distilled water at standard temperature and pressure (STP) is zero, and the radiodensity of air is -1000 HU. Slight variations in the choice of HU by the operator could easily account for the observed differences in pharyngeal volumes. 


\section{CHAPTER 6. CONCLUSIONS}

The present study used CBCT analysis to compare pharyngeal airway volumetric changes in two groups of patients treated for Class II malocclusions. The differing treatment modalities for dentoskeletal correction, the MARA and Class II elastics, produced significant cephalometric differences between the treatment groups. The resulting cephalometric treatment differences, however, were not great enough to produce significant differences in the pharyngeal airway volume. It is concluded that the dentofacial treatment differences obtained with these two Class II correction methods were not enough to have a significant effect on the pharyngeal airway volume. 


\section{LIST OF REFERENCES}

Aboudara C, Nielsen I, Huang JC, Maki K, Miller AJ, Hatcher D. Comparison of airway space with conventional lateral headfilms and 3-dimensional reconstruction from cone-beam computed tomography. Am J Orthod Dentofacial Orthop. 2009; 135:468-479.

Alan A. Lowe Treating obstructive sleep apnea: The case for oral appliances. American Journal of Orthodontics and Dentofacial Orthopedics Vol. 142, Issue 4, Page 434 October 2012.

Allen-Noble PS. Clinical management of MARA. Allesee Orthodontic Appliances. July 2005.

Andrews LF. The six keys to normal occlusion. Am J Orthod. 1972;62:296-309.

Athanasiou AE. Orthodontic cephalometry. London: Mosby-Wolfe; 1995.

Banno Katsuhisa, Kryger, Meir H. Sleep apnea: Clinical investigations in humans Sleep Medicine 8 2007:400-426.

Baume LJ, Horowitz HS, Summers CJ, Dirks OB, Brown WAB, Carlos JP, Cohen LK, Freer TJ, Harvold EP, Moorrees CFA, Salzmann JA, Schmuth G, Solow B, Taatz J. A method for measuring occlusal traits. Int Dent J 1973;23:530-7.

Baumrind S, Frantz RC. The reliability of head film measurements, 1. Landmark identification. Am J Orthod 1971;60:111-27.

Berco M, Rigali PH Jr, Miner RM, DeLuca S, Anderson NK, Will LA. Accuracy of linear measurements from imaging plate and lateral cephalometric images derived from cone-beam computed tomography. Am J Orthod Dentofacial Orthop. 2009;136: 17.e1-9; discussion 17-8.

Bergland O, The bony nasopharynx. A roentgen-craniometric study. Acta Odontol Scand. $1963 ; 21 ; 1-137$.

Bishara S. Functional appliances: a review. Am J Orthod Dentofacial Orthop 1989;95:250-8.

Bland JM, Altman DG. Statistical methods for assessing agreement between two methods of clinical measurement. Lancet 1986;i:307-10.

Brunelle JA, Bhat M, Lipton JA. Prevalence and distribution of selected occlusal characteristics in the US population, 1988-1991. J Dent Res 1996;75:706-13. 
Charlier JP, Petrovic A, Hermann-Stutzmann J. Effects of mandibular hyperpropulsion on the prechondroblastic zone of young rat condyle. Am J Orthod. 1969;55:71-74.

Cho BH, Ahn YW, Jung YH. Comparison of mandibular morphology between patients with temporomandibular joint osteoarthritis and asymptomatic normal subjects. Quintessence Int. 2009;40:e49-54.

Dahlberg G. Statistical methods for medical and biological students. London: George Allen and Unwin, Ltd, 1940.

Damstra J, Fourie Z, Huddleston Slater JJ, Ren Y. Accuracy of linear measurements from cone-beam computed tomography-derived surface models of different voxel size. Am J Orthod Dentofacial Orthop. 2010;137: 16.e1-6; discussion 16-7.

El H, Palomo JM. Airway volume for different dentofacial skeletal patterns. Am J Orthod Dentofacial Orthop. 2011;139:e511-521.

El H, Palomo JM. Measuring the airway in 3 dimensions: a reliability and accuracy study. Am J Orthod Dentofacial Orthop. 2010;137: S50.e1-9; discussion S50-2.

Elgoyhen JC, Moyers RE, McNamara JA Jr, Riolo ML. Craniofacial adaptation to protrusive function in juvenile rhesus monkeys. Am J Orthod 1972;62:469-80

Enlow DH. Handbook of facial growth, 2nd ed. Philadelphia: WB Saunders; 1975;56-7.

Farman AG, Scarfe WC. Development of imaging selection criteria and procedures should precede cephalometric assessment with cone-beam computed tomography. Am J Orthod Dentofacial Orthop. 2006;130:257-265.

Fisk GV, Culbert MR, Grainger RM, Hemrend B, Moyers R. The morphology and physiology of distoclusion. Am J Orthod 1953;35:3-12.

Fränkel R, Fränkel C. Orofacial orthopedics with the function regulator. New York:Karger, 1989.

Graber TM. The upper airway and cranial morphology. In: Graber TM, Vanarsdall RL, Vig KWL, editors. Orthodontics: current principles and techniques. St. Louis: CV Mosby; 2005. p. 117-143.

Graber TM. Treatment of patients in the mixed dentition. In: Graber TM, Vanarsdall RL, Vig KWL, editors. Orthodontics: current principles and techniques. St. Louis: CV Mosby; 2005. p. 543-77.

Graber TM, Rakosi T, Petrovic A, editors: Dentofacial orthopedics with functional appliances, ed 2, St Louis, 1997, Mosby. 
Grauer D, Cevidanes LSH, Styner MA, Ackerman JL, Proffit WR. Pharyngeal airway volume and shape from cone-beam computed tomography: Relationship to facial morphology. Am J Orthod Dentofacial Orthop 2009;136:805-814.

Gray H. The pharynx. In: Goss CM, editor. Anatomy of the human body. Philidelphia: Lea \& Febiger; 1948. p. 1148-1152.

Guay AH, Brown LJ, Wall T. Orthodontic dental patients and expenditures-2004. Am J Orthod Dentofacial Orthop 2008;134:337-343.

Hänggi MP, Teuscher UM, Roos M, Peltomaki TA. Long-term changes in pharyngeal airway dimensions following activator-headgear and fixed appliance treatment. Eur J Orthod. 2008;30:598-605.

Harris EF, Corruccini RS. Quantification of dental occlusal variation: a review of methods. Dental Anthropology2008;21:1-11.

Harris EF, Smith RN. Accounting for measurement error: A critical but often overlooked process. Arch Oral Biol 2009; 54, Supplement 1:107-17.

Howe RP. The bonded Herbst appliance. J Clin Orthod 1982;16:663-667.

Houston WJ. The analysis of errors in orthodontic measurements. Am J Orthod 1983;83:382-90.

Ikeda K, Kawamura A. Assessment of optimal condylar position with limited cone-beam computed tomography. Am J Orthod Dentofacial Orthop. 2009;135:495-501.

Jacobson A, Jacobson R. Radiographic Cephalometry: From Basics to 3-D Imaging. 2nd ed. Hanover Park: Quintessence Publishing Co, Inc; 2006.

Kim YJ, Hong JS, Hwang YI, Park YH. Three-dimensional analysis of pharyngeal airway in preadolescent children with different anteroposterior skeletal patterns. Am J Orthod Dentofacial Orthop. 2010;137: 306.e1-11; discussion 306-7.

Kirjavainen M, Kirjavainen T. Upper airway dimensions in Class II malocclusion. Effects of headgear treatment. Angle Orthod. 2007;77:1046-1043.

Massler M, Frankel JM. Prevalence of malocclusion in children aged 14-18 years. Am J Orthod 1951;37:751-68.

McNamara JA. A method of cephalometric evaluation. Am J Orthod 1984;86:449-69.

McNamara JA. Components of class II malocclusion in children 8-10 years of age. Angle Orthod 1981;51:177-202. 
McNamara JA Jr. Neuromuscular and skeletal adaptations to altered function in the orofacial region. Am J Orthod. 1973;64:578-606.

McNamara JA Jr, Hinton RJ, Hoffman DL. Histologic analysis of rhesus monkeys (Macaca mulatta). AM J Orthod. 1982;84:288-298.

McNamara JA Jr, Bryan FA. Long-term mandibular adaptations to protrusive function: an experimental study in Macaca mulatta. Am J Orthod Dentofacial Orthop. 1987;92:98-108.

Morris H. The pharynx. In: Schaeffer JP, editor. Morris' human anatomy: a complete systematic treatise. New York: The Blackstone Company; 1953. p. 1323-1332.

Moshiri M, Scarfe WC, Hilgers ML, Scheetz JP, Silveira AM, Farman AG. Accuracy of linear measurements from imaging plate and lateral cephalometric images derived from cone-beam computed tomography. Am J Orthod Dentofacial Orthop. 2007; 132:550-560.

Moyers RE, Riolo ML, Guire KE, Wainright RL, Bookstein FL. Differential diagnosis of class II malocclusions. Part 1. Facial types associated with class II malocclusions. Am J Orthod 1980;78:477-94.

Osorio F, Perilla M, Doyle DJ, Palomo JM. Cone beam computed tomography: an innovative tool for airway assessment. Anesth Analg. 2008;106:1803-1807.

Pangrazio-Kulbersh V, Berger JL, Chermak DS, Kaczynski R, Simon ES, Haerian A. Treatment effect of the mandibular anterior repositioning appliance on patients with Class II malocclusion. Am J Orthod Dentofacial Orthop 2003;123:286-95.

Park JW, Kim NK, Kim JW, Kim MJ, Chang YI. Volumetric, planar, and linear analyses of pharyngeal airway change on computed tomography and cephalometry after mandibular setback surgery. Am J Orthod Dentofacial Orthop 2010;138:292-299.

Proffit WR, Fields HW, Sarver DM. Contemporary Orthodontics. 4th ed. St. Louis: Mosby Elsevier; 2006.

Restrepo C, Santamaria A, Peláez S, Tapias A. Oropharyngeal airway dimensions after treatment with functional appliances in class II retrognathic children. J Oral Rehabil. 2011;38 no. doi: 10.1111/j.1365-2842.2011.02199.x.

Ricketts RM. Variations of the temporomandibular joint as revealed by cephalometric laminography. Am J Orthodontics. 1950;36;877-97.

Righellis EG. Treatment effects of Fränkel, activator and extraoral traction appliances. Angle Orthod 1983;53: 107-121. 
Riolo ML, Moyers RE, McNamara JA Jr, Hunter WS. An atlas of craniofacial growth: cephalometric standards from the University School Growth Study, the University of Michigan. Monograph 2, Craniofacial Growth Series. Ann Arbor: Center for Human Growth and Development, University of Michigan; 1974, 379 pages.

Rodrigues AF, Fraga MR, Vitral RW. Computed tomography evaluation of the temporomandibular joint in Class II Division 1 and Class III malocclusion patients: condylar symmetry and condyle-fossa relationship. Am J Orthod Dentofacial Orthop. 2009;136:199-206.

Scarfe WC, Farman AG, Sukovic P. Clinical applications of cone-beam computed tomography in dental practice. J Can Dent Assoc. 2006; 72:75-80.

Siara-Olds NJ, Pangrazio-Kulbersh V, Berger J, Bayirli B. Long-term dentoskeletal changes with the Bionator, Herbst, Twin Block, and MARA functional appliances. Angle Orthod. 2010;80:18-29.

Sicher H. The pharynx. In: Sicher H, editor. Oral Anatomy. St. Louis: CV Mosby; 1952. P. 286-288.

Sokal RR, Rohlf FJ. Biometry: the principles and practice of statistics in biological research, 3rd ed. San Francisco: WH Freeman and Company, 1995.

Stöckli PW, Willert HG. Tissue reactions in the temporomandibular joint resulting from anterior displacement of the mandible in the monkey. Am J Orthod 1971;60:14255 .

Wahl N. Orthodontics in 3 millennia: Chapter 9 functional appliances to midcentury. Am J Orthod Dentofacial Orthop 2006;129:829-33.

Winer BJ, Brown DR, Michels KM. Statistical principles in experimental design. 3rd ed. New York: McGraw-Hill Book Company, 1991.

Woodside DG, Metaxas A, Altuna G. The influence of functional appliance therapy on glenoid fossa remodeling. Am J Orthod Dentofacial Orthop 1987;92:181-188.

Young T, Palta M, Dempsey J, Skatrud J, Weber S, Badr S. The occurrence of sleepdisordered breathing among middle-ages adults. N Engl J Med 1993;328:1230-5. 


\section{APPENDIX A. RESULTS OF TESTING FOR SEX AND TREATMENT DIFFERENCE AT START OF TREATMENT}

Table A-1. Results of two-way ANOVA testing for treatment and sex differences between samples at the start of treatment; variable is Airway 1 Volume (Nasopharyngeal).

\begin{tabular}{ccccc}
\hline Source & df & SSQ & F Ratio & P-value \\
\hline Treatment & 1 & 1870694 & 0.86 & 0.3583 \\
Sex & 1 & 6108 & 0.00 & 0.9580 \\
$\begin{array}{c}\text { Treatment-x- } \\
\text { Sex }\end{array}$ & 1 & 2977903 & 1.36 & 0.2474 \\
\hline
\end{tabular}

Table A-2. Results of two-way ANOVA testing for treatment and sex differences between samples at the start of treatment; variable is initial patient age; variable is Airway 1 Area (Nasopharyngeal).

\begin{tabular}{crrrr}
\hline Source & df & SSQ & F Ratio & P-value \\
\hline Treatment & 1 & 11.73 & 0.00 & 0.9566 \\
Sex & 1 & 74.89 & 0.02 & 0.8906 \\
$\begin{array}{c}\text { Treatment-x- } \\
\text { Sex }\end{array}$ & 1 & 856.90 & 0.22 & 0.6419 \\
\hline
\end{tabular}

Table A-3. Results of two-way ANOVA testing for treatment and sex differences between samples at the start of treatment; variable is Airway $1+2$ Volume.

\begin{tabular}{crrrr}
\hline Source & df & SSQ & F Ratio & P-value \\
\hline Treatment & 1 & 18496375 & 1.23 & 0.2710 \\
Sex & 1 & 34243554 & 2.28 & 0.1357 \\
$\begin{array}{c}\text { Treatment- } \\
\text { x-Sex }\end{array}$ & 1 & 17492743 & 1.17 & 0.2843 \\
\hline
\end{tabular}


Table A-4. Results of two-way ANOVA testing for treatment and sex differences between samples at the start of treatment; variable is initial patient age Airway $1+2$ Area $\left(\mathbf{m m}^{2}\right)$.

\begin{tabular}{ccccc}
\hline Source & df & SSQ & F Ratio & P-value \\
\hline Treatment & 1 & 8816.19 & 0.72 & 0.3998 \\
Sex & 1 & 6063.06 & 0.49 & 0.4847 \\
$\begin{array}{c}\text { Treatment- } \\
\text { x-Sex }\end{array}$ & 1 & 10553.69 & 0.86 & 0.3572 \\
\hline
\end{tabular}

Table A-5. Results of two-way ANOVA testing for treatment and sex differences between samples at the start of treatment; variable is Airway 2 Volume (Superior).

\begin{tabular}{ccccc}
\hline Source & df & SSQ & F Ratio & P-value \\
\hline Treatment & 1 & 8602536.00 & 0.89 & 0.3482 \\
Sex & 1 & 35164359.00 & 3.65 & 0.0605 \\
Treatment- & 1 & 6035731.00 & 0.63 & 0.4316 \\
x-Sex & & & & \\
\hline
\end{tabular}

Table A- 6. Results of two-way ANOVA testing for treatment and sex differences between samples at the start of treatment; variable is Airway 2 Area (Superior).

\begin{tabular}{ccccc}
\hline Source & df & SSQ & F Ratio & P-value \\
\hline Treatment & 1 & 8184.69 & 1.08 & 0.3029 \\
Sex & 1 & 7485.68 & 0.99 & 0.3243 \\
Treatment-x- & 1 & 5396.13 & 0.71 & 0.4022 \\
Sex & & & & \\
\hline
\end{tabular}


Table A- 7. Results of two-way ANOVA testing for treatment and sex differences between samples at the start of treatment; variable is Airway $1+2+3$ Volume $\left(\mathrm{mm}^{3}\right)$.

\begin{tabular}{ccccc}
\hline Source & df & SSQ & F Ratio & P-value \\
\hline Treatment & 1 & 39871007.00 & 1.33 & 0.2528 \\
Sex & 1 & 20827879.00 & 0.70 & 0.4074 \\
Treatment- & 1 & 6495004.00 & 0.22 & 0.6430 \\
x-Sex & & & & \\
\hline
\end{tabular}

Table A-8. Results of two-way ANOVA testing for treatment and sex differences between samples at the start of treatment; variable is Airway $1+2+3$ Area $\left(\mathrm{mm}^{2}\right)$.

\begin{tabular}{ccccc}
\hline Source & df & SSQ & F Ratio & P-value \\
\hline Treatment & 1 & 4746.31 & 0.17 & 0.6832 \\
Sex & 1 & 497.44 & 0.02 & 0.8948 \\
Treatment-x- & 1 & 5677.95 & 0.20 & 0.6554 \\
Sex & & & & \\
\hline
\end{tabular}

Table A-9. Results of two-way ANOVA testing for treatment and sex differences between samples at the start of treatment; variable is Airway 3 Volume (Inferior).

\begin{tabular}{ccccc}
\hline Source & df & SSQ & F Ratio & P-value \\
\hline Treatment & 1 & 4054617.70 & 0.77 & 0.3819 \\
Sex & 1 & 1659052.50 & 0.32 & 0.5753 \\
$\begin{array}{c}\text { Treatment- } \\
\text { x-Sex }\end{array}$ & 1 & 2669638.80 & 0.51 & 0.4776 \\
\hline
\end{tabular}


Table A-10. Results of two-way ANOVA testing for treatment and sex differences between samples at the start of treatment; variable is Airway 3 Area (Inferior).

\begin{tabular}{cccrr}
\hline Source & df & SSQ & F Ratio & P-value \\
\hline Treatment & 1 & 625.05 & 0.09 & 0.7692 \\
Sex & 1 & 3087.16 & 0.43 & 0.5148 \\
$\begin{array}{c}\text { Treatment-x- } \\
\text { Sex }\end{array}$ & 1 & 749.61 & 0.10 & 0.7479 \\
\hline
\end{tabular}

Table A-11. Results of two-way ANOVA testing for treatment and sex differences between samples at the start of treatment; variable is Total Airway.

\begin{tabular}{crrrr}
\hline Source & df & SSQ & F Ratio & P-value \\
\hline Treatment & 1 & 39871007 & 1.33 & 0.2528 \\
Sex & 1 & 20827879 & 0.70 & 0.4074 \\
$\begin{array}{c}\text { Treatment- } \\
\text { x-Sex }\end{array}$ & 1 & 6495004 & 0.22 & 0.6430 \\
\hline
\end{tabular}

Table A-12. Results of two-way ANOVA testing for treatment and sex differences between samples at the start of treatment; variable is distance $(\mathrm{mm})$ to the Minimum Constriction.

\begin{tabular}{cccrr}
\hline Source & df & SSQ & F Ratio & P-value \\
\hline Treatment & 1 & 19814.93 & 2.73 & 0.1034 \\
Sex & 1 & 3349.92 & 0.46 & 0.4995 \\
$\begin{array}{c}\text { Treatment- } \\
\text { x-Sex }\end{array}$ & 1 & 4.33 & 0.00 & 0.9806 \\
\hline
\end{tabular}


Table A-13. Results of two-way ANOVA testing for treatment and sex differences between samples at the start of treatment; variable is $\mathrm{PFH} / \mathrm{AFH} \%$.

\begin{tabular}{ccccc}
\hline Source & df & SSQ & F Ratio & P-value \\
\hline Treatment & 1 & 0.00 & 0.31 & 0.5826 \\
Sex & 1 & 0.00 & 0.24 & 0.6274 \\
Treatment-x- & 1 & 0.00 & 0.22 & 0.6443 \\
Sex & & & & \\
\hline
\end{tabular}

Table A-14. Results of two-way ANOVA testing for treatment and sex differences between samples at the start of treatment; variable is the angle $\mathrm{Y}$-Axis.

\begin{tabular}{crrrr}
\hline Source & df & \multicolumn{1}{c}{ SSQ } & F Ratio & \multicolumn{1}{c}{ P-value } \\
\hline Treatment & 1 & 14.00 & 1.37 & 0.2462 \\
Sex & 1 & 8.89 & 0.87 & 0.3546 \\
Treatment-x- & 1 & 19.03 & 1.86 & 0.1772 \\
Sex & & & & \\
\hline
\end{tabular}

Table A-15. Results of two-way ANOVA testing for treatment and sex differences between samples at the start of treatment; variable is the angle Facial Convexity.

\begin{tabular}{ccccc}
\hline Source & df & SSQ & F Ratio & P-value \\
\hline Treatment & 1 & 4.93 & 0.29 & 0.5914 \\
Sex & 1 & 7.25 & 0.43 & 0.5151 \\
$\begin{array}{c}\text { Treatment-x- } \\
\text { Sex }\end{array}$ & 1 & 1.50 & 0.09 & 0.7671 \\
\hline
\end{tabular}


Table A-16. Results of two-way ANOVA testing for treatment and sex differences between samples at the start of treatment; variable is the angle SNA.

\begin{tabular}{ccccc}
\hline Source & df & SSQ & F Ratio & P-value \\
\hline Treatment & 1 & 1.24 & 0.11 & 0.7377 \\
Sex & 1 & 0.15 & 0.01 & 0.9061 \\
$\begin{array}{c}\text { Treatment-x- } \\
\text { Sex }\end{array}$ & 1 & 2.34 & 0.21 & 0.6462 \\
\hline
\end{tabular}

Table A-17. Results of two-way ANOVA testing for treatment and sex differences between samples at the start of treatment; variable is the angle SNB.

\begin{tabular}{ccccc}
\hline Source & df & SSQ & F Ratio & P-value \\
\hline Treatment & 1 & 3.59 & 0.41 & 0.5243 \\
Sex & 1 & 0.36 & 0.04 & 0.8391 \\
$\begin{array}{c}\text { Treatment-x- } \\
\text { Sex }\end{array}$ & 1 & 0.18 & 0.02 & 0.8851 \\
\hline
\end{tabular}

Table A-18. Results of two-way ANOVA testing for treatment and sex differences between samples at the start of treatment; variable is the angle ANB.

\begin{tabular}{ccccc}
\hline Source & df & SSQ & F Ratio & P-value \\
\hline Treatment & 1 & 0.72 & 0.30 & 0.5874 \\
Sex & 1 & 1.13 & 0.47 & 0.4958 \\
Treatment-x- & 1 & 1.06 & 0.44 & 0.5088 \\
Sex & & & & \\
\hline
\end{tabular}


Table A-19. Results of two-way ANOVA testing for treatment and sex differences between samples at the start of treatment; variable is Wits AOBO discrepancy.

\begin{tabular}{crrrr}
\hline Source & df & \multicolumn{1}{c}{ SSQ } & F Ratio & \multicolumn{1}{c}{ P-value } \\
\hline Treatment & 1 & 21.00 & 3.26 & 0.0757 \\
Sex & 1 & 1.76 & 0.27 & 0.6029 \\
$\begin{array}{c}\text { Treatment-x- } \\
\text { Sex }\end{array}$ & 1 & 0.00 & 0.00 & 0.9908 \\
\hline
\end{tabular}

Table A-20. Results of two-way ANOVA testing for treatment and sex differences between samples at the start of treatment; variable is the angle FMA.

\begin{tabular}{crrrr}
\hline Source & df & \multicolumn{1}{c}{ SSQ } & F Ratio & P-value \\
\hline Treatment & 1 & 12.27 & 0.46 & 0.5004 \\
Sex & 1 & 2.16 & 0.08 & 0.7769 \\
$\begin{array}{c}\text { Treatment-x- } \\
\text { Sex }\end{array}$ & 1 & 6.74 & 0.25 & 0.6173 \\
\hline
\end{tabular}

Table A-21. Results of two-way ANOVA testing for treatment and sex differences between samples at the start of treatment; variable is the angle IMPA.

\begin{tabular}{crrrr}
\hline Source & df & \multicolumn{1}{c}{ SSQ } & F Ratio & P-value \\
\hline Treatment & 1 & 162.17 & 3.35 & 0.0719 \\
Sex & 1 & 3.78 & 0.08 & 0.7810 \\
$\begin{array}{c}\text { Treatment-x- } \\
\text { Sex }\end{array}$ & 1 & 17.59 & 0.36 & 0.5490 \\
\hline
\end{tabular}


Table A-22. Results of two-way ANOVA testing for treatment and sex differences between samples at the start of treatment; variable is the angle FMIA.

\begin{tabular}{crrrr}
\hline Source & df & SSQ & F Ratio & P-value \\
\hline Treatment & 1 & 82.95 & 2.85 & 0.0962 \\
Sex & 1 & 0.24 & 0.01 & 0.9281 \\
$\begin{array}{c}\text { Treatment-x- } \\
\text { Sex }\end{array}$ & 1 & 47.37 & 1.63 & 0.2066 \\
\hline
\end{tabular}

Table A-23. Results of two-way ANOVA testing for treatment and sex differences between samples at the start of treatment; variable is the Interincisal Angle.

\begin{tabular}{crrrr}
\hline Source & df & SSQ & F Ratio & P-value \\
\hline Treatment & 1 & 643.31 & 8.71 & 0.0044 \\
Sex & 1 & 93.68 & 1.27 & 0.2643 \\
Treatment-x- & 1 & 33.44 & 0.45 & 0.5035 \\
Sex & & & & \\
\hline
\end{tabular}

Table A-24. Results of two-way ANOVA testing for treatment and sex differences between samples at the start of treatment; variable is the angle U1-SeNa.

\begin{tabular}{crrrr}
\hline Source & df & SSQ & F Ratio & \multicolumn{1}{c}{ P-value } \\
\hline Treatment & 1 & 346.63 & 6.88 & 0.0108 \\
Sex & 1 & 50.12 & 0.99 & 0.3223 \\
Treatment-x- & 1 & 0.64 & 0.01 & 0.9103 \\
Sex & & & & \\
\hline
\end{tabular}


Table A-25. Results of two-way ANOVA testing for treatment and sex differences between samples at the start of treatment; variable is the angle L1-NB $\left(^{\circ}\right)$

\begin{tabular}{crrrr}
\hline Source & df & \multicolumn{1}{c}{ SSQ } & F Ratio & P-value \\
\hline Treatment & 1 & 74.51 & 2.55 & 0.1152 \\
Sex & 1 & 4.32 & 0.15 & 0.7018 \\
$\begin{array}{c}\text { Treatment-x- } \\
\text { Sex }\end{array}$ & 1 & 20.69 & 0.71 & 0.4033 \\
\hline
\end{tabular}

Table A-26. Results of two-way ANOVA testing for treatment and sex differences between samples at the start of treatment; variable is the distance L1-NB (mm).

\begin{tabular}{ccrrr}
\hline Source & df & SSQ & F Ratio & P-value \\
\hline Treatment & 1 & 5.55 & 1.55 & 0.2171 \\
Sex & 1 & 1.99 & 0.56 & 0.4580 \\
$\begin{array}{c}\text { Treatment-x- } \\
\text { Sex }\end{array}$ & 1 & 2.06 & 0.58 & 0.4506 \\
\hline
\end{tabular}

Table A-27. Results of two-way ANOVA testing for treatment and sex differences between samples at the start of treatment; variable is the angle U1-NA $\left(^{\circ}\right)$.

\begin{tabular}{crrrr}
\hline Source & df & \multicolumn{1}{c}{ SSQ } & F Ratio & P-value \\
\hline Treatment & 1 & 303.22 & 6.64 & 0.0122 \\
Sex & 1 & 45.20 & 0.99 & 0.3236 \\
$\begin{array}{c}\text { Treatment-x- } \\
\text { Sex }\end{array}$ & 1 & 5.03 & 0.11 & 0.7411 \\
\hline
\end{tabular}


Table A-28. Results of two-way ANOVA testing for treatment and sex differences between samples at the start of treatment; variable is the distance U1-NA (mm).

\begin{tabular}{crrrr}
\hline Source & df & SSQ & F Ratio & P-value \\
\hline Treatment & 1 & 16.49 & 4.19 & 0.0447 \\
Sex & 1 & 6.01 & 1.53 & 0.2209 \\
$\begin{array}{c}\text { Treatment-x- } \\
\text { Sex }\end{array}$ & 1 & 3.20 & 0.81 & 0.3702 \\
\hline
\end{tabular}

Table A-29. Results of two-way ANOVA testing for treatment and sex differences between samples at the start of treatment; variable is Incisor Overbite.

\begin{tabular}{ccccc}
\hline Source & df & SSQ & F Ratio & P-value \\
\hline Treatment & 1 & 0.62 & 0.16 & 0.6870 \\
Sex & 1 & 2.39 & 0.64 & 0.4281 \\
$\begin{array}{c}\text { Treatment-x- } \\
\text { Sex }\end{array}$ & 1 & 3.85 & 1.03 & 0.3150 \\
\hline
\end{tabular}

Table A-30. Results of two-way ANOVA testing for treatment and sex differences between samples at the start of treatment; variable is Incisor Overjet.

\begin{tabular}{ccccc}
\hline Source & df & SSQ & F Ratio & P-value \\
\hline Treatment & 1 & 0.66 & 0.18 & 0.6745 \\
Sex & 1 & 2.18 & 0.58 & 0.4472 \\
$\begin{array}{c}\text { Treatment-x- } \\
\text { Sex }\end{array}$ & 1 & 0.11 & 0.03 & 0.8660 \\
\hline
\end{tabular}


Table A-31. Results of two-way ANOVA testing for treatment and sex differences between samples at the start of treatment; variable is Superior Airway Space.

\begin{tabular}{ccrcr}
\hline Source & df & \multicolumn{1}{c}{ SSQ } & F Ratio & P-value \\
\hline Treatment & 1 & 21.08 & 3.01 & 0.0876 \\
Sex & 1 & 0.01 & 0.00 & 0.9756 \\
$\begin{array}{c}\text { Treatment-x- } \\
\text { Sex }\end{array}$ & 1 & 10.73 & 1.53 & 0.2205 \\
\hline
\end{tabular}

Table A-32. Results of two-way ANOVA testing for treatment and sex differences between samples at the start of treatment; variable is the distance Condylion-APoint.

\begin{tabular}{crrrr}
\hline Source & df & SSQ & F Ratio & \multicolumn{1}{c}{ P-value } \\
\hline Treatment & 1 & 598.49 & 32.69 & $<0.0001$ \\
Sex & 1 & 0.32 & 0.02 & 0.8960 \\
Treatment-x- & 1 & 13.94 & 0.76 & 0.3861 \\
Sex & & & & \\
\hline
\end{tabular}

Table A-33. Results of two-way ANOVA testing for treatment and sex differences between samples at the start of treatment; variable is the distance CondylionGnathion.

\begin{tabular}{crrrr}
\hline Source & df & SSQ & F Ratio & \multicolumn{1}{c}{ P-value } \\
\hline Treatment & 1 & 363.08 & 11.95 & 0.0010 \\
Sex & 1 & 4.07 & 0.13 & 0.7154 \\
Treatment-x- & 1 & 25.63 & 0.84 & 0.3617 \\
Sex & & & & \\
\hline
\end{tabular}


Table A-34. Results of two-way ANOVA testing for treatment and sex differences between samples at the start of treatment; variable is the distance A-to-NasionPerpendicular.

\begin{tabular}{ccrcr}
\hline Source & df & SSQ & F Ratio & P-value \\
\hline Treatment & 1 & 1.05 & 0.11 & 0.7464 \\
Sex & 1 & 4.81 & 0.48 & 0.4900 \\
$\begin{array}{c}\text { Treatment-x- } \\
\text { Sex }\end{array}$ & 1 & 11.03 & 1.11 & 0.2967 \\
\hline
\end{tabular}

Table A-35. Results of two-way ANOVA testing for treatment and sex differences between samples at the start of treatment; variable is the distance Pogonion-toNasion-Perpendicular.

\begin{tabular}{ccrcr}
\hline Source & df & SSQ & F Ratio & P-value \\
\hline Treatment & 1 & 4.45 & 0.15 & 0.7039 \\
Sex & 1 & 6.96 & 0.23 & 0.6346 \\
Treatment-x- & 1 & 40.84 & 1.34 & 0.2516 \\
Sex & & & & \\
\hline
\end{tabular}

Table A-36. Results of two-way ANOVA testing for treatment and sex differences between samples at the start of treatment; variable is the distance B-to-NasionPerpendicular.

\begin{tabular}{ccccc}
\hline Source & df & SSQ & F Ratio & P-value \\
\hline Treatment & 1 & 0.00 & 0.00 & 0.9870 \\
Sex & 1 & 1.44 & 0.23 & 0.6300 \\
Treatment-x- & 1 & 0.53 & 0.09 & 0.7699 \\
Sex & & & & \\
\hline
\end{tabular}


Table A-37. Results of two-way ANOVA testing for treatment and sex differences between samples at the start of treatment; variable is Anterior Facial Height.

\begin{tabular}{crrrr}
\hline Source & df & SSQ & F Ratio & P-value \\
\hline Treatment & 1 & 74.65 & 2.29 & 0.1348 \\
Sex & 1 & 19.94 & 0.61 & 0.4368 \\
Treatment-x- & 1 & 125.48 & 3.85 & 0.0539 \\
Sex & & & & \\
\hline
\end{tabular}

Table A-38. Results of two-way ANOVA testing for treatment and sex differences between samples at the start of treatment; variable is the distance Molar Relationship.

\begin{tabular}{ccccc}
\hline Source & df & SSQ & F Ratio & P-value \\
\hline Treatment & 1 & 2.07 & 1.18 & 0.2822 \\
Sex & 1 & 2.65 & 1.50 & 0.2244 \\
$\begin{array}{c}\text { Treatment-x- } \\
\text { Sex }\end{array}$ & 1 & 0.17 & 0.10 & 0.7556 \\
\hline
\end{tabular}

Table A-39. Results of two-way ANOVA testing for treatment and sex differences between samples at the start of treatment; variable is the distance Posterior Facial Height.

\begin{tabular}{ccccc}
\hline Source & df & SSQ & F Ratio & P-value \\
\hline Treatment & 1 & 33.70 & 1.56 & 0.2163 \\
Sex & 1 & 19.00 & 0.88 & 0.3520 \\
Treatment-x- & 1 & 72.47 & 3.35 & 0.0717 \\
Sex & & & & \\
\hline
\end{tabular}


Table A-40. Results of two-way ANOVA testing for treatment and sex differences between samples at the start of treatment; variable is the distance Gonion-Menton.

\begin{tabular}{crrrr}
\hline Source & df & \multicolumn{1}{c}{ SSQ } & F Ratio & \multicolumn{1}{c}{ P-value } \\
\hline Treatment & 1 & 227.27 & 10.35 & 0.0020 \\
Sex & 1 & 0.99 & 0.05 & 0.8326 \\
$\begin{array}{c}\text { Treatment-x- } \\
\text { Sex }\end{array}$ & 1 & 1.35 & 0.06 & 0.8050 \\
\hline
\end{tabular}

Table A-41. Results of two-way ANOVA testing for treatment and sex differences between samples at the start of treatment; variable is Sella-Perpendicular to-APoint.

\begin{tabular}{ccccc}
\hline Source & df & SSQ & F Ratio & P-value \\
\hline Treatment & 1 & 0.79 & 0.05 & 0.8241 \\
Sex & 1 & 3.07 & 0.19 & 0.6610 \\
$\begin{array}{c}\text { Treatment-x- } \\
\text { Sex }\end{array}$ & 1 & 0.03 & 0.00 & 0.9668 \\
\hline
\end{tabular}

Table A-42. Results of two-way ANOVA testing for treatment and sex differences between samples at the start of treatment; variable is the distance Sella-Vertical-toB Point.

\begin{tabular}{ccccc}
\hline Source & df & SSQ & F Ratio & P-value \\
\hline Treatment & 1 & 2.69 & 0.10 & 0.7471 \\
Sex & 1 & 4.11 & 0.16 & 0.6900 \\
Treatment-x- & 1 & 0.92 & 0.04 & 0.8499 \\
Sex & & & & \\
\hline
\end{tabular}


Table A-43. Results of two-way ANOVA testing for treatment and sex differences between samples at the start of treatment; variable is Sella-Vertical-to-Pogonion.

\begin{tabular}{crrrr}
\hline Source & df & SSQ & F Ratio & \multicolumn{1}{c}{ P-value } \\
\hline Treatment & 1 & 226.35 & 18.02 & $<0.0001$ \\
Sex & 1 & 3.99 & 0.32 & 0.5751 \\
$\begin{array}{c}\text { Treatment-x- } \\
\text { Sex }\end{array}$ & 1 & 6.70 & 0.53 & 0.4677 \\
\hline
\end{tabular}

Table A-44. Results of two-way ANOVA testing for treatment and sex differences between samples at the start of treatment; variable is Sella-Vertical-to-M Point.

\begin{tabular}{ccrrr}
\hline Source & df & SSQ & F Ratio & P-value \\
\hline Treatment & 1 & 0.45 & 0.02 & 0.8915 \\
Sex & 1 & 10.09 & 0.42 & 0.5194 \\
$\begin{array}{c}\text { Treatment-x- } \\
\text { Sex }\end{array}$ & 1 & 12.46 & 0.52 & 0.4742 \\
\hline
\end{tabular}




\section{APPENDIX B. RESULTS OF TESTING FOR SEX AND TREATMENT DIFFERENCES FOR THE IN-TREATMENT CHANGES}

Table B-1. Results of two-way ANOVA testing for treatment and sex differences between samples measuring the in-treatment changes; variable is Airway 1 Volume (Nasopharyngeal).

\begin{tabular}{ccccr}
\hline Source & df & SSQ & F Ratio & P-value \\
\hline Treatment & 1 & 18767.00 & 0.00 & 0.9486 \\
Sex & 1 & 2855842.10 & 0.64 & 0.4276 \\
Treatment- & 1 & 1813673.30 & 0.40 & 0.5269 \\
x-Sex & & & & \\
\hline
\end{tabular}

Table B-2. Results of two-way ANOVA testing for treatment and sex differences between samples measuring the in-treatment changes; variable is Airway 1 Area (Nasopharyngeal).

\begin{tabular}{ccccc}
\hline Source & df & SSQ & F Ratio & P-value \\
\hline Treatment & 1 & 1120.59 & 0.12 & 0.7338 \\
Sex & 1 & 1062.92 & 0.11 & 0.7404 \\
$\begin{array}{c}\text { Treatment-x- } \\
\text { Sex }\end{array}$ & 1 & 11681.86 & 1.22 & 0.2741 \\
\hline
\end{tabular}

Table B-3. Results of two-way ANOVA testing for treatment and sex differences between samples measuring the in-treatment changes; variable is Airway 1+2 Volume.

\begin{tabular}{ccccc}
\hline Source & df & SSQ & F Ratio & P-value \\
\hline Treatment & 1 & 34685830.00 & 1.32 & 0.2543 \\
Sex & 1 & 23319191.00 & 0.89 & 0.3492 \\
Treatment- & 1 & 13021941.00 & 0.50 & 0.4836 \\
x-Sex & & & & \\
\hline
\end{tabular}


Table B-4. Results of two-way ANOVA testing for treatment and sex differences between samples measuring the in-treatment changes; variable is Airway 1+2 Area $\left(\mathrm{mm}^{2}\right)$.

\begin{tabular}{ccccr}
\hline Source & df & SSQ & F Ratio & P-value \\
\hline Treatment & 1 & 17709.41 & 0.60 & 0.4399 \\
Sex & 1 & 41068.80 & 1.40 & 0.2409 \\
Treatment-x- & 1 & 4847.30 & 0.17 & 0.6857 \\
Sex & & & & \\
\hline
\end{tabular}

Table B-5. Results of two-way ANOVA testing for treatment and sex differences between samples measuring the in-treatment changes; variable is Airway 2 Volume (Superior).

\begin{tabular}{ccccc}
\hline Source & df & SSQ & F Ratio & P-value \\
\hline Treatment & 1 & 33090969.00 & 2.18 & 0.1447 \\
Sex & 1 & 9853767.00 & 0.65 & 0.4235 \\
$\begin{array}{c}\text { Treatment- } \\
\text { x-Sex }\end{array}$ & 1 & 5116037.00 & 0.34 & 0.5637 \\
\hline
\end{tabular}

Table B-6. Results of two-way ANOVA testing for treatment and sex differences between samples measuring the in-treatment changes; variable is Airway 2 Area (Superior).

\begin{tabular}{ccccc}
\hline Source & df & SSQ & F Ratio & P-value \\
\hline Treatment & 1 & 9920.46 & 0.69 & 0.4093 \\
Sex & 1 & 28917.67 & 2.01 & 0.1610 \\
Treatment-x- & 1 & 1479.18 & 0.10 & 0.7495 \\
Sex & & & & \\
\hline
\end{tabular}


Table B-7. Results of two-way ANOVA testing for treatment and sex differences between samples measuring the in-treatment changes; variable is Airway $1+2+3$ Volume.

\begin{tabular}{ccccc}
\hline Source & df & SSQ & F Ratio & P-value \\
\hline Treatment & 1 & 66034135.00 & 1.72 & 0.1942 \\
Sex & 1 & 55141968.00 & 1.44 & 0.2350 \\
$\begin{array}{c}\text { Treatment- } \\
\text { x-Sex }\end{array}$ & 1 & 3669558.00 & 0.10 & 0.7582 \\
\hline
\end{tabular}

Table B-8. Results of two-way ANOVA testing for treatment and sex differences between samples measuring the in-treatment changes; variable is Airway $1+2+3$ Area.

\begin{tabular}{ccccc}
\hline Source & df & SSQ & F Ratio & P-value \\
\hline Treatment & 1 & 20403.66 & 0.46 & 0.5005 \\
Sex & 1 & 41167.10 & 0.93 & 0.3394 \\
Treatment-x- & 1 & 15287.79 & 0.34 & 0.5596 \\
Sex & & & & \\
\hline
\end{tabular}

Table B-9. Results of two-way ANOVA testing for treatment and sex differences between samples measuring the in-treatment changes; variable is Airway 3 Volume (Inferior).

\begin{tabular}{ccccr}
\hline Source & df & SSQ & F Ratio & P-value \\
\hline Treatment & 1 & 5002698.60 & 1.11 & 0.2962 \\
Sex & 1 & 6743209.30 & 1.49 & 0.2258 \\
Treatment- & 1 & 2866193.20 & 0.64 & 0.4283 \\
X-Sex & & & & \\
\hline
\end{tabular}


Table B-10. Results of two-way ANOVA testing for treatment and sex differences between samples measuring the in-treatment changes; variable is Airway 3 Area (Inferior).

\begin{tabular}{crrrr}
\hline Source & df & SSQ & F Ratio & \multicolumn{1}{c}{ P-value } \\
\hline Treatment & 1 & 95.35 & 0.01 & 0.9170 \\
Sex & 1 & 0.06 & 0.00 & 0.9979 \\
Treatment-x- & 1 & 2918.30 & 0.33 & 0.5648 \\
Sex & & & & \\
\hline
\end{tabular}

Table B-11. Results of two-way ANOVA testing for treatment and sex differences between samples measuring the in-treatment changes variable is Total Airway.

\begin{tabular}{ccccr}
\hline Source & df & SSQ & F Ratio & P-value \\
\hline Treatment & 1 & 66034135.00 & 1.72 & 0.1942 \\
Sex & 1 & 55141968.00 & 1.44 & 0.2350 \\
Treatment- & 1 & 3669558.00 & 0.10 & 0.7582 \\
X-Sex & & & & \\
\hline
\end{tabular}

Table B-12. Results of two-way ANOVA testing for treatment and sex differences between samples measuring the in-treatment changes variable is the distance to Minimum Constriction.

\begin{tabular}{ccccc}
\hline Source & df & SSQ & F Ratio & P-value \\
\hline Treatment & 1 & 2688.58 & 0.24 & 0.6236 \\
Sex & 1 & 97.11 & 0.01 & 0.9256 \\
Treatment-x- & 1 & 16.31 & 0.00 & 0.9695 \\
Sex & & & & \\
\hline
\end{tabular}


Table B-13. Results of two-way ANOVA testing for treatment and sex differences between samples measuring the in-treatment changes; variable is $\mathrm{PFH} / \mathrm{AFH} \%$.

\begin{tabular}{ccccc}
\hline Source & df & SSQ & F Ratio & P-value \\
\hline Treatment & 1 & 0.00 & 1.17 & 0.2839 \\
Sex & 1 & 0.00 & 0.28 & 0.5995 \\
$\begin{array}{c}\text { Treatment-x- } \\
\text { Sex }\end{array}$ & 1 & 0.00 & 0.28 & 0.5995 \\
\hline
\end{tabular}

Table B-14. Results of two-way ANOVA testing for treatment and sex differences between samples measuring the in-treatment changes; variable is the angle Facial Convexity.

\begin{tabular}{crrrr}
\hline Source & df & SSQ & F Ratio & P-value \\
\hline Treatment & 1 & 29.40 & 1.90 & 0.1732 \\
Sex & 1 & 14.99 & 0.97 & 0.3291 \\
Treatment-x- & 1 & 0.02 & 0.00 & 0.9716 \\
Sex & & & & \\
\hline
\end{tabular}

Table B-15. Results of two-way ANOVA testing for treatment and sex differences between samples measuring the in-treatment changes; variable is the angle SNA.

\begin{tabular}{crrrr}
\hline Source & df & SSQ & F Ratio & P-value \\
\hline Treatment & 1 & 41.82 & 10.39 & 0.0020 \\
Sex & 1 & 0.25 & 0.06 & 0.8022 \\
$\begin{array}{c}\text { Treatment-x- } \\
\text { Sex }\end{array}$ & 1 & 0.01 & 0.00 & 0.9682 \\
\hline
\end{tabular}


Table B-16. Results of two-way ANOVA testing for treatment and sex differences between samples measuring the in-treatment changes; variable is the angle SNB.

\begin{tabular}{crrrr}
\hline Source & df & \multicolumn{1}{c}{ SSQ } & F Ratio & \multicolumn{1}{c}{ P-value } \\
\hline Treatment & 1 & 24.26 & 4.28 & 0.0424 \\
Sex & 1 & 2.25 & 0.40 & 0.5305 \\
Treatment-x- & 1 & 0.07 & 0.01 & 0.9096 \\
Sex & & & & \\
\hline
\end{tabular}

Table B-17. Results of two-way ANOVA testing for treatment and sex differences between samples measuring the in-treatment changes; variable is the angle ANB.

\begin{tabular}{ccccc}
\hline Source & df & SSQ & F Ratio & P-value \\
\hline Treatment & 1 & 2.00 & 0.83 & 0.3670 \\
Sex & 1 & 0.88 & 0.36 & 0.5504 \\
Treatment-x- & 1 & 0.07 & 0.03 & 0.8691 \\
Sex & & & & \\
\hline
\end{tabular}

Table B-18. Results of two-way ANOVA testing for treatment and sex differences between samples measuring the in-treatment changes; variable is the Wits appraisal.

\begin{tabular}{ccrcr}
\hline Source & df & SSQ & F Ratio & P-value \\
\hline Treatment & 1 & 15.65 & 1.61 & 0.2087 \\
Sex & 1 & 0.31 & 0.03 & 0.8593 \\
Treatment-x- & 1 & 5.33 & 0.55 & 0.4614 \\
Sex & & & & \\
\hline
\end{tabular}


Table B-19. Results of two-way ANOVA testing for treatment and sex differences between samples measuring the in-treatment changes; variable is the angle FMA.

\begin{tabular}{crrrr}
\hline Source & df & SSQ & F Ratio & \multicolumn{1}{c}{ P-value } \\
\hline Treatment & 1 & 230.97 & 10.32 & 0.0020 \\
Sex & 1 & 0.89 & 0.04 & 0.8423 \\
$\begin{array}{c}\text { Treatment-x- } \\
\text { Sex }\end{array}$ & 1 & 5.14 & 0.23 & 0.6333 \\
\hline
\end{tabular}

Table B-20. Results of two-way ANOVA testing for treatment and sex differences between samples at the end of treatment; variable is IMPA.

\begin{tabular}{crrrr}
\hline Source & df & SSQ & F Ratio & P-value \\
\hline Treatment & 1 & 676.98 & 12.53 & 0.0007 \\
Sex & 1 & 119.02 & 2.20 & 0.1425 \\
$\begin{array}{c}\text { Treatment-x- } \\
\text { Sex }\end{array}$ & 1 & 18.99 & 0.35 & 0.5553 \\
\hline
\end{tabular}

Table B-21. Results of two-way ANOVA testing for treatment and sex differences between samples measuring the in-treatment changes; variable is FMIA.

\begin{tabular}{crrrr}
\hline Source & df & SSQ & F Ratio & \multicolumn{1}{c}{ P-value } \\
\hline Treatment & 1 & 120.90 & 2.39 & 0.1268 \\
Sex & 1 & 140.88 & 2.79 & 0.0998 \\
Treatment-x- & 1 & 4.82 & 0.10 & 0.7585 \\
Sex & & & & \\
\hline
\end{tabular}


Table B-22. Results of two-way ANOVA testing for treatment and sex differences between samples at the end of treatment; variable is Interincisal Angle.

\begin{tabular}{crrrr}
\hline Source & df & \multicolumn{1}{c}{ SSQ } & F Ratio & \multicolumn{1}{c}{ P-value } \\
\hline Treatment & 1 & 1686.87 & 20.80 & $<0.0001$ \\
Sex & 1 & 19.45 & 0.24 & 0.6260 \\
Treatment-x- & 1 & 1.09 & 0.01 & 0.9081 \\
Sex & & & & \\
\hline
\end{tabular}

Table B-23. Results of two-way ANOVA testing for treatment and sex differences between samples measuring the in-treatment changes; variable is U1-SeNa.

\begin{tabular}{crrrr}
\hline Source & df & SSQ & F Ratio & P-value \\
\hline Treatment & 1 & 174.05 & 3.26 & 0.0755 \\
Sex & 1 & 224.74 & 4.21 & 0.0441 \\
Treatment-x- & 1 & 9.62 & 0.18 & 0.6725 \\
Sex & & & & \\
\hline
\end{tabular}

Table B-24. Results of two-way ANOVA testing for treatment and sex differences between samples measuring the in-treatment changes; variable is L1-NB $\left(^{\circ}\right)$.

\begin{tabular}{crrrr}
\hline Source & df & SSQ & F Ratio & \multicolumn{1}{c}{ P-value } \\
\hline Treatment & 1 & 525.39 & 12.59 & 0.0007 \\
Sex & 1 & 82.35 & 1.97 & 0.1647 \\
$\begin{array}{c}\text { Treatment-x- } \\
\text { Sex }\end{array}$ & 1 & 5.46 & 0.13 & 0.7187 \\
\hline
\end{tabular}


Table B-25. Results of two-way ANOVA testing for treatment and sex differences between samples at the end of treatment; variable is L1-NB ( $\mathrm{mm})$.

\begin{tabular}{ccccc}
\hline Source & df & SSQ & F Ratio & P-value \\
\hline Treatment & 1 & 5.82 & 1.44 & 0.2351 \\
Sex & 1 & 2.17 & 0.53 & 0.4673 \\
Treatment-x- & 1 & 0.14 & 0.03 & 0.8539 \\
Sex & & & & \\
\hline
\end{tabular}

Table B-26. Results of two-way ANOVA testing for treatment and sex differences between samples measuring the in-treatment changes; variable is U1-NA $\left(^{\circ}\right)$.

\begin{tabular}{crrrr}
\hline Source & df & SSQ & F Ratio & P-value \\
\hline Treatment & 1 & 389.28 & 7.76 & 0.0070 \\
Sex & 1 & 209.83 & 4.18 & 0.0448 \\
$\begin{array}{c}\text { Treatment-x- } \\
\text { Sex }\end{array}$ & 1 & 9.86 & 0.20 & 0.6591 \\
\hline
\end{tabular}

Table B-27. Results of two-way ANOVA testing for treatment and sex differences between samples measuring the in-treatment changes; variable is U1-NA (mm).

\begin{tabular}{crrrr}
\hline Source & Df & SSQ & F Ratio & P-value \\
\hline Treatment & 1 & 0.48 & 0.11 & 0.7361 \\
Sex & 1 & 11.82 & 2.80 & 0.0991 \\
Treatment-x- & 1 & 0.17 & 0.04 & 0.8411 \\
Sex & & & & \\
\hline
\end{tabular}


Table B-28. Results of two-way ANOVA testing for treatment and sex differences between samples at the end of treatment; variable is Incisor Overbite.

\begin{tabular}{ccccc}
\hline Source & Df & SSQ & F Ratio & P-value \\
\hline Treatment & 1 & 0.14 & 0.04 & 0.8480 \\
Sex & 1 & 9.61 & 2.46 & 0.1218 \\
$\begin{array}{c}\text { Treatment-x- } \\
\text { Sex }\end{array}$ & 1 & 20.60 & 5.27 & 0.0249 \\
\hline
\end{tabular}

Table B-29. Results of two-way ANOVA testing for treatment and sex differences between samples measuring the in-treatment changes; variable is Overjet.

\begin{tabular}{crrrr}
\hline Source & Df & SSQ & F Ratio & P-value \\
\hline Treatment & 1 & 12.99 & 3.19 & 0.0785 \\
Sex & 1 & 0.61 & 0.15 & 0.6991 \\
$\begin{array}{c}\text { Treatment-x- } \\
\text { Sex }\end{array}$ & 1 & 0.56 & 0.14 & 0.7110 \\
\hline
\end{tabular}

Table B-30. Results of two-way ANOVA testing for treatment and sex differences between samples measuring the in-treatment changes; variable is Superior Airway Space.

\begin{tabular}{ccccc}
\hline Source & Df & SSQ & F Ratio & P-value \\
\hline Treatment & 1 & 0.80 & 0.10 & 0.7577 \\
Sex & 1 & 1.09 & 0.13 & 0.7190 \\
Treatment-x- & 1 & 6.72 & 0.80 & 0.3734 \\
Sex & & & & \\
\hline
\end{tabular}


Table B-31. Results of two-way ANOVA testing for treatment and sex differences between samples measuring the in-treatment changes; variable is Condylion-A.

\begin{tabular}{crrrr}
\hline Source & df & SSQ & F Ratio & P-value \\
\hline Treatment & 1 & 86.21 & 4.66 & 0.0345 \\
Sex & 1 & 153.48 & 8.30 & 0.0054 \\
$\begin{array}{c}\text { Treatment-x- } \\
\text { Sex }\end{array}$ & 1 & 3.50 & 0.19 & 0.6652 \\
\hline
\end{tabular}

Table B-32. Results of two-way ANOVA testing for treatment and sex differences between samples measuring the in-treatment changes; variable is CondylionGnathion.

\begin{tabular}{crrrr}
\hline Source & df & SSQ & F Ratio & \multicolumn{1}{c}{ P-value } \\
\hline Treatment & 1 & 24.72 & 1.26 & 0.2649 \\
Sex & 1 & 399.76 & 20.45 & $<0.0001$ \\
Treatment-x- & 1 & 1.83 & 0.09 & 0.7604 \\
Sex & & & & \\
\hline
\end{tabular}

Table B-33. Results of two-way ANOVA testing for treatment and sex differences between samples measuring the in-treatment changes; variable is $\mathrm{A}-\mathrm{Na}$ Perpendicular.

\begin{tabular}{crrrr}
\hline Source & df & SSQ & F Ratio & \multicolumn{1}{c}{ P-value } \\
\hline Treatment & 1 & 104.89 & 16.60 & 0.0001 \\
Sex & 1 & 2.97 & 0.47 & 0.4956 \\
Treatment-x- & 1 & 0.19 & 0.03 & 0.8630 \\
Sex & & & & \\
\hline
\end{tabular}


Table B-34. Results of two-way ANOVA testing for treatment and sex differences between samples measuring the in-treatment changes; variable is $\mathrm{Pg}-\mathrm{Na}$ Perpendicular.

\begin{tabular}{crrrr}
\hline Source & df & SSQ & F Ratio & \multicolumn{1}{c}{ P-value } \\
\hline Treatment & 1 & 527.99 & 19.98 & $<0.0001$ \\
Sex & 1 & 43.19 & 1.63 & 0.2056 \\
$\begin{array}{c}\text { Treatment-x- } \\
\text { Sex }\end{array}$ & 1 & 1.36 & 0.05 & 0.8215 \\
\hline
\end{tabular}

Table B-35. Results of two-way ANOVA testing for treatment and sex differences between samples measuring the in-treatment changes; variable is $\mathrm{B}-\mathrm{Na}$ Perpendicular.

\begin{tabular}{crrrr}
\hline Source & df & SSQ & F Ratio & P-value \\
\hline Treatment & 1 & 11.12 & 1.65 & 0.2040 \\
Sex & 1 & 0.77 & 0.11 & 0.7369 \\
$\begin{array}{c}\text { Treatment-x- } \\
\text { Sex }\end{array}$ & 1 & 0.02 & 0.00 & 0.9595 \\
\hline
\end{tabular}

Table B-36. Results of two-way ANOVA testing for treatment and sex differences between samples measuring the in-treatment changes; variable is $\mathrm{AFH}$.

\begin{tabular}{crrrr}
\hline Source & df & \multicolumn{1}{c}{ SSQ } & F Ratio & P-value \\
\hline Treatment & 1 & 0.00 & 0.00 & 0.9985 \\
Sex & 1 & 305.11 & 16.27 & 0.0001 \\
Treatment-x- & 1 & 0.32 & 0.02 & 0.8959 \\
Sex & & & & \\
\hline
\end{tabular}


Table B-37. Results of two-way ANOVA testing for treatment and sex differences between samples measuring the in-treatment changes; variable is Mesial Molar Relation.

\begin{tabular}{ccccc}
\hline Source & df & SSQ & F Ratio & P-value \\
\hline Treatment & 1 & 8.43 & 3.33 & 0.0727 \\
Sex & 1 & 0.20 & 0.08 & 0.7822 \\
$\begin{array}{c}\text { Treatment-x- } \\
\text { Sex }\end{array}$ & 1 & 0.62 & 0.25 & 0.6218 \\
\hline
\end{tabular}

Table B-38. Results of two-way ANOVA testing for treatment and sex differences between samples measuring the in-treatment changes; variable is PFH.

\begin{tabular}{crrrr}
\hline Source & df & SSQ & F Ratio & P-value \\
\hline Treatment & 1 & 4.21 & 0.23 & 0.6336 \\
Sex & 1 & 120.21 & 6.55 & 0.0128 \\
$\begin{array}{c}\text { Treatment-x- } \\
\text { Sex }\end{array}$ & 1 & 0.28 & 0.02 & 0.9013 \\
\hline
\end{tabular}

Table B-39. Results of two-way ANOVA testing for treatment and sex differences between samples measuring the in-treatment changes; variable is Go-Me.

\begin{tabular}{crrrr}
\hline Source & df & SSQ & F Ratio & P-value \\
\hline Treatment & 1 & 12.10 & 0.74 & 0.3933 \\
Sex & 1 & 173.27 & 10.57 & 0.0018 \\
Treatment-x- & 1 & 1.96 & 0.12 & 0.7309 \\
Sex & & & & \\
\hline
\end{tabular}


Table B-40. Results of two-way ANOVA testing for treatment and sex differences between samples measuring the in-treatment changes; variable is Sella-Vertical-A.

\begin{tabular}{crrrr}
\hline Source & df & SSQ & F Ratio & P-value \\
\hline Treatment & 1 & 103.76 & 7.02 & 0.0101 \\
Sex & 1 & 171.07 & 11.57 & 0.0011 \\
$\begin{array}{c}\text { Treatment-x- } \\
\text { Sex }\end{array}$ & 1 & 7.81 & 0.53 & 0.4698 \\
\hline
\end{tabular}

Table B-41. Results of two-way ANOVA testing for treatment and sex differences between samples at the end of treatment; variable is Sella-Vertical-B.

\begin{tabular}{crrrr}
\hline Source & df & SSQ & F Ratio & \multicolumn{1}{c}{ P-value } \\
\hline Treatment & 1 & 403.54 & 16.55 & 0.0001 \\
Sex & 1 & 225.82 & 9.26 & 0.0034 \\
$\begin{array}{c}\text { Treatment-x- } \\
\text { Sex }\end{array}$ & 1 & 6.12 & 0.25 & 0.6179 \\
\hline
\end{tabular}

Table B-42. Results of two-way ANOVA testing for treatment and sex differences between samples measuring the in-treatment changes; variable is Sella-VerticalPogonion.

\begin{tabular}{ccccc}
\hline Source & df & SSQ & F Ratio & P-value \\
\hline Treatment & 1 & 2.10 & 0.20 & 0.6547 \\
Sex & 1 & 2.19 & 0.21 & 0.6477 \\
Treatment-x- & 1 & 2.48 & 0.24 & 0.6272 \\
Sex & & & & \\
\hline
\end{tabular}


Table B-43. Results of two-way ANOVA testing for treatment and sex differences between samples measuring the in-treatment changes; variable is Sella-Vertical-M.

\begin{tabular}{crrrr}
\hline Source & df & SSQ & F Ratio & P-value \\
\hline Treatment & 1 & 427.49 & 17.37 & $<0.0001$ \\
Sex & 1 & 286.87 & 11.65 & 0.0011 \\
Treatment-x- & 1 & 12.43 & 0.51 & 0.4798 \\
Sex & & & & \\
\hline
\end{tabular}




\section{APPENDIX C. RESULTS OF TESTING FOR SEX AND TREATMENT DIFFERENCES AT THE END OF TREATMENT}

Table C-1. Results of two-way ANOVA testing for treatment and sex differences between samples at the end of treatment; variable is Airway 1 Volume (Nasopharyngeal).

\begin{tabular}{ccccc}
\hline Source & df & SSQ & F Ratio & P-value \\
\hline Treatment & 1 & 2776353 & 0.46 & 0.5001 \\
Sex & 1 & 5255358 & 0.87 & 0.3543 \\
$\begin{array}{c}\text { Treatment- } \\
\text { x-Sex }\end{array}$ & 1 & 86539 & 0.01 & 0.9051 \\
\hline
\end{tabular}

Table C-2. Results of two-way ANOVA testing for treatment and sex differences between samples at the end of treatment; variable is Airway 1 Area (Nasopharyngeal).

\begin{tabular}{ccccc}
\hline Source & df & SSQ & F Ratio & P-value \\
\hline Treatment & 1 & 1815.46 & 0.23 & 0.6352 \\
Sex & 1 & 2873.71 & 0.36 & 0.5508 \\
$\begin{array}{c}\text { Treatment- } \\
\text { x-Sex }\end{array}$ & 1 & 11619.03 & 1.45 & 0.2322 \\
\hline
\end{tabular}

Table C-3. Results of two-way ANOVA testing for treatment and sex differences between samples at the end of treatment; variable is Airway $1+2$ Volume $\left(\mathrm{mm}^{3}\right)$.

\begin{tabular}{cccrr}
\hline Source & df & SSQ & F Ratio & P-value \\
\hline Treatment & 1 & 98579591.00 & 2.77 & 0.1010 \\
Sex & 1 & 84747709.00 & 2.38 & 0.1278 \\
$\begin{array}{c}\text { Treatment- } \\
\text { x-Sex }\end{array}$ & 1 & 4388796.00 & 0.12 & 0.7267 \\
\hline
\end{tabular}


Table C-4. Results of two-way ANOVA testing for treatment and sex differences between samples at the end of treatment; variable is Airway $1+2$ Area $\left(\mathrm{mm}^{2}\right)$.

\begin{tabular}{ccccc}
\hline Source & df & SSQ & F Ratio & P-value \\
\hline Treatment & 1 & 48893.70 & 1.76 & 0.1889 \\
Sex & 1 & 56129.20 & 2.02 & 0.1596 \\
Treatment- & 1 & 46997.29 & 1.69 & 0.1976 \\
x-Sex & & & & \\
\hline
\end{tabular}

Table C-5. Results of two-way ANOVA testing for treatment and sex differences between samples at the end of treatment; variable is Airway 2 Volume (Superior).

\begin{tabular}{ccccc}
\hline Source & df & SSQ & F Ratio & P-value \\
\hline Treatment & 1 & 68268678.00 & 3.58 & 0.0629 \\
Sex & 1 & 47795030.00 & 2.50 & 0.1183 \\
$\begin{array}{c}\text { Treatment- } \\
\text { x-Sex }\end{array}$ & 1 & 5707899.00 & 0.30 & 0.5863 \\
\hline
\end{tabular}

Table C-6. Results of two-way ANOVA testing for treatment and sex differences between samples at the end of treatment; variable is Airway 2 Area (Superior).

\begin{tabular}{ccccc}
\hline Source & df & SSQ & F Ratio & P-value \\
\hline Treatment & 1 & 31866.19 & 2.16 & 0.1463 \\
Sex & 1 & 33602.19 & 2.28 & 0.1359 \\
$\begin{array}{c}\text { Treatment- } \\
\text { x-Sex }\end{array}$ & 1 & 11880.34 & 0.81 & 0.3726 \\
\hline
\end{tabular}


Table C-7. Results of two-way ANOVA testing for treatment and sex differences between samples at the end of treatment; variable is Airway $1+2+3$ Volume.

\begin{tabular}{ccccc}
\hline Source & df & SSQ & F Ratio & P-value \\
\hline Treatment & 1 & 199943839 & 3.76 & 0.0568 \\
Sex & 1 & 105304721 & 1.98 & 0.1641 \\
Treatment- & 1 & 5728140 & 0.11 & 0.7438 \\
x-Sex & & & & \\
\hline
\end{tabular}

Table C-8. Results of two-way ANOVA testing for treatment and sex differences between samples at the end of treatment; variable is Airway $1+2+3$ Area $\left(\mathrm{mm}^{2}\right)$.

\begin{tabular}{ccccc}
\hline Source & df & SSQ & F Ratio & P-value \\
\hline Treatment & 1 & 42295 & 0.91 & 0.3448 \\
Sex & 1 & 30949 & 0.66 & 0.4186 \\
Treatment- & 1 & 61861 & 1.32 & 0.2540 \\
x-Sex & & & & \\
\hline
\end{tabular}

Table C-9. Results of two-way ANOVA testing for treatment and sex differences between samples at the end of treatment; variable is Airway 3 Volume (Inferior).

\begin{tabular}{ccccc}
\hline Source & df & SSQ & F Ratio & P-value \\
\hline Treatment & 1 & 17736095 & 4.87 & 0.0309 \\
Sex & 1 & 1115045 & 0.31 & 0.5820 \\
Treatment- & 1 & 89047 & 0.02 & 0.8763 \\
x-Sex & & & & \\
\hline
\end{tabular}


Table C-10. Results of two-way ANOVA testing for treatment and sex differences between samples at the end of treatment; variable is Airway 3 Area (Inferior).

\begin{tabular}{ccccc}
\hline Source & df & SSQ & F Ratio & P-value \\
\hline Treatment & 1 & 239.05 & 0.03 & 0.8535 \\
Sex & 1 & 3719.82 & 0.54 & 0.4671 \\
Treatment-x- & 1 & 1019.60 & 0.15 & 0.7030 \\
Sex & & & & \\
\hline
\end{tabular}

Table C-11. Results of two-way ANOVA testing for treatment and sex differences between samples at the end of treatment; variable is Total Airway.

\begin{tabular}{ccccc}
\hline Source & df & SSQ & F Ratio & P-value \\
\hline Treatment & 1 & 199943839.0 & 3.76 & 0.0568 \\
Sex & 1 & 105304721.0 & 1.98 & 0.1641 \\
$\begin{array}{c}\text { Treatment- } \\
\text { x-Sex }\end{array}$ & 1 & 5728140.0 & 0.11 & 0.7438 \\
\hline
\end{tabular}

Table C-12. Results of two-way ANOVA testing for treatment and sex differences between samples at the end of treatment; variable is distance $(\mathrm{mm})$ to Minimum Constriction.

\begin{tabular}{ccccc}
\hline Source & df & SSQ & F Ratio & P-value \\
\hline Treatment & 1 & 37968.68 & 2.67 & 0.1070 \\
Sex & 1 & 4679.30 & 0.33 & 0.5682 \\
Treatment- & 1 & 688.74 & 0.05 & 0.8265 \\
x-Sex & & & & \\
\hline
\end{tabular}


Table C-13. Results of two-way ANOVA testing for treatment and sex differences between samples at the end of treatment; variable is PFH/AFH \%.

\begin{tabular}{ccccc}
\hline Source & df & SSQ & F Ratio & P-value \\
\hline Treatment & 1 & 0.00 & 0.10 & 0.7479 \\
Sex & 1 & 0.00 & 0.05 & 0.8205 \\
Treatment-x- & 1 & 0.00 & 0.01 & 0.9084 \\
Sex & & & & \\
\hline
\end{tabular}

Table C-14. Results of two-way ANOVA testing for treatment and sex differences between samples at the end of treatment; variable is the angle $\mathrm{Y}$-Axis.

\begin{tabular}{crrrr}
\hline Source & df & \multicolumn{1}{c}{ SSQ } & F Ratio & \multicolumn{1}{c}{ P-value } \\
\hline Treatment & 1 & 139.52 & 13.16 & 0.0006 \\
Sex & 1 & 0.28 & 0.03 & 0.8721 \\
$\begin{array}{c}\text { Treatment-x- } \\
\text { Sex }\end{array}$ & 1 & 17.49 & 1.65 & 0.2035 \\
\hline
\end{tabular}

Table C-15. Results of two-way ANOVA testing for treatment and sex differences between samples at the end of treatment; variable is the angle Facial Convexity.

\begin{tabular}{ccrcr}
\hline Source & df & SSQ & F Ratio & \multicolumn{1}{c}{ P-value } \\
\hline Treatment & 1 & 9.97 & 0.47 & 0.4970 \\
Sex & 1 & 43.57 & 2.04 & 0.1581 \\
Treatment-x- & 1 & 1.13 & 0.05 & 0.8185 \\
Sex & & & & \\
\hline
\end{tabular}


Table C-16. Results of two-way ANOVA testing for treatment and sex differences between samples at the end of treatment; variable is the angle SNA.

\begin{tabular}{ccrrr}
\hline Source & df & \multicolumn{1}{c}{ SSQ } & F Ratio & P-value \\
\hline Treatment & 1 & 28.23 & 2.79 & 0.0993 \\
Sex & 1 & 0.26 & 0.03 & 0.8723 \\
$\begin{array}{c}\text { Treatment-x- } \\
\text { Sex }\end{array}$ & 1 & 3.45 & 0.34 & 0.5607 \\
\hline
\end{tabular}

Table C-17. Results of two-way ANOVA testing for treatment and sex differences between samples at the end of treatment; variable is the angle SNB.

\begin{tabular}{ccccc}
\hline Source & df & SSQ & F Ratio & P-value \\
\hline Treatment & 1 & 8.85 & 0.95 & 0.3329 \\
Sex & 1 & 6.71 & 0.72 & 0.3988 \\
$\begin{array}{c}\text { Treatment-x- } \\
\text { Sex }\end{array}$ & 1 & 1.41 & 0.15 & 0.6987 \\
\hline
\end{tabular}

Table C-18. Results of two-way ANOVA testing for treatment and sex differences between samples at the end of treatment; variable is the angle ANB.

\begin{tabular}{ccccc}
\hline Source & df & SSQ & F Ratio & P-value \\
\hline Treatment & 1 & 5.17 & 1.98 & 0.1646 \\
Sex & 1 & 4.24 & 1.62 & 0.2079 \\
Treatment-x- & 1 & 0.53 & 0.20 & 0.6558 \\
Sex & & & & \\
\hline
\end{tabular}


Table C-19. Results of two-way ANOVA testing for treatment and sex differences between samples at the end of treatment; variable is the distance (mm) Wits AOBO discrepancy.

\begin{tabular}{ccccc}
\hline Source & df & SSQ & F Ratio & P-value \\
\hline Treatment & 1 & 0.30 & 0.05 & 0.8249 \\
Sex & 1 & 2.74 & 0.45 & 0.5024 \\
Treatment-x- & 1 & 1.97 & 0.33 & 0.5700 \\
Sex & & & & \\
\hline
\end{tabular}

Table C-20. Results of two-way ANOVA testing for treatment and sex differences between samples at the end of treatment; variable is the angle FMA.

\begin{tabular}{crrrr}
\hline Source & df & \multicolumn{1}{c}{ SSQ } & F Ratio & \multicolumn{1}{c}{ P-value } \\
\hline Treatment & 1 & 338.64 & 11.03 & 0.0015 \\
Sex & 1 & 5.47 & 0.18 & 0.6744 \\
$\begin{array}{c}\text { Treatment-x- } \\
\text { Sex }\end{array}$ & 1 & 9.43 & 0.31 & 0.5814 \\
\hline
\end{tabular}

Table C-21. Results of two-way ANOVA testing for treatment and sex differences between samples at the end of treatment; variable is the angle IMPA.

\begin{tabular}{crrrr}
\hline Source & df & \multicolumn{1}{c}{ SSQ } & F Ratio & \multicolumn{1}{c}{ P-value } \\
\hline Treatment & 1 & 1523.05 & 28.91 & $<0.0001$ \\
Sex & 1 & 157.07 & 2.98 & 0.0889 \\
Treatment-x- & 1 & 0.22 & 0.00 & 0.9482 \\
Sex & & & & \\
\hline
\end{tabular}


Table C-22. Results of two-way ANOVA testing for treatment and sex differences between samples at the end of treatment; variable is the angle FMIA.

\begin{tabular}{crrrr}
\hline Source & df & SSQ & F Ratio & \multicolumn{1}{c}{ P-value } \\
\hline Treatment & 1 & 427.55 & 9.72 & 0.0027 \\
Sex & 1 & 104.50 & 2.38 & 0.1280 \\
Treatment-x- & 1 & 6.66 & 0.15 & 0.6984 \\
Sex & & & & \\
\hline
\end{tabular}

Table C-23. Results of two-way ANOVA testing for treatment and sex differences between samples at the end of treatment; variable is Interincisal Angle.

\begin{tabular}{ccrrr}
\hline Source & df & SSQ & F Ratio & \multicolumn{1}{c}{ P-value } \\
\hline Treatment & 1 & 4622.54 & 63.39 & $<0.0001$ \\
Sex & 1 & 1.44 & 0.02 & 0.8885 \\
$\begin{array}{c}\text { Treatment-x- } \\
\text { Sex }\end{array}$ & 1 & 0.11 & 0.00 & 0.9687 \\
\hline
\end{tabular}

Table C-24. Results of two-way ANOVA testing for treatment and sex differences between samples at the end of treatment; variable is the angle U1-SeNa.

\begin{tabular}{crrrr}
\hline Source & df & \multicolumn{1}{c}{ SSQ } & F Ratio & \multicolumn{1}{c}{ P-value } \\
\hline Treatment & 1 & 1080.83 & 27.18 & $<0.0001$ \\
Sex & 1 & 162.90 & 4.10 & 0.0470 \\
Treatment-x- & 1 & 0.95 & 0.02 & 0.8776 \\
Sex & & & & \\
\hline
\end{tabular}


Table C-25. Results of two-way ANOVA testing for treatment and sex differences between samples at the end of treatment; variable is the angle L1-NB $\left(^{\circ}\right)$.

\begin{tabular}{ccrrr}
\hline Source & df & \multicolumn{1}{c}{ SSQ } & F Ratio & \multicolumn{1}{c}{ P-value } \\
\hline Treatment & 1 & 1030.31 & 32.47 & $<0.0001$ \\
Sex & 1 & 82.29 & 2.59 & 0.1121 \\
Treatment-x- & 1 & 0.02 & 0.00 & 0.9801 \\
Sex & & & & \\
\hline
\end{tabular}

Table C-26. Results of two-way ANOVA testing for treatment and sex differences between samples at the end of treatment; variable is the distance L1-NB (mm).

\begin{tabular}{ccrcr}
\hline Source & df & \multicolumn{1}{c}{ SSQ } & F Ratio & P-value \\
\hline Treatment & 1 & 24.35 & 5.09 & 0.0274 \\
Sex & 1 & 0.31 & 0.06 & 0.8006 \\
$\begin{array}{c}\text { Treatment-x- } \\
\text { Sex }\end{array}$ & 1 & 0.32 & 0.07 & 0.7957 \\
\hline
\end{tabular}

Table C-27. Results of two-way ANOVA testing for treatment and sex differences between samples at the end of treatment; variable is the angle U1-NA $\left({ }^{\circ}\right)$.

\begin{tabular}{crrrr}
\hline Source & df & \multicolumn{1}{c}{ SSQ } & F Ratio & \multicolumn{1}{c}{ P-value } \\
\hline Treatment & 1 & 1456.82 & 41.57 & $<0.0001$ \\
Sex & 1 & 149.18 & 4.26 & 0.0430 \\
Treatment-x- & 1 & 0.83 & 0.02 & 0.8783 \\
Sex & & & & \\
\hline
\end{tabular}


Table C-28. Results of two-way ANOVA testing for treatment and sex differences between samples at the end of treatment; variable is Incisor Overjet.

\begin{tabular}{ccccc}
\hline Source & df & SSQ & F Ratio & P-value \\
\hline Treatment & 1 & 6.95 & 8.08 & 0.0059 \\
Sex & 1 & 0.00 & 0.00 & 0.9498 \\
$\begin{array}{c}\text { Treatment-x- } \\
\text { Sex }\end{array}$ & 1 & 0.11 & 0.13 & 0.7168 \\
\hline
\end{tabular}

Table C-29. Results of two-way ANOVA testing for treatment and sex differences between samples at the end of treatment; variable is Superior Airway Space.

\begin{tabular}{crrrr}
\hline Source & df & SSQ & F Ratio & P-value \\
\hline Treatment & 1 & 11.92 & 1.27 & 0.2643 \\
Sex & 1 & 5.14 & 0.55 & 0.4624 \\
$\begin{array}{c}\text { Treatment-x- } \\
\text { Sex }\end{array}$ & 1 & 0.19 & 0.02 & 0.8862 \\
\hline
\end{tabular}

Table C-30. Results of two-way ANOVA testing for treatment and sex differences between samples at the end of treatment; variable is the distance Condylion-to- $A$.

\begin{tabular}{crrrr}
\hline Source & df & SSQ & F Ratio & \multicolumn{1}{c}{ P-value } \\
\hline Treatment & 1 & 247.60 & 19.40 & $<0.0001$ \\
Sex & 1 & 232.04 & 18.18 & $<0.0001$ \\
Treatment-x- & 1 & 0.16 & 0.01 & 0.9114 \\
Sex & & & & \\
\hline
\end{tabular}


Table C-31. Results of two-way ANOVA testing for treatment and sex differences between samples at the end of treatment; variable is the distance Condylion-toGnathion.

\begin{tabular}{crrrr}
\hline Source & df & SSQ & F Ratio & \multicolumn{1}{c}{ P-value } \\
\hline Treatment & 1 & 225.27 & 7.15 & 0.0095 \\
Sex & 1 & 719.35 & 22.82 & $<0.0001$ \\
Treatment-x- & 1 & 2.69 & 0.09 & 0.7711 \\
Sex & & & & \\
\hline
\end{tabular}

Table C-32. Results of two-way ANOVA testing for treatment and sex differences between samples at the end of treatment; variable is the distance A-to-Nasion Perpendicular.

\begin{tabular}{crrrr}
\hline Source & df & SSQ & F Ratio & P-value \\
\hline Treatment & 1 & 84.04 & 8.15 & 0.0057 \\
Sex & 1 & 0.32 & 0.03 & 0.8599 \\
$\begin{array}{c}\text { Treatment-x- } \\
\text { Sex }\end{array}$ & 1 & 7.91 & 0.77 & 0.3843 \\
\hline
\end{tabular}

Table C-33. Results of two-way ANOVA testing for treatment and sex differences between samples at the end of treatment; variable is the distance Pogonion-toNasion Perpendicular.

\begin{tabular}{crrrr}
\hline Source & df & SSQ & F Ratio & P-value \\
\hline Treatment & 1 & 425.10 & 12.12 & 0.0009 \\
Sex & 1 & 9.12 & 0.26 & 0.6118 \\
$\begin{array}{c}\text { Treatment-x- } \\
\text { Sex }\end{array}$ & 1 & 18.96 & 0.54 & 0.4648 \\
\hline
\end{tabular}


Table C-34. Results of two-way ANOVA testing for treatment and sex differences between samples at the end of treatment; variable is the distance B-to-Nasion Perpendicular.

\begin{tabular}{ccrrr}
\hline Source & df & SSQ & F Ratio & P-value \\
\hline Treatment & 1 & 10.37 & 1.43 & 0.2353 \\
Sex & 1 & 2.86 & 0.40 & 0.5314 \\
$\begin{array}{c}\text { Treatment-x- } \\
\text { Sex }\end{array}$ & 1 & 0.98 & 0.13 & 0.7145 \\
\hline
\end{tabular}

Table C-35. Results of two-way ANOVA testing for treatment and sex differences between samples at the end of treatment; variable is Anterior Facial Height.

\begin{tabular}{crrrr}
\hline Source & df & SSQ & F Ratio & \multicolumn{1}{c}{ P-value } \\
\hline Treatment & 1 & 98.38 & 2.88 & 0.0945 \\
Sex & 1 & 824.99 & 24.14 & $<0.0001$ \\
Treatment-x- & 1 & 15.33 & 0.45 & 0.5054 \\
Sex & & & & \\
\hline
\end{tabular}

Table C-36. Results of two-way ANOVA testing for treatment and sex differences between samples at the end of treatment; variable is the distance Molar Relationship.

\begin{tabular}{ccrrr}
\hline Source & df & SSQ & F Ratio & P-value \\
\hline Treatment & 1 & 18.19 & 17.33 & $<0.0001$ \\
Sex & 1 & 3.02 & 2.87 & 0.0947 \\
Treatment-x- & 1 & 0.00 & 0.00 & 0.9763 \\
Sex & & & & \\
\hline
\end{tabular}


Table C-37. Results of two-way ANOVA testing for treatment and sex differences between samples at the end of treatment; variable is Posterior Facial Height.

\begin{tabular}{crrrr}
\hline Source & df & \multicolumn{1}{c}{ SSQ } & F Ratio & \multicolumn{1}{c}{ P-value } \\
\hline Treatment & 1 & 22.15 & 0.90 & 0.3464 \\
Sex & 1 & 420.85 & 17.09 & 0.0001 \\
$\begin{array}{c}\text { Treatment-x- } \\
\text { Sex }\end{array}$ & 1 & 8.11 & 0.33 & 0.5681 \\
\hline
\end{tabular}

Table C-38. Results of two-way ANOVA testing for treatment and sex differences between samples at the end of treatment; variable is the distance Gonion-to-Menton.

\begin{tabular}{crrrr}
\hline Source & df & SSQ & F Ratio & P-value \\
\hline Treatment & 1 & 342.18 & 20.86 & $<0.0001$ \\
Sex & 1 & 188.48 & 11.49 & 0.0012 \\
$\begin{array}{c}\text { Treatment-x- } \\
\text { Sex }\end{array}$ & 1 & 4.54 & 0.28 & 0.6004 \\
\hline
\end{tabular}

Table C-39. Results of two-way ANOVA testing for treatment and sex differences between samples at the end of treatment; variable is Sella-Vertical-to-A.

\begin{tabular}{crrrr}
\hline Source & df & SSQ & F Ratio & P-value \\
\hline Treatment & 1 & 93.12 & 6.87 & 0.0109 \\
Sex & 1 & 175.48 & 12.94 & 0.0006 \\
Treatment-x- & 1 & 20.76 & 1.53 & 0.2204 \\
Sex & & & & \\
\hline
\end{tabular}


Table C-40. Results of two-way ANOVA testing for treatment and sex differences between samples at the end of treatment; variable is Sella-Vertical-to-B.

\begin{tabular}{crrrr}
\hline Source & df & SSQ & F Ratio & P-value \\
\hline Treatment & 1 & 349.31 & 13.67 & 0.0004 \\
Sex & 1 & 206.95 & 8.10 & 0.0059 \\
$\begin{array}{c}\text { Treatment-x- } \\
\text { Sex }\end{array}$ & 1 & 23.40 & 0.92 & 0.3421 \\
\hline
\end{tabular}

Table C-41. Results of two-way ANOVA testing for treatment and sex differences between samples at the end of treatment; variable is the distance Sella-Vertical-toPogonion.

\begin{tabular}{crrrr}
\hline Source & df & SSQ & F Ratio & P-value \\
\hline Treatment & 1 & 191.49 & 26.35 & $<0.0001$ \\
Sex & 1 & 20.12 & 2.77 & 0.1009 \\
Treatment-x- & 1 & 10.10 & 1.39 & 0.2428 \\
Sex & & & & \\
\hline
\end{tabular}

Table C-42. Results of two-way ANOVA testing for treatment and sex differences between samples at the end of treatment; variable is Sella-Vertical-to-M.

\begin{tabular}{crrrr}
\hline Source & df & SSQ & F Ratio & P-value \\
\hline Treatment & 1 & 386.32 & 14.13 & 0.0004 \\
Sex & 1 & 134.82 & 4.93 & 0.0298 \\
Treatment-x- & 1 & 24.37 & 0.89 & 0.3486 \\
Sex & & & & \\
\hline
\end{tabular}




\section{APPENDIX D. RESULTS OF PAIRED T TESTS}

Table D-1. Results of intraobserver repeatability test (paired t test) for the variable AFH.

\begin{tabular}{lc}
\hline \multicolumn{1}{c}{ Statistic } & Value \\
\hline Second Session & 112.33 \\
First Session & 105.73 \\
Mean Difference & 6.60 \\
Standard Error & 0.85 \\
Upper 95\% & 8.42 \\
Lower 95\% & 4.78 \\
Sample size & 15 \\
Correlation & 0.89 \\
t ratio (two tail) & 7.79 \\
degrees of freedom & 14 \\
Probability (two tail) & $<0.0001$ \\
\hline
\end{tabular}


Table D-2. Results of intraobserver repeatability test (paired $t$ test) for the variable Airway 1 Area (Nasopharyngeal).

\begin{tabular}{lc}
\hline \multicolumn{1}{c}{ Statistic } & Value \\
\hline Second Session & 300.44 \\
First Session & 210.07 \\
Mean Difference & 90.37 \\
Standard Error & 18.14 \\
Upper 95\% & 129.28 \\
Lower 95\% & 51.45 \\
Sample size & 15 \\
Correlation coefficient & 0.72 \\
t ratio (two tail) & 4.98 \\
degrees of freedom & 14 \\
Probability (two tail) & 0.0002 \\
\hline
\end{tabular}


Table D-3. Results of intraobserver repeatability test (paired $t$ test) for the variable Airway 1 Volume (Nasopharyngeal).

\begin{tabular}{lc}
\hline \multicolumn{1}{c}{ Statistic } & Value \\
\hline Second Session & 7308.40 \\
First Session & 5415.08 \\
Mean Difference & 1893.32 \\
Standard Error & 454.95 \\
Upper 95\% & 2869.09 \\
Lower 95\% & 917.55 \\
Sample size & 15 \\
Correlation coefficient & 0.88 \\
t ratio (two tail) & 4.16 \\
degrees of freedom & 14 \\
Probability (two tail) & 0.0010 \\
\hline
\end{tabular}


Table D-4. Results of intraobserver repeatability test (paired $t$ test) for the variable Airway 1+2 Area.

\begin{tabular}{lc}
\hline \multicolumn{1}{c}{ Statistic } & Value \\
\hline Second Session & 628.93 \\
First Session & 531.97 \\
Mean Difference & 96.95 \\
Standard Error & 43.49 \\
Upper 95\% & 190.24 \\
Lower 95\% & 3.67 \\
Sample size & 15 \\
Correlation coefficient & 0.69 \\
t ratio (two tail) & 2.23 \\
degrees of freedom & 14 \\
Probability (two tail) & 0.0427 \\
\hline
\end{tabular}


Table D-5. Results of intraobserver repeatability test (paired $t$ test) for the variable Airway 1+2 Volume.

\begin{tabular}{lc}
\hline \multicolumn{1}{c}{ Statistic } & Value \\
\hline Second Session & 16126.00 \\
First Session & 13658.00 \\
Mean Difference & 2468.01 \\
Standard Error & 1489.21 \\
Upper 95\% & 5662.05 \\
Lower 95\% & -726.02 \\
Sample size & 15 \\
Correlation coefficient & 0.67 \\
t ratio (two tail) & 1.66 \\
degrees of freedom & 14 \\
Probability (two tail) & 0.1197 \\
\hline
\end{tabular}


Table D-6. Results of intraobserver repeatability test (paired $t$ test) for the variable Airway 1+2+3 Area.

\begin{tabular}{lc}
\hline \multicolumn{1}{c}{ Statistic } & Value \\
\hline Second Session & 813.83 \\
First Session & 731.35 \\
Mean Difference & 82.48 \\
Standard Error & 59.00 \\
Upper 95\% & 209.02 \\
Lower 95\% & -44.06 \\
Sample size & 15 \\
Correlation coefficient & 0.62 \\
t ratio (two tail) & 1.40 \\
degrees of freedom & 14 \\
Probability (two tail) & 0.1839 \\
\hline
\end{tabular}


Table D-7. Results of intraobserver repeatability test (paired t test) for the variable Airway $1+2+3$ Volume.

\begin{tabular}{lc}
\hline \multicolumn{1}{c}{ Statistic } & Value \\
\hline Second Session & 20956.6 \\
First Session & 18051.5 \\
Mean Difference & 2905.13 \\
Standard Error & 1954.32 \\
Upper 95\% & 7096.72 \\
Lower 95\% & -1286.5 \\
Sample size & 15 \\
Correlation coefficient & 0.60 \\
t ratio (two tail) & 1.49 \\
degrees of freedom & 14 \\
Probability (two tail) & 0.1593 \\
\hline
\end{tabular}


Table D-8. Results of intraobserver repeatability test (paired t test) for the variable Airway 2 Area (Superior).

\begin{tabular}{lc}
\hline \multicolumn{1}{c}{ Statistic } & Value \\
\hline Second Session & 328.49 \\
First Session & 321.90 \\
Mean Difference & 6.59 \\
Standard Error & 30.52 \\
Upper 95\% & 72.04 \\
Lower 95\% & -58.87 \\
Sample size & 15 \\
Correlation coefficient & 0.63 \\
t ratio (two tail) & 0.22 \\
degrees of freedom & 14 \\
Probability (two tail) & 0.8322 \\
\hline
\end{tabular}


Table D-9. Results of intraobserver repeatability test (paired t test) for the variable Airway 2 Volume (Superior).

\begin{tabular}{lc}
\hline \multicolumn{1}{c}{ Statistic } & Value \\
\hline Second Session & 8817.59 \\
First Session & 8242.89 \\
Mean Difference & 574.71 \\
Standard Error & 1122.98 \\
Upper 95\% & 2983.25 \\
Lower 95\% & -1833.80 \\
Sample size & 15 \\
Correlation coefficient & 0.48 \\
t ratio (two tail) & 0.51 \\
degrees of freedom & 14 \\
Probability (two tail) & 0.6168 \\
\hline
\end{tabular}


Table D-10. Results of intraobserver repeatability test (paired t test) for the variable Airway 3 Area (Inferior).

\begin{tabular}{lc}
\hline \multicolumn{1}{c}{ Statistic } & Value \\
\hline Second Session & 184.91 \\
First Session & 199.38 \\
Mean Difference & -14.47 \\
Standard Error & 24.84 \\
Upper 95\% & 38.81 \\
Lower 95\% & -67.76 \\
Sample size & 15 \\
Correlation coefficient & 0.26 \\
t ratio (two tail) & -0.58 \\
degrees of freedom & 14 \\
Probability (two tail) & 0.5694 \\
\hline
\end{tabular}


Table D-11. Results of intraobserver repeatability test (paired t test) for the variable Airway 3 Volume (Inferior).

\begin{tabular}{lc}
\hline \multicolumn{1}{c}{ Statistic } & Value \\
\hline Second Session & 4803.93 \\
First Session & 4393.49 \\
Mean Difference & 410.45 \\
Standard Error & 602.46 \\
Upper 95\% & 1702.59 \\
Lower 95\% & -881.69 \\
Sample size & 15 \\
Correlation coefficient & 0.27 \\
t ratio (two tail) & 0.68 \\
degrees of freedom & 14 \\
Probability (two tail) & 0.5068 \\
\hline
\end{tabular}


Table D-12. Results of intraobserver repeatability test (paired $t$ test) for the variable A-Nasion Perpendicular.

\begin{tabular}{lc}
\hline \multicolumn{1}{c}{ Statistic } & Value \\
\hline Second Session & 1.19 \\
First Session & 0.89 \\
Mean Difference & 0.31 \\
Standard Error & 0.47 \\
Upper 95\% & 1.31 \\
Lower 95\% & -0.70 \\
Sample size & 15 \\
Correlation coefficient & 0.91 \\
t ratio (two tail) & 0.66 \\
degrees of freedom & 14 \\
Probability (two tail) & 0.5224 \\
\hline
\end{tabular}


Table D-13. Results of intraobserver repeatability test (paired $t$ test) for the variable ANB.

\begin{tabular}{lc}
\hline \multicolumn{1}{c}{ Statistic } & Value \\
\hline Second Session & 4.91 \\
First Session & 5.57 \\
Mean Difference & -0.65 \\
Standard Error & 0.23 \\
Upper 95\% & -0.15 \\
Lower 95\% & -1.16 \\
Sample size & 15 \\
Correlation coefficient & 0.84 \\
t ratio (two tail) & -2.79 \\
degrees of freedom & 14 \\
Probability (two tail) & 0.0144 \\
\hline
\end{tabular}


Table D-14. Results of intraobserver repeatability test (paired t test) for the variable B-Nasion Perpendicular.

\begin{tabular}{lc}
\hline \multicolumn{1}{c}{ Statistic } & Value \\
\hline Second Session & -8.08 \\
First Session & -8.77 \\
Mean Difference & 0.69 \\
Standard Error & 0.36 \\
Upper 95\% & 1.46 \\
Lower 95\% & -0.09 \\
Sample size & 15 \\
Correlation coefficient & 0.8638 \\
t ratio (two tail) & 1.904564 \\
degrees of freedom & 14 \\
Probability (two tail) & 0.0776 \\
\hline
\end{tabular}


Table D-15. Results of intraobserver repeatability test (paired $t$ test) for the variable Condylion-A.

\begin{tabular}{lc}
\hline \multicolumn{1}{c}{ Statistic } & Value \\
\hline Second Session & 84.38 \\
First Session & 83.04 \\
Mean Difference & 1.34 \\
Standard Error & 0.79 \\
Upper 95\% & 3.04 \\
Lower 95\% & -0.36 \\
Sample size & 15 \\
Correlation coefficient & 0.84 \\
t ratio (two tail) & 1.70 \\
degrees of freedom & 14 \\
Probability (two tail) & 0.1122 \\
\hline
\end{tabular}


Table D-16. Results of intraobserver repeatability test (paired t test) for the variable Condylion-Gnathion.

\begin{tabular}{lc}
\hline \multicolumn{1}{c}{ Statistic } & Value \\
\hline Second Session & 112.99 \\
First Session & 107.55 \\
Mean Difference & 5.43 \\
Standard Error & 0.85 \\
Upper 95\% & 7.25 \\
Lower 95\% & 3.62 \\
Sample size & 15 \\
Correlation coefficient & 0.89 \\
t ratio (two tail) & 6.42 \\
degrees of freedom & 14 \\
Probability (two tail) & $<0.0001$ \\
\hline
\end{tabular}


Table D-17. Results of intraobserver repeatability test (paired $t$ test) for the variable Convexity.

\begin{tabular}{lc}
\hline \multicolumn{1}{c}{ Statistic } & Value \\
\hline Second Session & 8.34 \\
First Session & 10.40 \\
Mean Difference & -2.06 \\
Standard Error & 0.64 \\
Upper 95\% & -0.69 \\
Lower 95\% & -3.43 \\
Sample size & 15 \\
Correlation coefficient & 0.83 \\
t ratio (two tail) & -3.22 \\
degrees of freedom & 14 \\
Probability (two tail) & 0.0062 \\
\hline
\end{tabular}


Table D-18. Results of intraobserver repeatability test (paired $t$ test) for the variable FMA.

\begin{tabular}{lc}
\hline \multicolumn{1}{c}{ Statistic } & Value \\
\hline Second Session & 23.04 \\
First Session & 24.05 \\
Mean Difference & -1.01 \\
Standard Error & 0.66 \\
Upper 95\% & 0.40 \\
Lower 95\% & -2.42 \\
Sample size & 15 \\
Correlation coefficient & 0.92 \\
t ratio (two tail) & -1.53 \\
degrees of freedom & 14 \\
Probability (two tail) & 0.1479 \\
\hline
\end{tabular}


Table D-19. Results of intraobserver repeatability test (paired $t$ test) for the variable FMIA.

\begin{tabular}{lc}
\hline \multicolumn{1}{c}{ Statistic } & Value \\
\hline Second Session & 55.47 \\
First Session & 58.46 \\
Mean Difference & -2.99 \\
Standard Error & 2.09 \\
Upper 95\% & 1.49 \\
Lower 95\% & -7.47 \\
Sample size & 15 \\
Correlation coefficient & 0.11 \\
t ratio (two tail) & -1.43 \\
degrees of freedom & 14 \\
Probability (two tail) & 0.1747 \\
\hline
\end{tabular}


Table D-20. Results of intraobserver repeatability test (paired $t$ test) for the variable Gonion-Menton.

\begin{tabular}{lc}
\hline \multicolumn{1}{c}{ Statistic } & Value \\
\hline Second Session & 60.14 \\
First Session & 57.88 \\
Mean Difference & 2.26 \\
Standard Error & 0.71 \\
Upper 95\% & 3.78 \\
Lower 95\% & 0.74 \\
Sample size & 15 \\
Correlation coefficient & 0.88 \\
t ratio (two tail) & 3.18 \\
degrees of freedom & 14 \\
Probability (two tail) & 0.0067 \\
\hline
\end{tabular}


Table D-21. Results of intraobserver repeatability test (paired $t$ test) for the variable IMPA.

\begin{tabular}{lc}
\hline \multicolumn{1}{c}{ Statistic } & Value \\
\hline Second Session & 101.49 \\
First Session & 97.50 \\
Mean Difference & 3.99 \\
Standard Error & 2.26 \\
Upper 95\% & 8.84 \\
Lower 95\% & -0.87 \\
Sample size & 15 \\
Correlation coefficient & 0.43 \\
t ratio (two tail) & 1.76 \\
degrees of freedom & 14 \\
Probability (two tail) & 0.1001 \\
\hline
\end{tabular}


Table D-22. Results of intraobserver repeatability test (paired t test) for the variable Interincisal Angle.

\begin{tabular}{lc}
\hline \multicolumn{1}{c}{ Statistic } & Value \\
\hline Second Session & 123.28 \\
First Session & 128.45 \\
Mean Difference & -5.17 \\
Standard Error & 3.02 \\
Upper 95\% & 1.31 \\
Lower 95\% & -11.64 \\
Sample size & 15 \\
Correlation coefficient & 0.26 \\
t ratio (two tail) & -1.71 \\
degrees of freedom & 14 \\
Probability (two tail) & 0.1092 \\
\hline
\end{tabular}


Table D-23. Results of intraobserver repeatability test (paired $t$ test) for the variable L1-NB $\left({ }^{\circ}\right)$.

\begin{tabular}{lc}
\hline \multicolumn{1}{c}{ Statistic } & Value \\
\hline Second Session & 30.77 \\
First Session & 26.93 \\
Mean Difference & 3.84 \\
Standard Error & 2.12 \\
Upper 95\% & 8.38 \\
Lower 95\% & -0.70 \\
Sample size & 15 \\
Correlation coefficient & -0.16 \\
t ratio (two tail) & 1.81 \\
degrees of freedom & 14 \\
Probability (two tail) & 0.0912 \\
\hline
\end{tabular}


Table D-24. Results of intraobserver repeatability test (paired $t$ test) for the variable L1-Nasion-B (mm).

\begin{tabular}{lc}
\hline \multicolumn{1}{c}{ Statistic } & Value \\
\hline Second Session & 6.89 \\
First Session & 5.15 \\
Mean Difference & 1.73 \\
Standard Error & 0.46 \\
Upper 95\% & 2.72 \\
Lower 95\% & 0.75 \\
Sample size & 15 \\
Correlation coefficient & 0.53 \\
t ratio (two tail) & 3.77 \\
degrees of freedom & 14 \\
Probability (two tail) & 0.0021 \\
\hline
\end{tabular}


Table D-25. Results of intraobserver repeatability test (paired $t$ test) for the variable Mesial Molar Relation.

\begin{tabular}{lc}
\hline \multicolumn{1}{c}{ Statistic } & Value \\
\hline Second Session & -0.44 \\
First Session & 1.41 \\
Mean Difference & -1.85 \\
Standard Error & 0.31 \\
Upper 95\% & -1.19 \\
Lower 95\% & -2.50 \\
Sample size & 15 \\
Correlation coefficient & 0.22 \\
t ratio (two tail) & -6.03 \\
degrees of freedom & 14 \\
Probability (two tail) & $<.0001$ \\
\hline
\end{tabular}


Table D-26. Results of intraobserver repeatability test (paired $t$ test) for the variable Minimum Constriction.

\begin{tabular}{lc}
\hline \multicolumn{1}{c}{ Statistic } & Value \\
\hline Second Session & 208.61 \\
First Session & 196.71 \\
Mean Difference & 11.90 \\
Standard Error & 24.86 \\
Upper 95\% & 65.21 \\
Lower 95\% & -41.41 \\
Sample size & 15 \\
Correlation coefficient & 0.72 \\
t ratio (two tail) & 0.48 \\
degrees of freedom & 14 \\
Probability (two tail) & 0.6395 \\
\hline
\end{tabular}


Table D-27. Results of intraobserver repeatability test (paired $t$ test) for the variable Overbite.

\begin{tabular}{lc}
\hline \multicolumn{1}{c}{ Statistic } & Value \\
\hline Second Session & 1.34 \\
First Session & 4.63 \\
Mean Difference & -3.29 \\
Standard Error & 0.39 \\
Upper 95\% & -2.45 \\
Lower 95\% & -4.12 \\
Sample size & 15 \\
Correlation coefficient & 0.55 \\
t ratio (two tail) & -8.42 \\
degrees of freedom & 14 \\
Probability (two tail) & $<.0001$ \\
\hline
\end{tabular}


Table D-28. Results of intraobserver repeatability test (paired $t$ test) for the variable Overjet.

\begin{tabular}{lc}
\hline \multicolumn{1}{c}{ Statistic } & Value \\
\hline Second Session & 2.79 \\
First Session & 5.75 \\
Mean Difference & -2.96 \\
Standard Error & 0.42 \\
Upper 95\% & -2.05 \\
Lower 95\% & -3.87 \\
Sample size & 15 \\
Correlation coefficient & 0.26 \\
t ratio (two tail) & -7.00 \\
degrees of freedom & 14 \\
Probability (two tail) & $<0.0001$ \\
\hline
\end{tabular}


Table D-29. Results of intraobserver repeatability test (paired $t$ test) for the variable PFH.

\begin{tabular}{lc}
\hline \multicolumn{1}{c}{ Statistic } & Value \\
\hline Second Session & 76.35 \\
First Session & 70.19 \\
Mean Difference & 6.17 \\
Standard Error & 0.85 \\
Upper 95\% & 7.98 \\
Lower 95\% & 4.35 \\
Sample size & 15 \\
Correlation coefficient & 0.83 \\
t ratio (two tail) & 7.30 \\
degrees of freedom & 14 \\
Probability (two tail) & $<0.0001$ \\
\hline
\end{tabular}


Table D-30. Results of intraobserver repeatability test (paired $t$ test) for the variable PFH/AFH \%.

\begin{tabular}{lc}
\hline \multicolumn{1}{c}{ Statistic } & Value \\
\hline Second Session & 0.69 \\
First Session & 0.67 \\
Mean Difference & 0.02 \\
Standard Error & 0.01 \\
Upper 95\% & 0.03 \\
Lower 95\% & 0.00 \\
Sample size & 15 \\
Correlation coefficient & 0.84 \\
t ratio (two tail) & 2.09 \\
degrees of freedom & 14 \\
Probability (two tail) & 0.0557 \\
\hline
\end{tabular}


Table D-31. Results of intraobserver repeatability test (paired $t$ test) for the variable Pogonion-Nasion-Perpendicular.

\begin{tabular}{lc}
\hline \multicolumn{1}{c}{ Statistic } & Value \\
\hline Second Session & -5.34 \\
First Session & -7.15 \\
Mean Difference & 1.81 \\
Standard Error & 1.02 \\
Upper 95\% & 4.00 \\
Lower 95\% & -0.39 \\
Sample size & 15 \\
Correlation coefficient & 0.85 \\
t ratio (two tail) & 1.77 \\
degrees of freedom & 14 \\
Probability (two tail) & 0.0991 \\
\hline
\end{tabular}


Table D-32. Results of intraobserver repeatability test (paired $t$ test) for the variable Sella-Vertical-A.

\begin{tabular}{lc}
\hline \multicolumn{1}{c}{ Statistic } & Value \\
\hline Second Session & 68.71 \\
First Session & 66.68 \\
Mean Difference & 2.03 \\
Standard Error & 0.48 \\
Upper 95\% & 3.06 \\
Lower 95\% & 0.99 \\
Sample size & 15 \\
Correlation coefficient & 0.88 \\
t ratio (two tail) & 4.21 \\
degrees of freedom & 14 \\
Probability (two tail) & 0.0009 \\
\hline
\end{tabular}


Table D-33. Results of intraobserver repeatability test (paired $t$ test) for the variable Sella-Vertical-B.

\begin{tabular}{lc}
\hline \multicolumn{1}{c}{ Statistic } & Value \\
\hline Second Session & 61.37 \\
First Session & 58.57 \\
Mean Difference & 2.80 \\
Standard Error & 0.86 \\
Upper 95\% & 4.65 \\
Lower 95\% & 0.95 \\
Sample size & 15 \\
Correlation coefficient & 0.87 \\
t ratio (two tail) & 3.25 \\
degrees of freedom & 14 \\
Probability (two tail) & 0.0058 \\
\hline
\end{tabular}


Table D-34. Results of intraobserver repeatability test (paired t test) for the variable Sella-Vertical-M.

\begin{tabular}{lc}
\hline \multicolumn{1}{c}{ Statistic } & Value \\
\hline Second Session & 47.98 \\
First Session & 45.07 \\
Mean Difference & 2.91 \\
Standard Error & 0.88 \\
Upper 95\% & 4.80 \\
Lower 95\% & 1.01 \\
Sample size & 15 \\
Correlation coefficient & 0.89 \\
t ratio (two tail) & 3.29 \\
degrees of freedom & 14 \\
Probability (two tail) & 0.0054 \\
\hline
\end{tabular}


Table D-35. Results of intraobserver repeatability test (paired $t$ test) for the variable Sella-Vertical-Pogonion.

\begin{tabular}{lc}
\hline \multicolumn{1}{c}{ Statistic } & Value \\
\hline Second Session & 23.29 \\
First Session & 23.50 \\
Mean Difference & -0.21 \\
Standard Error & 0.39 \\
Upper 95\% & 0.63 \\
Lower 95\% & -1.05 \\
Sample size & 15 \\
Correlation coefficient & 0.91 \\
t ratio (two tail) & -0.53 \\
degrees of freedom & 14 \\
Probability (two tail) & 0.6065 \\
\hline
\end{tabular}


Table D-36. Results of intraobserver repeatability test (paired $t$ test) for the variable SNA.

\begin{tabular}{lc}
\hline \multicolumn{1}{c}{ Statistic } & Value \\
\hline Second Session & 81.62 \\
First Session & 82.03 \\
Mean Difference & -0.41 \\
Standard Error & 0.50 \\
Upper 95\% & 0.66 \\
Lower 95\% & -1.49 \\
Sample size & 15 \\
Correlation coefficient & 0.86 \\
t ratio (two tail) & -0.83 \\
degrees of freedom & 14 \\
Probability (two tail) & 0.4231 \\
\hline
\end{tabular}


Table D-37. Results of intraobserver repeatability test (paired $t$ test) for the variable SNB.

\begin{tabular}{lc}
\hline \multicolumn{1}{c}{ Statistic } & Value \\
\hline Second Session & 76.69 \\
First Session & 76.46 \\
Mean Difference & 0.23 \\
Standard Error & 0.40 \\
Upper 95\% & 1.10 \\
Lower 95\% & -0.63 \\
Sample size & 15 \\
Correlation coefficient & 0.91 \\
t ratio (two tail) & 0.58 \\
degrees of freedom & 14 \\
Probability (two tail) & 0.5725 \\
\hline
\end{tabular}


Table D-38. Results of intraobserver repeatability test (paired t test) for the variable Superior Airway Space.

\begin{tabular}{lc}
\hline \multicolumn{1}{c}{ Statistic } & Value \\
\hline Second Session & 9.35 \\
First Session & 8.63 \\
Mean Difference & 0.73 \\
Standard Error & 0.66 \\
Upper 95\% & 2.13 \\
Lower 95\% & -0.68 \\
Sample size & 15 \\
Correlation coefficient & 0.71 \\
t ratio (two tail) & 1.11 \\
degrees of freedom & 14 \\
Probability (two tail) & 0.2862 \\
\hline
\end{tabular}


Table D-39. Results of intraobserver repeatability test (paired t test) for the variable Total Airway Volume.

\begin{tabular}{lc}
\hline \multicolumn{1}{c}{ Statistic } & Value \\
\hline Second Session & 20929.90 \\
First Session & 18051.50 \\
Mean Difference & 2878.46 \\
Standard Error & 1961.42 \\
Upper 95\% & 7085.30 \\
Lower 95\% & -1328.40 \\
Sample size & 15 \\
Correlation coefficient & 0.60 \\
t ratio (two tail) & 1.47 \\
degrees of freedom & 14 \\
Probability (two tail) & 0.1643 \\
\hline
\end{tabular}


Table D-40. Results of intraobserver repeatability test (paired $t$ test) for the variable U1-NA $\left({ }^{\circ}\right)$.

\begin{tabular}{lc}
\hline \multicolumn{1}{c}{ Statistic } & Value \\
\hline Second Session & 21.03 \\
First Session & 19.05 \\
Mean Difference & 1.98 \\
Standard Error & 1.49 \\
Upper 95\% & 5.19 \\
Lower 95\% & -1.23 \\
Sample size & 15 \\
Correlation coefficient & 0.79 \\
t ratio (two tail) & 1.32 \\
degrees of freedom & 14 \\
Probability (two tail) & 0.2065 \\
\hline
\end{tabular}


Table D-41. Results of intraobserver repeatability test (paired $t$ test) for the variable U1-NA (mm).

\begin{tabular}{lc}
\hline \multicolumn{1}{c}{ Statistic } & Value \\
\hline Second Session & 4.53 \\
First Session & 3.43 \\
Mean Difference & 1.10 \\
Standard Error & 1.73 \\
Upper 95\% & 4.81 \\
Lower 95\% & -2.61 \\
Sample size & 15 \\
Correlation coefficient & -0.04 \\
t ratio (two tail) & 0.64 \\
degrees of freedom & 14 \\
Probability (two tail) & 0.5400 \\
\hline
\end{tabular}


Table D-42. Results of intraobserver repeatability test (paired $t$ test) for the variable U1-Sella-Nasion.

\begin{tabular}{lc}
\hline \multicolumn{1}{c}{ Statistic } & Value \\
\hline Second Session & 102.64 \\
First Session & 101.07 \\
Mean Difference & 1.57 \\
Standard Error & 1.39 \\
Upper 95\% & 4.56 \\
Lower 95\% & -1.42 \\
Sample size & 15 \\
Correlation coefficient & 0.81 \\
t ratio (two tail) & 1.13 \\
degrees of freedom & 14 \\
Probability (two tail) & 0.2800 \\
\hline
\end{tabular}


Table D-43. Results of intraobserver repeatability test (paired $t$ test) for the variable Wits appraisal.

\begin{tabular}{lc}
\hline \multicolumn{1}{c}{ Statistic } & Value \\
\hline Second Session & 2.15 \\
First Session & 3.12 \\
Mean Difference & -0.97 \\
Standard Error & 0.47 \\
Upper 95\% & 0.05 \\
Lower 95\% & -1.99 \\
Sample size & 15 \\
Correlation coefficient & 0.62 \\
t ratio (two tail) & -2.05 \\
degrees of freedom & 14 \\
Probability (two tail) & 0.0655 \\
\hline
\end{tabular}


Table D-44. Results of intraobserver repeatability test (paired t test) for the variable $\mathrm{Y}$-Axis.

\begin{tabular}{lc}
\hline \multicolumn{1}{c}{ Statistic } & Value \\
\hline Second Session & 59.12 \\
First Session & 59.29 \\
Mean Difference & -0.17 \\
Standard Error & 0.52 \\
Upper 95\% & 0.94 \\
Lower 95\% & -1.28 \\
Sample size & 15 \\
Correlation coefficient & 0.86 \\
t ratio (two tail) & -0.32 \\
degrees of freedom & 14 \\
Probability (two tail) & 0.7500 \\
\hline
\end{tabular}




\section{APPENDIX E. THE DAHLBERG STATISTIC}

Table E-1. Dahlberg Statistic for 44 measured variables.

\begin{tabular}{|c|c|}
\hline Variable & Dahlberg Statistic \\
\hline AFH & 5.18 \\
\hline Airway 1 Area (Naso) & 79.92 \\
\hline Airway 1 Volume (Naso) & $1,800.33$ \\
\hline Airway $1+2$ Area & 133.95 \\
\hline Airway $1+2$ Volume & $4,309.26$ \\
\hline Airway $1+2+3$ Area & 166.63 \\
\hline Airway 1+2+3 Volume & $5,563.76$ \\
\hline Airway 2 Area (Superior) & 80.88 \\
\hline Airway 2 Volume (Superior) & $2,998.78$ \\
\hline Airway 3 Area (Inferior) & 66.52 \\
\hline Airway 3 Volume (Inferior) & $1,620.16$ \\
\hline A-Na Perp & 1.26 \\
\hline ANB & 0.77 \\
\hline B-Na Perp & 1.07 \\
\hline Co-A & 2.30 \\
\hline Co-Gn & 4.45 \\
\hline Convexity & 2.24 \\
\hline FMA & 1.88 \\
\hline FMIA & 5.92 \\
\hline Go-Me & 2.47 \\
\hline IMPA & 6.62 \\
\hline Interincisal & 8.79 \\
\hline L1-NB $\left(^{\circ}\right)$ & 6.23 \\
\hline L1-NB (mm) & 1.73 \\
\hline Mesial Molar Relation & 1.54 \\
\hline Min Constriction & 66.30 \\
\hline Overbite & 2.54 \\
\hline Overjet & 2.37 \\
\hline $\mathrm{PFH}$ & 4.90 \\
\hline Pg-Na Perp & 2.99 \\
\hline SellaV-A & 1.92 \\
\hline SellaV-B & 3.02 \\
\hline SellaV-M & 3.11 \\
\hline SellaV-Pogonion & 1.05 \\
\hline SNA & 1.36 \\
\hline SNB & 1.08 \\
\hline Sup Airway Space & 1.81 \\
\hline Total Airway & $5,574.32$ \\
\hline U1-NA $\left(^{\circ}\right)$ & 4.19 \\
\hline U1-NA (mm) & 4.64 \\
\hline
\end{tabular}


Table E-1. (Continued).

\begin{tabular}{ll}
\hline Variable & Dahlberg Statistic \\
\hline U1-SN & 3.85 \\
Wits (AOBO) discrepancy & 1.43 \\
Y-Axis & 1.37 \\
\hline
\end{tabular}




\section{VITA}

Born in Wichita, Kansas in 1983 to parents Ken and Becky Dillehay, JK is the eldest of two children. Following high school, JK continued his education at the University of Mississippi, earning a B.A. in Biology. Upon graduation, JK entered dental school at the University of Tennessee Health Science Center where he obtained his Doctor of Dental Surgery degree. Following in his father's footsteps, JK then chose to continue his education in the specialty of orthodontics, earning his Master of Dental Science degree in May of 2013. 